Portland State University

PDXScholar

Winter 2-23-2015

\title{
Activist Doctors: Explaining Physician Activism in the Oregon Movement for Single-Payer Healthcare
}

Jennifer Cullen Loomis

Portland State University

Follow this and additional works at: https://pdxscholar.library.pdx.edu/open_access_etds

Part of the Medicine and Health Commons, and the Politics and Social Change Commons Let us know how access to this document benefits you.

\section{Recommended Citation}

Loomis, Jennifer Cullen, "Activist Doctors: Explaining Physician Activism in the Oregon Movement for Single-Payer Healthcare" (2015). Dissertations and Theses. Paper 2214.

https://doi.org/10.15760/etd.2211

This Dissertation is brought to you for free and open access. It has been accepted for inclusion in Dissertations and Theses by an authorized administrator of PDXScholar. Please contact us if we can make this document more accessible: pdxscholar@pdx.edu. 
Activist Doctors: Explaining Physician Activism in the Oregon Movement for Single-Payer Healthcare

\author{
by \\ Jennifer Cullen Loomis
}

A dissertation submitted in partial fulfillment of the requirements for the degree of

\author{
Doctor of Philosophy \\ in \\ Sociology
}

\author{
Dissertation Committee: \\ Robert Liebman, Chair \\ Matthew Carlson \\ Amy Lubitow \\ Jill Rissi
}

Portland State University

2015 


\begin{abstract}
Changes in American healthcare over the last half century have created social and economic crises, presenting challenges for doctors and patients. The recentlyimplemented Patient Protection and Affordable Care Act is an incremental reform that does little to change the complex multi-payer financing characterizing American healthcare. There have been growing demands for more equitable financing arrangements, notably, a single-payer healthcare system in which medical care is financed through a single, non-profit payer and in which medical care is treated as a public good and medically-necessary care is available to everyone.

Nationally-representative surveys have demonstrated widespread physician support for single-payer legislation. Yet, very little scholarship has examined physician activism and virtually no studies have examined physician activism for single-payer healthcare. It is important to examine physician activism for single-payer because their participation is considered fundamental to achieving the goals of the movement. If the movement is successful in implementing single-payer financing, more efficient use of healthcare resources will ensure that all residents have access to needed medical care without being saddled by financial burdens from their care.

Oregon is one of several US states with a growing grassroots movement to enact single-payer healthcare at the state level. This study seeks to examine the determinants of collective action for physicians in the Oregon movement for single-payer healthcare by answering two research questions. First, what accounts for differences in activism among physicians who support single-payer healthcare system? And second, for those physicians who are active, what activities do they do and what shapes those choices of activities?
\end{abstract}


Data includes 21 semi-structured interviews with physicians around the state of Oregon supplemented with participant observation data. The interview data was analyzed using techniques from grounded theory and thematic analysis.

I find that among collective action theories, collective identity theory best accounts for whether or not a physician engages in single-payer activism. A strength of collective identity theory is that it brings to light the importance of subjective interpretations of structural conditions by movement actors. The findings suggest that differences in interpretation shape the influence of motivators for and barriers to an individual's decision to engage in activism.

Physicians that become active are primed to engage in single-payer activism because of their moral value sets and frustrating work experiences. They seek out groups of like-minded physicians who then are part of the process of socially-constructing a collective identity. This collective identity is emotionally-laden, is a reaction to state policies, serves to distinguish insiders from outsiders, and facilitates activism. Activist physicians engaging in the process of collective identity come to believe that altering financing is the only way to solve healthcare system issues. The activists view the political and cultural barriers to single-payer as surmountable by their activism.

In contrast, non-activists interpret structural conditions like American politics and American culture as immutable barriers that will prevent the attainment of single-payer at the national or state level. In addition, non-activists lack the collective identity activists share because their beliefs contradict key beliefs of activists. The combination of the lack of collective identity and the perception of immutable barriers results in their nonparticipation. 


\section{ACKNOWLEDGEMENTS}

In Sociology, we recognize the myriad social influences that act upon individuals. I would not have been able to complete this research project without the encouragement and support of several people.

I must thank first and foremost my family. My parents, John and Jayne Loomis have instilled in me since an early age the value of an education and the virtue of pushing the frontiers of knowledge. I want to also thank Kelly Loomis as well as John and Virginia Cullen for their unwavering support. The guidance from my family members has made this journey possible.

Gratitude is also due to my committee members Amy Lubitow, Matthew Carlson, Jill Rissi, and in particular, my chair, Robert Liebman. Their faith and confidence in me have allowed project to grow from an idea to a reality. Indeed, this project would not have been possible without their guidance.

Additionally, many thanks go to the activist physicians who inspired this project and took some of their scarce free time to chat with me. Their commitment for an American healthcare system that guarantees access to all sustained my engagement in this project and I look forward to working with them on the campaign for single-payer healthcare. It is hoped that this scholarship will be one small part of the long road ahead to bring accessible and affordable healthcare to all Oregonians. 


\section{TABLE OF CONTENTS}

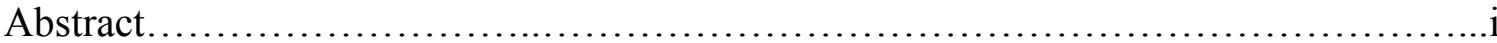

Acknowledgements...........................................................

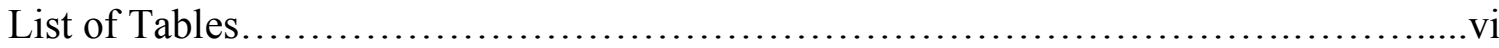

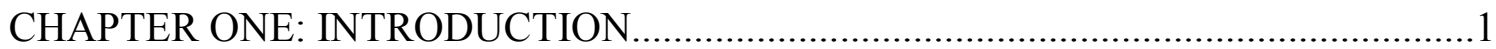

Background and Research Problem ..................................................................

Social Movement Theory to Explain Activism....................................................

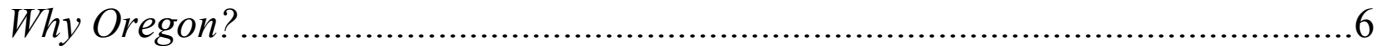

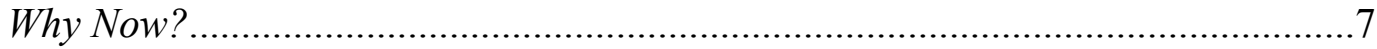

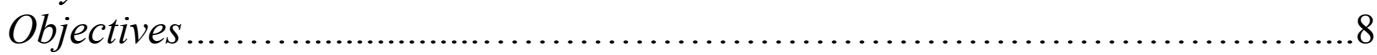

Methods............................................................. 9

Overview of Chapters................................................ 10

CHAPTER TWO: SOCIAL MOVEMENT LITERATURE REVIEW ....................12

Theoretical Perspectives for Studying Physician Mobilization............................13

Collective Identity: A Definition..........................................................19

New Social Movements Theory ................................................20

Developing a "We" With Boundaries.............................21

Politicization of Collective Identity: Conflict with the State..........23

Collective Identities Formed through Framing Discourse...........25

Emotional Reactions to Value Violations Provide Motivational

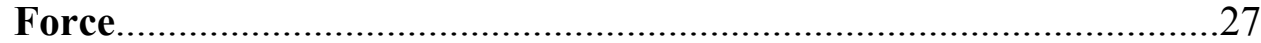

Collective Identity as Process or Product?.......................................29

Other Factors Influencing Activism: Efficacy and Availability .....................31

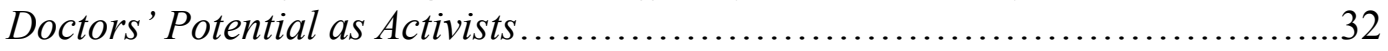

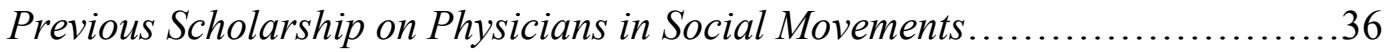

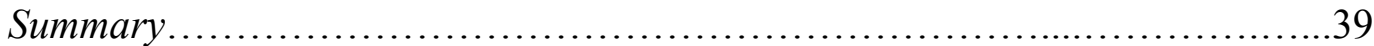

CHAPTER THREE: REVIEW OF THE US HEALTHCARE SYSTEM AND OREGON

HEALTHCARE REFORM...................................................................................41

US Healthcare History: From the Golden Age to the Commercialized Age.........42

Cost Containment in the Commercialized Age..................................................47

Consequences for Physicians: Deprofessionalization.........................................50

Consequences for Patients: Increasing Barriers to Care.....................................54

The Single-Payer Alternative: Growing Support for a Fair System......................58

Political Difficulties Achieving Single-payer Healthcare at the National Level...62

Health Reform in Oregon: Failure to Achieve Universal Coverage.....................65

Successful Single-payer Campaign in Vermont Inspired Oregon.........................75

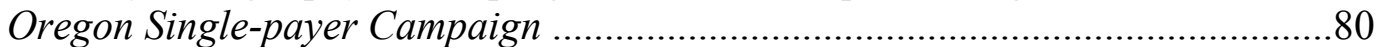

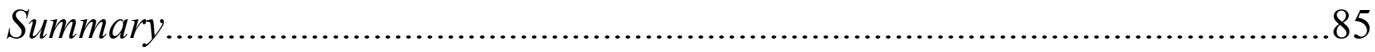




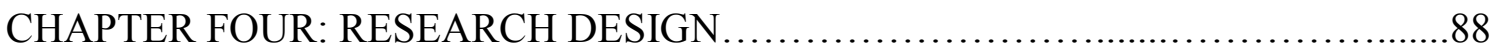

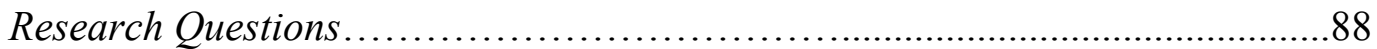

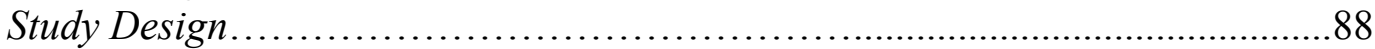

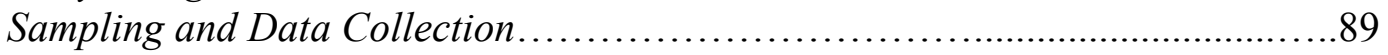

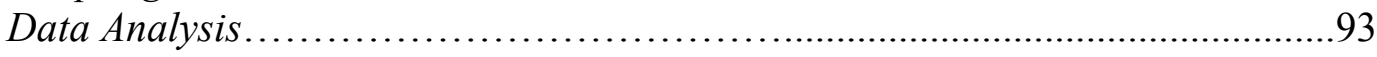

CHAPTER FIVE: PHYSICIAN ACTIVISTS........................................96

Five Main Beliefs Anchoring Collective Identity..................................99

Interpersonal Values of Equality and Justice...............................98

Frustrating Work Experiences Cause Emotional Reactions..............102

Desire to Help Others and the Need for Collective Action..................113

Networking Emphasizes a Focus on Financing........................118

Political Opportunities Shifting to State Level..........................123

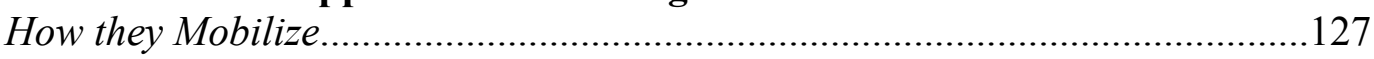

What Does Physician Activism Look Like?.......................................129

How do Physicians Choose Their Activities? ........................133

Discouragement at Work and Burnout..............................137

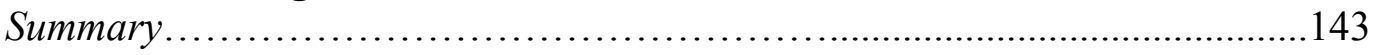

CHAPTER SIX: NON-ACTIVIST PHYSICIANS ..................................146

Comparison of Motivational Factors.........................................................147

Less Experience of Deprofessionalization...........................................149

Feasibility Makes Single-Payer Activism Unattractive.........................152

Americans' Distrust of Government...............................152

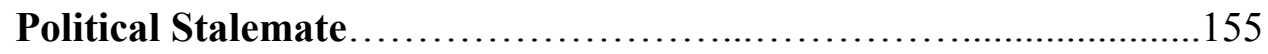

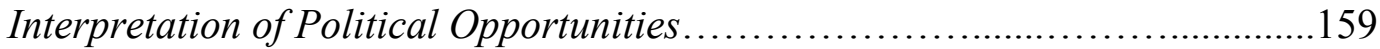

Resistance of the Single-payer Collective Identity .............................................160

Summary ............................................................... 162

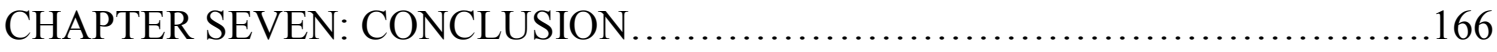

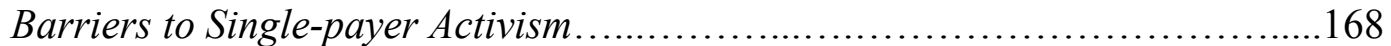

Comparison of Collective Identity Factors......................................................170

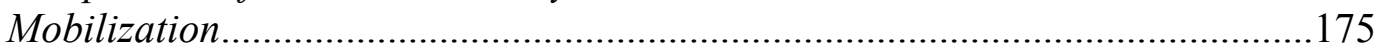

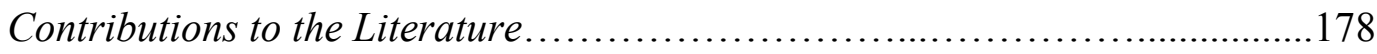

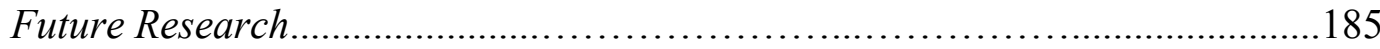

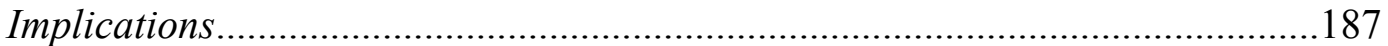

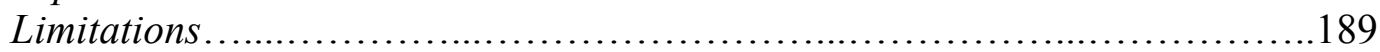

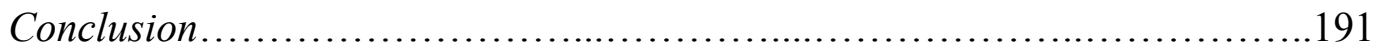

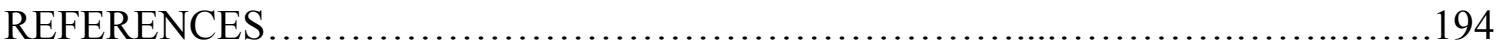

Appendices

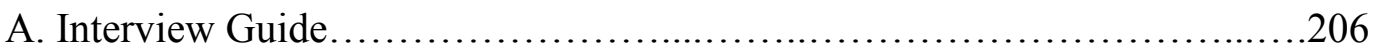

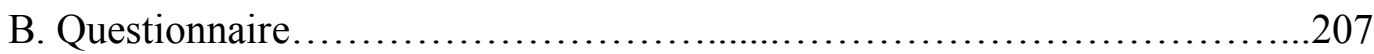

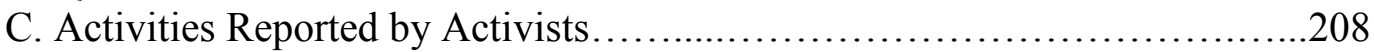




\section{LIST OF TABLES}

Table 3.1: Factors Affecting Vermont and Oregon's Single-payer Campaigns................84

Table 4.1: Sample Characteristics..........................................93

Table 5.1: Collective Identity Beliefs ...........................................127

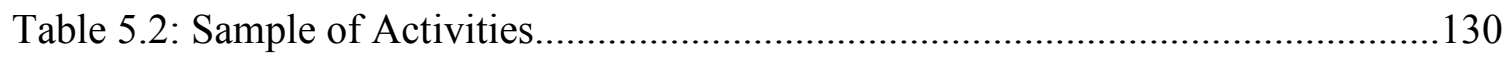

Table 6.1: Comparison of Extent of Collective Identity Beliefs..................................148

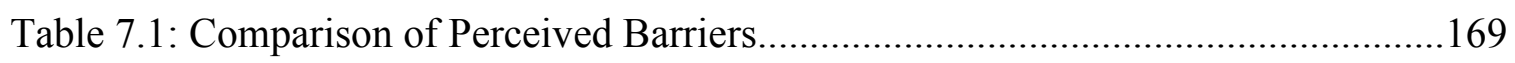

Table 7.2: Comparison of Extent of Collective Identity Beliefs..................................171 


\section{CHAPTER ONE: INTRODUCTION}

This study seeks to examine the determinants of collective action for physicians in the Oregon movement for single-payer healthcare. Scant attention has been paid to physician mobilization in social movements. Some scholars have examined proactive behavior on the part of physicians to minimize health disparities (Vanderbilt et al. 2007; Dittmer 2009) or physicians who advocated for making procedures medically-legal to reduce unnecessary suffering (for example, Quill [1993] promoted physician-assisted suicide and Joffe, Weitz, and Stacey [2004] discussed physicians' involvement in the prochoice movement). However, scholars have yet to systematically examine physician involvement in social movement efforts to achieve a single-payer, universal healthcare system. This dissertation provides a case study of physicians in a US state at the forefront of healthcare activism during a time of national health reforms.

In this introduction chapter, I will present the research problem by providing a brief context about the crisis of access to healthcare caused by a commercialized medical system, its effects on physicians, and the rising calls for single-payer healthcare. I will then introduce standard theories sociologists use to explain trends in social movements with an emphasis on collective identity. The chapter finishes with a review of the methods and upcoming chapters.

\section{Background and Research Problem}

Unlike most industrialized nations, the healthcare system in the United States is dominated by the interests of for-profit medical companies (Relman 2007). This is the 
result of numerous failed attempts to enact a universal national health insurance system (Quadagno 2004). Due to this, the United States is considered the only developed nation that does not provide universal healthcare for its citizens (Waitzkin 2012; Mechanic 2006; Schoen et al. 2012), causing the United States to be a seedbed for protests about access to healthcare and the avoidable suffering that results from lack of access. The lack of national health insurance system led to about 49 million Americans under age 65 being uninsured in 2010 (US Census 2011). The implementation of early provisions in the Affordable Care Act caused this number to decline to 42 million in 2013 (US Census 2014). Yet, even those with private health insurance coverage often find it to be inadequate when they fall ill (Himmelstein et al. 2005). Patients are bearing more of the cost and risk associated with medical care as they experience financial and administrative barriers to accessing care (Schoen et al. 2012; Hancock 2012). The effect of shifting costs and risks onto patients is that they find it increasingly difficult to access care and when they do, the costs and limited reimbursement by insurance companies restrict the range of treatment options available to physicians, reducing their professional autonomy.

While the ascension of for-profit medicine has brought great wealth to many doctors, it also brought negative consequences. Using 2014 US dollars, full-time workers classified as "physicians and surgeons" went from making yearly salaries of $\$ 117,524$ in 1968 to making $\$ 215,607$ in 2013 . But at the same time, physicians have experienced an intrusion into their clinical decisions, increases in the amount of paperwork required for reimbursement, and are graduating with an average of $\$ 169,901$ in medical school debt in 2013 (Casalino et al. 2009; Morra et al. 2011; Association of American Medical Colleges 2014). They have less control over how they spend their time and many feel medical 
ethics are compromised in the current system (Burdi and Baker 1999; Angell 1993; Navarro 1993). The result of this infringement on their professional autonomy and widespread lack of access to care is frustration, anger, and increasingly mobilization.

"Single-payer systems are systems in which a single public or quasipublic agency handles all health care financing" (Drasga and Einhorn 2013:1). Delivery of medical care is either public or private, costs of procedures are publicized, and treatment protocols are made explicit (Geyman 2005). A single-payer healthcare system can restore some physician autonomy by simplifying reimbursement and allowing a greater focus on patient care (Geyman 2005). This would benefit physicians as well as patients. In fact, different studies demonstrate that support for a universal, single-payer healthcare system is growing among US physicians (Carroll and Ackermann 2008; McCormick et al. 2004). Using a nationally-representative sample, Carroll and Ackermann (2008) demonstrate that support to pass single-payer legislation in the United State increased from $49 \%$ of US physicians in 2003 to $59 \%$ in 2008.

Additionally, some prominent physicians, including past editors of the New England Journal of Medicine, have become advocates for meaningful health reform aimed at enacting a nonprofit, single-payer, universal healthcare system (Relman 2007; Himmelstein and Woolhandler 2003; Earnest, Wong, and Federico 2009; Birenbaum 2002) that will expand medically-necessary care to everyone without increasing expenditures (Friedman 2012; Hsiao et al. 2011; IHSP 2009). In fact, some health policy scholars argue that physicians have a professional responsibility to address systemic barriers to care that have a direct relationship to health (Gruen, Pearson, and Brennan 2004). 
A consequence of these trends is the emergence of a movement of physicians as single-payer advocates and activists. Given that physicians are seen as trustworthy, benevolent, and credible (Lupton 2003), they are in a privileged positioned to counteract the messages from the for-profit medical interests that seek to maintain the current wasteful system (Ross 2009). It is believed that a vocal medical provider community may be the key force in pushing America toward a universal healthcare system (Mechanic 2006; Himmelstein and Woolhandler 2003). The single-payer movement in Oregon is directed toward the goal of achieving universal healthcare in the state through singlepayer financing. Advocates believe that if single-payer is achieved, it means Oregon's healthcare resources will be used in a more efficient way to ensure people are not suffering needlessly and that physicians' professional autonomy will be restored. Achieving single-payer in Oregon will also help ameliorate the social and economic crises caused by the commercialized US medical system. Given that physicians are expected to be influential in helping the movement achieve its goals, I wanted to know what factors lead physicians to single-payer activism. For this, I turned to social movement frameworks that seek to explain activism.

\section{Social Movement Theory to Explain Activism}

Scholars have long sought to explain why mobilization occurs in social movements (Downs 1957). Early work utilized an economic approach and asserted that individuals were rational actors weighing the costs and benefits of action (Olson 1965). It proposed that rational individuals would choose to let others bear the costs of activism unless incentivized to participate. In the 1970s and 1980s resource mobilization theory 
was widely-used and focused on organizations, fundraising, and the resources opposing groups could marshal (McCarthy and Zald 1973, 1977). It assumed groups with the greatest amount of resources are more likely to win struggles.

The Political Process Model advocated by Tilly (1978) and Tarrow (1996) examines political structures, power, and factors external to the movement. It asserts that an expansion of political opportunities encourages activism by lowering the costs of engagement. However, in more recent decades, these approaches have been critiqued for marginalizing the subjective experiences, meanings, and interpretations individuals create as they navigate their culture and attempt to change it through collective action (Mueller 1992; McAdam 2004; Taylor and Whittier 1998).

The notion of collective identity has been proposed as an analytic tool to bridge structure and meaning to bring to light why individuals engage in collective action (Melucci 1989; Taylor and Whittier 1992). Collective identity theory can do this by highlighting individuals' perceptions and interpretations of structural conditions and political opportunities. Differences in the perception and interpretation of the structure can explain why some individuals engage in action and why others do not, provided the same set of conditions. Collective identity theory highlights how individuals react to policies of the state (Meyer 2002), create boundaries that distinguish themselves from the larger society (Taylor and Whittier 1992), react emotionally to moral violations (Gecas 2000), and use framing discourses to clarify their position (Snow and McAdam 2000). Collective identity theory has been successfully used to demonstrate how women in the US lesbian movement mobilized (Taylor and Whittier 1992, 1998) and how Dutch farmers mobilized (Klandermans and de Weerd 2000). Participating in the process of 
generating a collective identity provides a motivational force framework for those who adopt it, allowing them to overcome barriers to participation (Klandermans and Oegema 1987).

Why Oregon?

This dissertation is a case study of physician activism for single-payer, universal healthcare in Oregon. While I have the customary benefits of being in place and an insider, Oregon is a privileged site for research for a number of reasons. Oregon has often been at the vanguard in health policy research and is no stranger to bold health policy experiments. Since practitioners and policymakers in the state are familiar with changes to the state's healthcare system, Oregon may be one of the few places that a change like single-payer is possible. In the last thirty years, Oregon has completed four experiments with delivery of care to its Medicaid population. The first, in the 1980s, called Oregon Health Decisions, was innovative because it solicited and incorporated public input into what services should be covered. I will later discuss in detail the evolution of the healthcare system and Oregon's numerous healthcare reform experiments in Chapter Three.

The second, in the early 1990s, sought to achieve universal coverage in the state and established the Oregon Health Plan (OHP). This involved a system of explicit rationing to determine the benefits package for its Medicaid population. A list was created which identified what tests and treatments were covered and were prioritized based on cost-effectiveness (Oberlander 2007). While some critics were concerned about the plan's sensitivity to public funding, it was met with much satisfaction (Leichter 
1999). The uninsured rate declined in the state at a time when its population was increasing, hospitals reported less uncompensated care, and client satisfaction rates increased (Leichter 1999).

The third, in the 2000s, was a natural experiment due to a lottery in which some individuals gained coverage and some did not. This provided a randomized control trial format for an interdisciplinary team to track the lottery participants over time. The fourth experiment, in the 2010s, is the launch of Oregon's Coordinated Care Organizations and a flexible budget to address social causes of illness in hopes of reducing the rate of growth of Medicaid spending.

Oregon has also attempted to enact a single-payer plan at the state level seven times since 1987 (Hammond 2012). The most recent legislation (as of 2014) is House Bill 2922, which is similar to measures in previous years in that it sets up a single-payer financing system for all persons who work or reside in Oregon $\left(77^{\text {th }}\right.$ Oregon Legislative Assembly 2013). There are 24 sponsors of the bill, which is double the number of sponsors one year earlier. This bill also has the backing of physician groups such as Physicians for a National Health Program - Oregon Chapter and Mad as Hell Doctors in addition to Nurses for Single Payer - Oregon Chapter and numerous labor unions. The growing number of sponsors suggests increased support from around the state.

\section{Why Now?}

In addition to the advantages of my research site, I was fortunate to start the research at a time of change that triggered intense conversations about the state of health care in America. The national Patient Protection and Affordable Care Act (ACA) was 
passed in 2010 and upheld by the Supreme Court in 2012. Its complete implementation began in 2014. States cannot opt out of the Affordable Care Act until 2017, giving activists in Oregon until then to pass a single-payer bill. The ACA does little to control costs because it preserves the multi-payer arrangement of American healthcare. It furthermore strengthens the preeminent position of private health insurance companies in our economy because individuals making over $138 \%$ of the federal poverty level will be required to purchase private insurance coverage (US Department of Health and Human Services 2014).

Advocates of universal healthcare are confident that the incrementalist approach in the ACA will do very little to solve physician and patient grievances, which will sustain interest in the movement for single-payer healthcare (Oberlander and Lyons 2009; McCanne 2003). As the Affordable Care Act is implemented and people participate in it, high hopes will wane, providing more impetus to seriously consider single-payer healthcare legislation in Oregon.

\section{Objectives}

Even with growing support for single-payer among medical providers and substantial potential in physician activism, it is not known why physicians engage in single-payer activism. Past mobilization of physicians has been attributed to concerns of professionalism and reduced autonomy (Quadagno 2004; Hoffman 2001; Starr 1982). The purpose of this study is to examine the determinants of physician activism for singlepayer healthcare in the contemporary Oregon movement. It will utilize social movement theories to interpret the findings from the case study. The findings have implications for 
the literature on social movement studies, in particular, collective identity theory. It also has implications for the medical sociology literature on physician professionalism (Freidson 2001; Casalino et al. 2009) and how the financing of the healthcare system affects physician experiences (Bodenheimer and Grumbach 2011; Angell 1993).

This study examines two research questions: First, among physicians who state they support enacting a single-payer healthcare system, what accounts for differences in mobilization and collective action? And second, for those physicians who do choose to become active in reform efforts, what activities do they do and what shapes those choices?

\section{Methods}

This study utilizes semi-structured interviews with 21 physicians in Oregon who support single-payer healthcare systems in principle. The sample includes physicians with a mix of specialties, practice locations, ages, level of involvement in single-payer activism, and both genders. It includes 14 activists and seven non-activists. The interviews were recorded and transcribed. Analysis utilized techniques from grounded theory and thematic analysis. The researcher began with open coding and progressed to focused coding by refining and finalizing a codebook (Lofland et al. 2006). Analytic memos that contained conjectures about relationships among the codes were maintained throughout analysis (Marshall and Rossman 2006). Through continual interaction with the data, conceptual categories and themes that reflect significant issues and form the basis of the collective identity for the activists were developed (Charmaz 1990). The interview data is supplemented with participant observation data. The researcher took 
fieldnotes at meetings, speeches, rallies, and conferences organized by the physicianactivists and had informal conversations for background and fact-checking during the research and writing process.

\section{Overview of Chapters}

This dissertation has seven chapters which introduce the standard theories sociologists use to explain activism, discusses the system in which physicians do their work, and presents findings as they relate to social movement theories to ascertain what causes single-payer activism among physicians in Oregon.

Chapter Two describes social movement theories and has two parts. The first part reviews literature on social movement theory with a focus on collective identity as a way of understanding mobilization and collective action. The second portion discusses physicians' potential as activists and reviews the limited scholarship that has touched on physician activism.

Chapter Three covers the US healthcare system and has four purposes: (1) to trace the development of the United States healthcare system and explain its impacts on physicians and patients; (2) to present single-payer healthcare as an alternative to the commercialized system in place now; (3) to review Oregon's unique recent history in healthcare reform to set the context; and (4) to review the state-level struggles to achieve single-payer in Vermont and in Oregon and compare the two situations.

Chapter Four includes information on the research design, data collection, and data analysis. Chapter Five answers the research questions by utilizing social movement theory to interpret the findings. This is done by presenting common background 
characteristics among the activists and the components of the collective identity they produce. I find that collective identity provides a compelling explanation because it brings to light the social construction of the problem and the interpretations of structural and political conditions. The activists view barriers as manageable and are strongly motivated by a collective identity. The chapter also reviews the activities activistphysicians engage in and the influences shaping the choice of activities.

Chapter Six reviews the smaller sample of non-activists and the reasons why they do not engage in single-payer activism. I find that they resist the collective identity shared by activists because they do not agree with all of its components. Additionally, they perceive formidable, fixed barriers to passing single-payer. Their non-activism results from the presence of these barriers and the absence of sufficient motivation. Chapter Seven concludes with a review of the findings in the framework of social movement literature. Limitations of the study, implications for future research, and contributions to the literature are included in the final chapter. 


\section{CHAPTER TWO: SOCIAL MOVEMENT LITERATURE REVIEW}

Sociologists and other social scientists have completed a significant amount of research on why individuals take action in social movements (Downs 1957; Olson 1965; Tilly 1978; McAdam 1982, 1988). Social movement theories address factors like motivation, availability, political opportunities, and group formation. However, there has been substantially less research on why physicians engage in social movement activity. A limited number of studies have examined health advocacy among physicians aimed at reducing health disparities (Vanderbilt et al. 2007; Mu, Shroff, and Dharamsi 2011) but this proactive behavior is not connected to larger social movements. Physician Timothy Quill (1993) penned a book advocating the legalization of physician-assisted suicide, but focuses on legality and patient stories to the neglect of collective physician mobilization. Further, one study examined physician involvement in making abortion services legal (Joffe, Weitz, and Stacey 2004) but ignored motivations for engagement.

Dittmer (2009) when providing a historical account of the Medical Committee for Human Rights touches on the physicians' calls for universal healthcare but only touches on the topic and does not relate it to social movement theory. Virtually no scholarship exists on why physicians participate in modern social movements to achieve single-payer healthcare. It is important to examine the activation of physicians as single-payer advocates because they believe that their participation will positively influence the movement given their insider experiences and high social status. Also, many in the single-payer movement are physicians and their participation is seen as instrumental to the success of the single-payer movement. This chapter will provide an overview of the 
literature that attempts to explain why individuals join social movements and finish with the potential inherent in physicians to be effective activists.

\section{Theoretical Perspectives for Studying Physician Mobilization}

Several theoretical perspectives have attempted to explain why individuals engage in collective action. This research began with four theoretical perspectives: rational actor, resource mobilization, political process, and collective identity. These theoretical frameworks have contributed to understandings of movement dynamics and to substantial scholarly discussions. I will discuss them as tools for understanding doctors as activists and judge their usefulness for my data.

Rational actor theory rests on Olson's seminal piece, The Logic of Collective Action (1965), in which he asserts that "rational actors" engage in a cost-benefit calculation that leads to their decision to let others bear the costs of activism; in other words, free-ride. This is most common in large groups and when the contribution is unseen or unlikely to make a difference. His solution to the problem of free-riding was the provision of selective incentives. Selective incentives are only available to those who participate and serve to induce participation. They can be tangible items like a t-shirt or social incentives like acceptance into the group for participation or social sanctions for non-participation.

But Gamson (1990) argues these incentives and sanctions are not enough to account for participation because the social sanction is likely taken into account in the actor's cost-benefit calculation and may not be enough to cause sustained participation. There can also be other inducements for participation that actors do not consciously 
include in their calculations. For instance, people may engage in collective action to alleviate guilt, satisfy moral beliefs, or because they find personal gratification and fulfillment through engaging with a group of like-minded others (Gamson 1990). As such, rational actor theory is more useful for explaining non-participation as it falls short of accounting for why individuals do engage in collective action (Klandermans 2002; Gamson 1990; Schlozman, Verba, and Brady 1995).

For Gamson (1990:155) the key to understanding social movement action lies in examining how “...people blend the personal and the collective in their own identities [because] solidarity and shared identities blur the distinction between the individual and the collective good." If an individual incorporates a collective group identity into their personal identity and are in solidarity with others, then they are more willing to make personal sacrifices for the collective good. Thus, highlighting individual's ties to group identities can help explain why they engage in collective action even when a cost-benefit calculation would suggest free-riding is a preferred choice.

In the latter half of the $20^{\text {th }}$ century, social movement studies shifted toward a focus on the resources and organizations available to a social movement (resource mobilization theory) or the structural conditions giving rise to collective action (e.g., political process theory/political opportunity theory). Resource mobilization theories originated in the 1960s and 1970s and focused on the resources and organizations that a challenging group can command (McCarthy and Zald 1973, 1977). These theories turned away from examining who joined social movements and why they joined to focus more on the organizations and resources necessary to sustain a movement. These resources include goods like office space, equipment, and supplies; knowledge about how to 
accomplish tasks like holding meetings, reaching out to media, or organizing protests; as well as human resources like labor and moral resources like legitimacy (Edwards and Gillham 2012).

Resource mobilization theory starts from the assumption that there are many grievances present at any time in society, yet mobilization only occurs in relation to few of the grievances. It suggests that what predicts movement emergence is an increase in the amount of resources available to the aggrieved group combined with a sufficient level of organization (McCarthy and Zald 1977). This theory focuses on attainment of resources and how utilization of resources by social movement organizations as requisites to activate individuals who are sympathetic to the cause pursued by the movement. This framework depends upon political sociological ideas and economic theories more so than upon the social psychology of collective behavior arguing that only with resources do social psychological factors lead to action. Soon after, other scholars asserted that the political system was an integral factor explaining the emergence or suppression of social movements and spurred the development of political process theories like political opportunity theory.

McAdam's (1982) work is foundational to this perspective. McAdam (1982) proposed three important factors for movement emergence: expanding political opportunities, established organizations, and the process of cognitive liberation. This framework drew attention to the political and social climate, asserting that activists do not choose goals, strategies, and tactics in response to structural conditions (Meyer 2004). It emphasizes that a social movement is a political phenomenon rather than a psychological 
phenomenon which is to say that individual dispositions are of little significance compared to political factors in accounting for mobilization (McAdam 2013).

The foundation of political process theory is the presence of political opportunities. It asserts that when political opportunities expand and consequently lower the cost of activism, then people are more likely to join a movement. Critics argued the opening up of opportunities is still insufficient to explain mobilization because it discounts or denies the role of perception and interpretation. The political opportunities must be perceived and interpreted in order to be favorable to movement organizing. There may be an "objective" expansion of political opportunity, but if it is not perceived and interpreted as such, it will not encourage activation and mobilization among supporters. Additionally, this framework suffers because there is no consensus about how the changes in the political opportunity structure affect movements. Sometimes movements emerge as a response to the contraction of political opportunities or when there are no changes in the political structure (Goodwin and Jasper 1999).

The concept of "cognitive liberation" provides a subjective component to a predominantly structural theory. McAdam argues that the political opportunities and organizations provide the structure for individuals to act, but in order to participate, the individuals must also undergo a cognitive liberation when they "feel that the current political system lacks legitimacy and their social movement participation could make meaningful change happen" (Caren 2007:2). Later social movement scholarship replaced this individual-level factor with the concept of framing processes, which is more dynamic and at the organizational level (Caren 2007). 
In addition to the limitations presented above, political process theories have been critiqued for other reasons. Two important reasons relate to the present discussion. First, it has a rationalist bias in that it emphasizes the costs and benefits of activism and proposes that lowering the costs of activism increase participation, harking to Olson's theory. Second, it neglects the critical role emotions play in guiding behavior and shaping collective action. As a response to the critiques of resource mobilization theory and political process theories, growing attention has been paid to cultural systems, social constructions of problems, and the interpretations of activists (McAdam 2004; Melucci 1995).

In the last few decades, a growing collection of studies has demonstrated that cultural and social psychological factors are important in generating and sustaining collective action (Morris 1992). Recognizing how cultural understandings guide social actors brings to light the role of subjective interpretation and the social construction of meaning in collective action (McAdam 2004). Collective identity theory has emerged as a way of overcoming gaps in the resource mobilization and political process frameworks (Polletta and Jasper 2001). Scholars deploying collective identity theory believe that psychosocial factors are more important than structural and political conditions because it is the perception and cultural interpretation of resources and political conditions that color activists' sense of possibilities and motivations. To become a collectivity, actors must share beliefs, labels, and rituals that distinguish and differentiate them from others.

Central to the task of highlighting the connections between structure and perception is the concept of collective identity. When a group of activists produce and share a collective identity, the "... activists come to see themselves as members of a group 
that is differentiated from outsiders, interpret their experiences in political terms, and politicize their actions in social movement contexts and in everyday life" (Meyer and Whittier 1994:281). Actors develop a shared sense of togetherness and a sense that their action together can achieve change (Flesher Fominaya 2010). Collective identity as an analytic tool can bridge the gap between structural preconditions and individual dispositions that incline individuals to act.

Taylor and Whittier (1998:361) argue that previous studies relying on political process theories or resource mobilization theories provide "...little understanding of how the injustices that are at the heart of most movements are translated into the everyday lives of collective actors." They argue the study of collective identity is important to understanding the process of collective action "because it highlights the role of meaning and ideology in the mobilization and maintenance of collective action" (Taylor and Whittier 1998:361). Paying attention to collective identities produced by actors allows us to examine "...the values and symbolic understandings created by discontented groups in the course of struggling to achieve change" (Taylor and Whittier 1992:106). McAdam (2004:227) goes as far as to say that producing a collective identity is a "requisite for the emergence of all social movements."

Melucci (1995) offers a constructionist view for understanding collective identity. For him, collective identity is the process of creating an action system and involves three aspects. First, using shared language, the actors define the ends, means, and field of action. Second, these actors share an active network of relationships that allows them to interact with and influence each other. And last, emotional investment shared by actors endows their participation with meaning and generates a sense of unity and solidarity. 
When actors engage in the process of collective identity, they interactively communicate to frame their grievances in emotional and cognitive terms. Social movements emerge through the collective work of creating meaning and are not preexistent as resource mobilization theorists contend.

In essence, collective identity theory asserts that subjective interpretation of structural conditions help individuals understand problems in their lives, find like-minded others to generate a sense of we-ness, and motivate them to act (McAdam 2004; Melucci 1995). In employing collective identity theory, we can link multiple levels of analysis to produce an understanding of how individuals come to engage in social movements.

\section{Collective Identity: A Definition}

Numerous scholars have utilized the concept of collective identity, with each operationalizing it a little differently (see Flesher Fominaya [2010]; Hunt and Benford [2004] for summaries). Hence, there is no standard definition, but instead, components about which most scholars agree. Hunt and Benford (2004) review the myriad ways in which collective identity has been deployed in social movement studies focusing on similarities and differences. Summarizing the areas in which scholars agree about collective identity in their conclusion section provides a complete accounting of the various aspects subsumed under collective identity:

Collective identity is conceptualized as individuals' identifications of, identifications with, and attachments to some collectivity in cognitive, emotional, and moral terms. Rooted in and shaped by particular sociocultural contexts, collective identities are produced and reproduced in ongoing interactions between allies, oppositional forces, and audiences who can be real or imagined. While providing a sense of we-ness and collective agency, collective identities also create a sense of other via 
boundary identification, construction, and maintenance. Collective identities, as shared meanings, provide cultural contexts for planning, enabling, carrying out, and evaluating individual participation and collective actions.

Separating out the different aspects of collective identity will provide the framework for the rest of this section. Before I begin to deconstruct Hunt and Benford's (2004) definition presented above, I will first address how this concept relates to the "new social movements" that tend to be based on identities instead of primarily one's socioeconomic class. Then, I explain the importance of boundaries in defining the group and contributing to the "we-ness" that is essential to collective identity. Next, I describe the importance of the collective identity being politicized in order to make it relevant to collective action. Then, I explain the centrality of framing processes to the creation of the collective identity. The following section touches on how values and emotions are necessarily a part of the injustice frames developed by movements sustaining a collective identity. All of these pieces come together to produce the collective identity that individuals adopt when they become activists for the social movement. Finally, I will review the debate over whether it is appropriate to consider collective identity a process or a product.

\section{New Social Movements Theory}

Buechler (1995) describes new social movements as different from the "old" social movements which were based on economic class struggles derived from one's position in the social structure. The "new social movements" theory shifted attention to socially-constructed grievances and struggles over postmaterialist values. As Hunt and Benford (2004: 437) argue, “[i]n a sense, collective identity replaced class consciousness 
as the factor that accounts for mobilization and individual attachments to new social movements."

This is because, as Taylor and Whittier (1992:114) explain, a collective identity involves a level of group consciousness that "imparts a larger significance to a collectivity." Taylor and Whittier (1992:114) write

"We see the development of consciousness as an ongoing process in which groups re-evaluate themselves, their subjective experiences, their opportunities, and their shared interests. Consciousness is imparted through a formal body of writings, speeches, and documents."

The group must come to recognize itself as a group and this happens through setting boundaries. Just as Karl Marx saw class consciousness as a pre-requisite for class-based action, new social movement theorists see the development of a conscious collective identity as a prerequisite for new social movement organizing.

\section{Developing a "We" With Boundaries}

In the process of creating the collective identity, the group must differentiate itself from other groups and the hegemonic social structure against which they are struggling. Engaging in this definitional process allows the group to regulate membership and define “...the requisites for joining the movement and the criteria by which its members recognize themselves and are recognized" (Melucci 1995:49). Taylor and Whittier (1992:111) define the boundaries aspect of the collective identity as "the social, psychological, and physical structures that establish differences between a challenging group and dominant groups." Taylor and Whittier (1992:114) emphasize that “...the important point is that collective actors must attribute their discontent to structural, 
cultural, or systemic causes rather than to personal failings or individual deviance." Hence, when social movement participants are creating their collective identity, they are reacting to the political system and power structures to help themselves gain a sense of who they are. This is a part of constructing the boundaries that delimit the group.

Once the collective actors have agreed upon the criteria necessary to create boundaries between "us" and "them," they can comprehend and sense the "we-ness" produced by the collective identity. "The collective, shared "sense of we" is animating and mobilizing cognitively, emotionally, and sometimes even morally" (Snow 2001:np). This is due to the shared feelings and solidarity generated in the networks that motivate people to act for the sake of the group and contribute to a sense of collective agency. Melucci (1995:47) emphasizes how this boundary setting involves an interaction effect between the social environment and others. He says that the aggrieved group must locate themselves within a system of relations to distinguish themselves from their "environment." The environment which he is referring to includes other social groups who may be allies or adversaries "... and especially the reaction of the political system and the apparatus of social control [because it] define[s] a field of opportunities and constraints within which the collective actor takes shape, perpetuates itself, or changes" (Melucci 1989:52).

The collective actors forming a social movement must clearly distinguish what it is about themselves that separates them from dominant society. Through communicating and negotiating with each other, they decide on boundaries that delimit themselves from others which serve to explicate requirements of membership. A sense of solidarity and we-ness is created through recognizing the common interests and adversaries of the 
group. Often, this adversary is identified to be the state which then politicizes the collective identity and imbues it with vitality.

\section{Politicization of Collective Identity: Conflict with the State}

There is agreement among scholars that a collective identity must become politicized in order to have bearing on political activism. Klandermans and de Weerd (2000:70) ask, “[w]hat, then, does make collective identity politically relevant?" Drawing on consensus from the literature, they propose the answer to be "...collectively defined grievances that produce a "we" feeling and causal attributions that denote a "they" that is held responsible for the collective grievances" (Klandermans and de Weerd 2000:70). Often, the "they" that is seen as responsible for creating the unjust conditions is the state. Additionally, when the culprit for the grievance is considered to be authorities, the interaction with these authorities also politicizes the collective identity (Klandermans 2002).

Indeed, social and political struggles often create the conditions to form a collective identity (Taylor and Whittier 1998). Meyer (2002) traces examples of how governmental policies create narrow constituencies through establishing and enforcing unfair policies attached to characteristics such as one's religion, sexual orientation, or skin hue. He says, “...the action of the state creates these collective identities and sets the boundaries of a dissident collective" (Meyer 2002:13).

When these groups are struggling against an unjust hegemonic system, "free spaces" become important. Drawing on the work of others, Polletta (1999:3) says that free spaces "refer to small-scale settings within a community or movement that are 
removed from the direct control of dominant groups, are voluntarily participated in, and generate the cultural challenge that precedes or accompanies political mobilization." Black churches in the South during the Civil Rights Movement represent a good example of free spaces (McAdam 1988). Free spaces are often small settings where an intimate atmosphere facilitates freely sharing of ideas and “....seem to provide institutional anchor for the cultural challenge that [critiques] structural arrangements" (Polletta 1999:1). Actors trying to weaken a hegemonic structure like the commercialized US healthcare system will benefit from safe spaces that permit a place to share radical counterhegemonic ideas with like-minded others. These spaces allow the collective actors to generate solidarity that would be difficult in locations serving the hegemonic system.

Political opportunity theories have long taken into consideration the role of the state in influencing social movement organizing. But the strength of collective identity theory is the attention it pays to the interpretation of structural conditions. This interpretation is critical to understanding why some individuals mobilize and others do not when presented with the same structural conditions. Over time this can manifest in a dialectical relationship as the social movement renegotiates and redefines itself in relation to changes in the state (Meyer 2002).

In short, state policies create constituencies and dissident, politicized groups develop in the process of struggling against state policies. As state policies change, the groups react and if successful, alter state policies. Collective identities may shift and evolve over time as groups react to changing factors in the state. 


\section{Collective Identities Formed through Framing Discourse}

How does a collective identity coalesce among members pushed into a group via state policies? It is through the discourse collective actors use to frame their case. Framing is an active process that helps an individual interpret issues and grievances by highlighting certain aspects or events to help make sense of them. Benford and Snow (2000:614) explain that "[f]rames help to render events or occurrences meaningful and thereby function to organize experience and guide action."

Snow and Benford (1992) describe three main functions of frames. The attributional function of a frame involves "...the identification of a problem and the attribution of blame or causality" for the problem (Snow and Benford 1992:138). The second function of frames is prognostic in that it identifies a solution for the problem which becomes the target of collective action. The last is the motivational function which provides the rationale for individuals to become engaged in the movement and supplies the "call to action." The frames are refined through interaction and contestation in groups and once agreed upon, come to represent fundamental beliefs and values defining membership in the group. These beliefs are constructed through discourse, discussion, and debate in networks which culminate in the agreed-upon frames.

As the group responds to the policies of the state, they start to clarify what they believe the problem is precisely, the viable solutions to address the problem, and the rationales for why the group must act. Snow and McAdam (2000:54) give concrete examples of activities that yield framing discourses and their relation to the generation of the collective identity. Framing discourses that result in the collective identity occur 
“...when preparing for and giving formal testimony at movement functions, when explaining the movement to others in the course of recruitment and proselytizing activities, when preparing press releases and making public pronouncements, when crafting reports and columns for newspapers, and when adherents are engaged in frame disputes or debates."

Essentially, a collective identity is formulated through the articulation and clarification of frames that define the core beliefs of the group. These frames are often deployed in recruitment efforts to gain new members or activate bystanders. The frames must resonate with individuals in a way that convinces them that action is necessary and their action with the group will make a difference in achieving the goals.

There is a bridge from McAdam's concept of cognitive liberation to collective identity theory in that both include the dual components of recognizing the political system lacks legitimacy and that social movement participation can make change happen (Caren 2007). The attributional and motivational frames facilitate cognitive liberation, but these frames are produced at the group level instead of being solely an individuallevel phenomenon. Additionally, frames add the prognostic component which highlights the precise solution the group desires and leads to the tactics expected to achieve the solution. The frames produced through debate by the activists define the core beliefs of the collective identity and play an important role in the adoption of the collective identity. Fundamental disagreement over key frames can lead to conflict and non-adoption of the collective identity. Values can also be an important part of the framing discourses and are a component of collective identity. The next section will discuss how emotions and values relate to collective identity. 


\section{Emotional Reactions to Value Violations Provide Motivational Force}

Growing consensus asserts that cultural and social-psychological aspects of collective action are foundational to explaining collective action (Morris 1992). The values that people hold guide interpretation of events, framing of issues, and motivate action (Gecas 2000; Jasper 1998; Melucci 1995; Klandermans 2002). Gecas (2000:95) defines values as the following:

"In general, values are defined as conceptions of beliefs about desirable modes of conduct or states of being that transcend specific situations, guide decision making and the evaluation of events, and are ordered by relative importance... Values serve as standards by which to live, as well as goals for which to strive."

Gecas (2000) describes how many movements are identified by their values such as prochoice or pro-environment. These values can be incorporated into the identity of the movement and have implications for the mobilization of adherents. Moral values such as liberty, equality, and justice often guide the struggles of activists.

Emotional reactions may hold the causal force for mobilization and result when deeply-held values are perceived to be violated (Jasper 1998). Jasper (1998) highlights how emotions are socially constructed, derive from one's culture, and accompany all aspects of social life. People will compare their observations of reality, like how policies of the state affect their quality of life, to their values. When the two are incongruent, emotions such as anger and frustration occur, which can motivate actors to seek likeminded others to engage in political action to change the system so it is more in line with such values. Klandermans (2002) notes that the affective, or emotional component of collective identity serves to overcome the dilemmas of collective action by mobilizing individuals. 
A growing number of scholars agree that there are important connections between values, emotions, and actors' motivations for collective action. Melucci (1995:45) says that values are emotionally-charged and that collective identity "always mobilizes emotions." Gecas (2000:95) asserts that the "emotional concomitants of values are part of the motivational force of values and value systems." This is to say, the collective identity formed among actors is emotionally laden and emotions play an important role in mobilization and action.

For example, actors may experience moral outrage if they feel that they have been unjustly deprived of something that others are receiving (Klandermans 1997). Anger and frustration are common emotions among actors who perceive their values to have been violated. Actors channel these emotions into the framing of the issue which takes shape in the collective identity. Indeed, Goodwin and Jasper (2004:25) say that collective identity and frame analysis “...gain much of their causal force from the emotions involved." In one study, the emotional and attitudinal component of collective identity had the greatest explanatory power in predicting why individuals engage in collective action (Klandermans 2002).

Actors respond to policies of the state and through discussing issues with others, frame their grievances, discuss them, and a collective identity forms. It is important to recognize that this process involves values and when the values are not being met, emotions become involved which can act as a motivator to engage in collective action. Emotional reactions can mobilize individuals and are strongly linked to social activism (Jasper 1998; Klandermans 2002). 


\section{Collective Identity as Process or Product?}

Among scholars employing collective identity theory, there is a debate whether a collective identity is a process or a product. Melucci (1995:51) insists that collective identity should be understood as a process and “...not a datum or an essence, not a “thing" with a "real" existence." He encourages us to conceive of it as "network of active relationships between actors who interact, communicate, influence each other, negotiate, and make decisions" (Melucci 1995:45). Other advocates of understanding collective identity as a process emphasize “...shared meanings, experiences, and reciprocal emotional ties as experienced by movement actors themselves through their interaction with each other" (Flesher Fominaya 2010:397). In short, collective identity as a process emphasizes the system of relations among actors and the representations of meaning they construct through debate and framing discourse.

On the other hand, while recognizing the processes required to create a collective identity, Snow (2001:np) asserts that "it is both questionable and unnecessary to contend that the process is more fundamental than the product to understanding the character and functionality of collective identity." A few arguments are offered below to recognize that collective identity may be just as much a product as it is a process.

First, a collective identity may not disappear even when the "groups or organizations within a movement dissolve" (Flesher Fominaya 2010:401). Which is to say, after the network of actors who constructed the collective identity disbands, the framings, grievances, and values that make up the collective identity may still persist and can be perceived by others. Flesher Fominaya (2010:397) explains this further: 
"The 'product' understanding refers to a sort of 'shorthand' reference point for insiders and outsiders that encapsulates key movement frames, issues, tactics, identities, ideologies and orientations. [...] The 'product' definition refers more to a perception of shared attributes, goals and interests [and is] something that can be felt by movement insiders but also by those outside the movement..."

Outsiders to the movement may not engage in framing discourses in the networks that produce the identity, but can be aware of the properties that make up the collective identity. In this sense, a collective identity is a constructed social object to which movement insiders and outsiders can perceive and orient themselves (Snow 2001). Also, if the heart of the collective identity resides in the shared sense of we-ness, then a collective identity could be understood as an essence or thing that exists, counter to Melucci's claims.

I recognize that a collective identity must fundamentally involve a process of individuals coming together in networks, engaging in framing discourses, setting up boundaries, and developing a conscious sense of we-ness that encourages solidarity. Yet, I also believe there is some currency to the idea of treating a collective identity as a product after it has been created, shared, and invoked. Treating collective identity as a product illuminates how outsiders distinguish themselves from members in the movement and react oppositionally to the collective identity produced by movement actors.

In summary, collective identity has been offered as a way of capturing the subjective emotional experiences of activists that motivate collective action and derive from cultural interpretations; factors neglected in other social movement paradigms. Developing a collective identity has been proposed as a prerequisite for new social movement organizing (McAdam 2004) because it allows the individuals to sense that 
they are part of a collective, in opposition to state policies, and different from others in the population. As activists engage in framing discourse, the collective identity is formed and renegotiated over time. Collective identity and the solidarity generated as actors engage in the process of creating a collective identity have been shown to be powerful motivating forces for engaging in collection action (Taylor and Whittier 1992, 1998).

\section{Other Factors Influencing Activism: Efficacy and Availability}

Collective identity is a useful analytical tool to assess how individuals become motivated and sustain engagement in collective action. However, there are two other noteworthy considerations that can help to explain why individuals do or do not join social movements.

One reason individuals choose to participate in protests or social movements because they believe their actions will be efficacious in altering the problematic conditions or policies (McAdam and Paulsen 1993). Activists tend to believe that collective action can shape the social structure and without group action, meaningful change is unlikely to occur. This belief in the efficacy of action may be broken down further into collective efficacy and political efficacy. Collective efficacy refers to the collective belief that the members will be able to solve their group problems by united effort and guides selection of targets and tactics (Bandura 1997). And political efficacy refers to the perception that the political process facilitates the achievement of movement goals. A strong sense of efficacy is a good predictor of engagement in activism (McAdam and Paulsen 1993). 
Additionally, individuals may be motivated and connected to others, but action will not occur if the individual does not have the availability to take part in the movement. Rochford (1985:45) describes availability as “...a lack of alternative commitments and obligations that might limit an individual's ability to participate." Snow, Zurcher, and Ekland-Olson (1980:793) refer to greater availability as having "a greater amount of unscheduled time." People with more availability tend to be under 30 years of age, be childfree, or employed part-time (Snow, Zurcher, and Ekland-Olson 1980; McAdam 1988). In other words, individuals with greater availability are to fit their activism around their normal obligations and time is not a barrier to participation (Cable 1992). The barrier of availability can also shape what tactics activists employ.

Participating in social movements is not easy; it takes time and energy. Any individual who pursues becoming an activist will have to navigate a balance of motivators and barriers. Doctors have busy work lives and their free time is at a premium, causing availability to be a substantial barrier. Yet, as the next section demonstrates, physicians as a group have serious potential to be effective advocates for single-payer healthcare due to their social position and professional obligations. It is believed that the coordinated participation of physicians in the single-payer movement could make a sizeable difference in the outcomes of the movement (Himmelstein and Woolhandler 2003).

\section{Doctors' Potential as Activists}

Currently, the most formidable opponent to single-payer healthcare is the forprofit health insurance industry represented by the American Association of Health Plans 
(formerly the Health Insurance Association of America) (Quadagno 2004). This industry has massive resources that can be mobilized to defeat movements aimed at enacting single-payer arrangements (Potter 2010). In order to overcome this, a unified and credible voice from the medical provider community must clearly outline the evidence and case for single-payer, universal healthcare (Mechanic 2006). There have been growing calls for physicians to be leading healthcare reform for the good of the public instead of reacting to what payers dictate (Birenbaum 2002; Himmelstein and Woolhandler 2003).

Physicians in particular, are in an ideal social location to be influential advocates for health reform. Americans in general retain a significant amount of respect and trust for their physicians and primary care physicians in particular because we interact with them more frequently (Hoff 2010; Boulware et al. 2003; Mechanic 2006). The media also contributes to the positive imaging of the doctor because it typically portrays them as benevolent, knowledgeable, and a voice of authority which gives them an aura of credibility and trustworthiness (Lupton 2003). Indeed, Ross (2009:783) agrees that movements striving for universal national health insurance “....will require substantial leadership from the provider community, whose credibility will be needed to overcome the insurance and business interests likely to oppose fundamental reform."

Himmelstein and Woolhandler (2003) strongly believe the factor that could make the difference for engaging and mobilizing the public is a vocal medical provider community. They say, "[w]e are convinced that a striking show of support for NHI [national health insurance] among health professionals would uniquely capture public attention, setting in motion vital public discussion of health care's future" (Himmelstein and Woolhandler 2003:104-105). In Canada, it is more generally recognized that 
"[p]hysicians have always been in a unique position to serve as activists. Seen as experts in the public eye and situated at the forefront of health care, physicians have the expertise and social clout to champion myriad topics" (Newman 2008). Earnest, Wong and Federico (2010:63-64) believe physicians are important stakeholders because given “...their social standing, physicians enjoy an unusual degree of access to policy makers, to local and national leaders, and to citizens; thus, they possess a great deal of leverage in influencing public processes and priorities." The physician population is ideally situated to be involved in health policy reform efforts aimed at reducing barriers to accessing medical care.

Earnest, Wong, and Federico (2010:63) define physician advocacy in the following way:

"Action by a physician to promote those social, economic, educational, and political changes that ameliorate the suffering and threats to human health and well-being that he or she identifies through his or her professional work and expertise."

This passage highlights how physicians can advocate changes to state policies that would reduce patient suffering. Changing the multi-payer, for-profit financing system that leaves millions uninsured would be one area worthy of physician activism.

Gruen, also a physician, is a proponent of physician activism. Gruen, Pearson, and Brennan (2004) believe though, if we are to take the calls to action for physicians seriously, we must be realistic about what the physicians should be professionally obligated to do. There must be limits to advocacy because the first imperative for a physician is to deliver excellent patient care. Beyond this, they argue physicians are professionally obligated to improve access to care by reducing systemic barriers 
including those derived from lack of health insurance; and expose direct socioeconomic influences on health, such as public policy. The authors believe that these three factors have a sufficiently direct relationship to health to obligate physicians to remedy the problems. They refer to this work outside of the regular practice as the physician's "public role."

Gruen, Pearson, and Brennan (2004) argue that broader socioeconomic influences, like inequalities in education, income, and adverse environmental exposure, lack strong evidence of causality of illness in individual patients, which limits the feasibility and efficacy of physician action. On the other hand, difficulties with access to care due to reliance on private health insurance is clearly and directly related to adverse health outcomes (Wilper et al. 2009; Hadley 2003) and physician action in this area is expected to be an efficacious and worthy endeavor. Hence, advocating for a single-payer system, which reduces the financial barriers to care, would be a laudable and justifiable goal. These authors believe "[a]lthough most public roles are not reimbursed directly, they can and should be considered aspects of patients' care" (Gruen, Pearson, and Brennan 2004:98).

Birenbaum (2002:138) believes the first wave of activists for single-payer will be physicians who have experienced the most erosion of their professional autonomy, discussed further in the next chapter. He believes the negative work experiences resulting from eroded autonomy will push doctors toward activism. But, he admits, activism among doctors may also come from having “...a stake in improving quality of care, a stake that comes from an innate sense that this is the right thing to do" (Birenbaum 2002:138). 
Therefore, physicians who are seen as credible, trustworthy, and benevolent have substantial potential to be influential educators or speakers. Their prestige affords them greater access to policymakers and their erosion of professional autonomy resulting from changes in the healthcare system may provide sufficient impetus for activation. And some argue that physicians have a professional obligation to change policies that have a direct negative effect on health outcomes.

\section{Previous Scholarship on Physicians in Social Movements}

Two areas in which there has been examination of physician involvement in social movements include the pro-choice movement ensuring women's access to safe abortion services and the Civil Rights Movement. Dittmer (2009) chronicles the tales of physicians who founded and participated in the Medical Committee for Human Rights (MCHR). This group was founded by physicians “... who chose to practice in Mississippi communities because they had seen firsthand the paucity of health services available to black citizens and they knew that the problem was political as well as medical" (Dittmer 2009:29). There was substantial unmet medical need in the area resulting in unnecessary suffering. The physicians supported civil rights activists in the south and also brought a contingent to the historic March on Washington in 1963. The MCHR protested discriminatory practices in the AMA and were a major force leading to the desegregation of hospitals (Dittmer 2009).

In the late 1960s and early 1970s, after the passage of legislation to create and implement Medicare and Medicaid, the Medical Committee for Human Rights was advocating for a national health system similar to Britain's (Dittmer 2009). The group 
asserted that "Healthcare is a Human Right" and proposed a plan that called for "prepaid comprehensive health care for all" (Dittmer 2009:240). The group utilized grassroots tactics like going door-to-door and leafleting at malls to educate the public and promised to "eliminate capitalism in the healthcare world" (Dittmer 2009:245). However, the proposals of the MCHR were seen as socialistic, communist, and radical and were never seriously considered. The group suffered from internal disagreement and its opponents used a divide and conquer tactic to weaken the group; it disappeared quietly in the early 1980s (Dittmer 2009). Dittmer is an American historian and does a nice job situating the group's work in the larger social and political context but does not examine physician activism from a social movement perspective.

In detailing how physicians came to be a part of the pro-choice movement in the pre-Roe v. Wade era, Joffe, Weitz, and Stacey (2004) make an interesting distinction between the motivations of professional autonomy and of ensuring patients are not suffering needlessly. They say that physicians who encountered the "ravages of illegal abortion" in hospital emergency rooms were affected in a way that led to them becoming dissatisfied with the status quo of illegal abortion. Sepsis infections resulting from illegal abortions were so common it led some hospitals to establish separate wards for these women. Witnessing the horrific consequences of illegal abortion pushed many physicians to support policies that would allow physicians to perform the procedure in a safe way. To me, this motivation for physicians to engage in activism around abortion reflects how physicians want to avoid unnecessary suffering. The physicians became politically-active because they disliked the avoidable pain and deaths caused by a particular policy. This is 
similar to what Quill (1993) describes as his impetus for writing his book advocating for physician-assisted suicide; to reduce unnecessary suffering.

However, it is interesting that the framing of the issue promoted by the American Medical Association (AMA) focused on professional autonomy (Joffe, Weitz, and Stacey 2004). In its decision to advocate for the right of the physician to perform abortions legally, the AMA explicated that the physician should not acquiesce to patient demands which would reflect a reduction of their autonomy. Indeed, the final decision in Roe v. Wade reads [410 US 113 1973]: “...the abortion decision in all its aspects is inherently, and primarily, a medical decision, and basic responsibility for it must rest with the physician." This framing of abortion being situated in the realm of professional medical decision-making irked feminists in the movement who sought to frame the issue as a woman's decision about her body. Nevertheless, in the years after Roe v. Wade, physicians and feminists were able to work together, bridge their divide, and frame the issue as providing women safe access to abortion services.

The framing of the issues in the pro-choice social movement raises questions for the motivations of physicians in the single-payer movement. Are they upset about the preventable and avoidable suffering they witness like Quill (1993) and the physicians of the MCHR or are they most upset over their deprofessionalization? The next chapter will trace the development of the healthcare system and explain how the consequences have resulted in deprofessionalization for physicians and difficulty accessing and affording care for patients with implications for motivations for engagement in the single-payer movement. 


\section{Summary}

This dissertation will utilize social movement theories to make sense of the findings about motivations and barriers for physician-activists in the Oregon single-payer movement to explain their activism. Collective identity theory has been offered as a way of examining individuals' motivations to engage in social movement activity while paying attention to the cultural context in which the actors operate (McAdam 2004; Melucci 1989). It highlights the interpretation activists' socially-construct and utilize to make sense of political opportunities and structures, overcoming weaknesses in older social movement paradigms.

Collective identities are produced as activists, inhered in networks, engage in framing discourses to distinguish between movement insiders and outsiders (Snow and McAdam 2000). Oftentimes in new social movements, individuals are reacting to policies of the state that they perceive as unjust or a violation of deeply-held morals and values (Meyer 2002; Taylor and Whittier 1992). Powerful emotions can result from these perceived injustices and can serve as a motivator to engage in political activity (Jasper 1998; Gecas 2000; Klandermans 2002). Single-payer activists often portray the lack of universal healthcare in the United States and the avoidable suffering that results as a violation of their values. The collective identity is formed through framing discourses that clarify the problem, solution, and rationale for action (Snow and Benford 1992; Snow and McAdam 2000). In short, “....activists come to see themselves as members of a group that is differentiated from outsiders, interpret their experiences in political terms, and politicize their actions in social movement contexts and in everyday life" (Meyer and Whittier 1994:281). Single-payer activists react to the lack of universal healthcare in the 
US and the negative consequences for patients and physicians, leading them to demand a change in state policies.

However, it is important to bear in mind that individuals fulfilling these criteria can still be prevented from engaging in action if they believe that their actions will not be efficacious or if they do not have available time to dedicate to movement activities. Those who do join the movement must navigate the balance of motivations and barriers (Klandermans and Oegema 1987).

Activism by physicians to promote single-payer healthcare is expected to be instrumental in achieving the goals of the movement. Physicians' status, prestige, and knowledge of healthcare systems give their statements greater impact than non-medical professionals. The next chapter traces fundamental changes to the US healthcare system and explains the consequences for physicians and patients. Understanding how the environment in which physicians practice medicine has changed will reveal sources of discontent and the impetus for desiring health system change. 


\section{CHAPTER THREE: CHANGES IN THE US HEALTHCARE SYSTEM AND TRIGGERS FOR ACTION}

This project gathers data in the framework of a case study examining physician activism for single-payer healthcare in Oregon in 2013. To give context in which the reader can better understand how interviews are situated within the history of health reform and health reform activism, it is useful to trace the development of the US healthcare system and recent state-level movements aimed at achieving single-payer healthcare. It is important to explore the changes in the US healthcare system, health reform policies, and their consequences because the environment in which physicians practice medicine profoundly shapes their views and goals for improving the system. At present, the commercialized era of medicine has created challenges for doctors as well as patients and have fomented demands for changes to the system.

This chapter has three parts. Part One reviews important changes in the US healthcare system which reveals the nation has failed to enact a universal system multiple times. The consequences of these failures for doctors and patients will be discussed to foreshadow potential motivations for political activism. In particular, the consideration of medicine as a profession is discussed and how that has changed over time. Then, singlepayer financing of healthcare will be presented as a solution to healthcare dilemmas. Part Two reviews Oregon's approaches to health reform that has set the groundwork for current health reform attempts in the state. It highlights that Oregon has a history of participatory health reform strategies that have earned it national and international attention, yet its efforts have yielded mixed results. Part Three turns to state-level singlepayer movements. It begins with the only case in which a state has successfully passed 
legislation to establish a state-level single-payer system. This state was Vermont and the section will describe what factors contributed to the successful single-payer movement there. The chapter finishes with details of Oregon's contemporary state-level movement for single-payer and compares it to Vermont. Examining what factors contributed to the success in Vermont can help us understand the context in which physicians are mobilizing in Oregon.

\section{US Healthcare History: From the Golden Age to the Commercialized Age}

Around the turn of the $20^{\text {th }}$ century, the profession of medicine was gaining prestige as physicians' remedies became more effective with the advancement of technology and diagnostic skills. For the first time, healthy individuals were visiting doctors to make sure everything was normal, which marked physicians' growing cultural and social authority (Starr 1982).

Early on, only some doctors had access to hospitals which greatly limited their incomes. Eventually hospitals opened their doors to all practitioners who had a membership with the local American Medical Association (AMA) chapter, because hospitals depended upon doctors for referrals. Doctors were able to practice at hospitals without being their employee. Starr (1982) highlights this fact because he describes it as a moment when doctors were able to "escape from corporate control." Since hospitals needed their beds to be occupied in order to receive patient payments, they increasingly depended upon the doctors to keep the beds filled. Starr (1982:218) says the doctors' “...strategic position in the system represented a resource that gave them power over institutions." At this time, physician autonomy was growing. 
The time period of the 1930s-1950s is referred to as the Golden Age of Medicine because doctors enjoyed significant professional autonomy and were held in high regard by the public. Freidson (1988) believes that physicians during this time are the best example of a profession. He argues "...the only truly important and uniform criterion for distinguishing professions from other occupations is the fact of autonomy -- a position of legitimate control over work. [...T]he single zone of activity in which autonomy must exist in order for professional status to exist is in the content of work itself" (Freidson 1988:82). Therefore, occupations with legitimate autonomy over the content of their work can be described as professions.

Building upon his earlier work, he says "[p]rofessionalism may be said to exist when an organized occupation gains the power to determine who is qualified to perform a defined set of tasks, to prevent all others from performing that work, and to control the criteria by which to evaluate performance" (Freidson 2001:12). Friedson (2001:184) says, "[d]uring the Golden Age, physicians had virtually complete control over the terms, conditions, and content of their work." Also of importance is that the tasks professionals perform require attention to variation found in individual cases. These professionals “...must be prepared to be sensitive to the necessity of altering routine for individual circumstances that require discretionary judgment and action" (Freidson 2001:23). In sum, during the Golden Age, physicians enjoyed unchecked professionalism as they successfully controlled licensing, education, practice, as well as judicial review of grievances. They could practice medicine in the manner they felt was best.

However, medical costs were rising during the 1930s and 40s and people were finding it difficult to pay healthcare bills. Health insurance was seen as a way of ensuring 
payments to doctors and hospitals and as a way of expanding the use of medical care (Starr 1982). Coverage was tied to employment to diminish the likelihood that only the sick would enroll and to reduce the administrative costs associated with individually-sold policies. This left the elderly and unemployed without any financial help for medical costs.

In 1945 Harry Truman proposed a single health insurance system that would cover all Americans, guided by Germany's model. But in the wake of World War II, antiGerman sentiment was high and German social insurance was seen as inconsistent with American values. The feeling helped the AMA successfully launch a campaign to tie Truman's health plan to socialism and largely brought about its defeat (Starr 1982). Furthermore, Robert Taft and other Republicans said they would boycott any hearings that tried to instate "socialized medicine" (Starr 1982:283). This led to most people supporting government subsidies for private insurance as the solution to expand access to care. Starr (1982:288) says, "[t]he rejection of [national] health insurance stands out as an exception to the postwar pattern of rising social welfare expenditures in the US and other advanced Western societies." So "instead of a single health insurance system for the entire population, America would have a system of private insurance for those who could afford it and public welfare services for the poor" (Starr 1982:286).

Toward the end of the Golden Age, the private insurance industry began the practice of "experience rating" in which healthier workers would be given cheaper rates and sicker workers would be charged more for their health insurance coverage. Private insurance justified experience rating by saying it was consistent with free-market principles. In a market system, equity means charging each person according to the risk 
that $\mathrm{s} /$ he experiences and not forcing someone to bear the cost for another person (Skocpol 1996).

At this time, private health insurance benefited the insurance companies, the doctors, and employers. The insurance companies used doctors as gatekeepers to benefits and the doctors used the insurance companies to raise their incomes. With a third party paying some of the bill, doctors could inflate their prices. And as private health insurance increasingly became tied to employment, it was a way to attract employees. The consequence of tying insurance to jobs, however, was that those who were unemployed, retired, self-employed, or underemployed were put in a precarious position since healthcare was more expensive now than ever (Starr 1982).

With significant portions of the population excluded from accessing health insurance, in the 1950s it became clear that government programs would be needed to cover these high-risk groups that private insurance had deemed unprofitable. But physicians and the AMA opposed further government involvement in healthcare because they feared the government would limit physicians' autonomy and pay by controlling their work. After numerous revisions, Congress passed two programs. Medicaid, the program for the indigent, had the stigma of public assistance and was left to the jurisdiction of the states. Under Medicaid, physicians could not charge more than the state would reimburse and participation among physicians was limited (Starr 1982). The other program, Medicare which extended medical insurance to the elderly, had broad support and would be organized at the national level. Medicare let physicians and hospitals set their own fees and participation was widespread. Medicare lodged the 
government program in private interests and greatly strengthened the financial position of hospitals (Starr 1982).

The successful passage of these government programs, over the opposition of the medical profession is generally regarded as the end of the Golden Age of Medicine. At this time, with medical insurance offered through employers and unions in conjunction with public programs for the elderly and poor, this quelled any great demands for national health insurance in the 1960s and 1970s (Quadagno 2004).

Medical costs began to rise again as it was common practice for Medicare and major insurance companies to pay doctors according to the physicians' set fees as long as they were not radically different from the fees of other doctors in the area (Hoff 2010). This payment method, called fee for service, generally included a financial incentive to overtreat because with each additional service came another payment (Bodenheimer and Grumbach 2009). Fee inflation, coupled with a higher percentage of procedures being performed in hospitals, caused healthcare costs to rise rapidly, outpacing general inflation and gains in Gross National Product (GNP) (Starr 1982). In fact, using 2014 US dollars, full-time workers classified as "physicians and surgeons" went from making \$58,222 in 1966 to $\$ 117,524$ in 1968 (Department of Commerce n.d.). The rapidly rising healthcare costs put a burden on employers and the government and ushered in an era focused on cost containment (Relman 2007). "The historical irony is that the private health insurance system that physicians helped to construct became a mechanism for undermining their sovereign rule, as the abuses of professional authority following the enactment of Medicare and Medicaid roused large firms and the insurance industry to seek redress in the form of managed care" (Quadagno 2004:39). At the time of this writing, "physician 
autonomy is threatened more by private insurance than by government interference" (Hoffman 2001:186). In short, the failure to enact national health insurance over unsubstantiated concerns of professional autonomy reduction had the ironic outcome of buoying the private insurance industry which had the tangible effect of eroding physician autonomy.

\section{Cost Containment in the Commercialized Age}

The commercialized age is characterized by the ascension of private market forces to dominance in the medical sector and the reduction of physician professionalism and autonomy (Hoff 2010). In the 1970s, cost containment became the prevailing concern in the era of managed care created with Richard Nixon's health maintenance organization (HMO) plan (Mechanic 2004). The belief was that free-market forces, through "managed competition," would be most effective at reducing costs and improving quality. Each HMO would be given a fixed pool of money from which to provide care to all its patients. This "capitated reimbursement" was expected to eliminate the incentives inherent in fee-for-service and reduce unnecessary utilization of care (Bodenheimer and Grumbach 2009). Nixon's plan represented a shift away from expanding access for the uninsured to cost containment for those with coverage and it further entrenched the private health insurance system in America while marginalizing and stigmatizing public assistance (Starr 1982).

The 1970s also saw the rise of the "medical-industrial complex" (MIC) described as "... a large and growing network of private corporations engaged in the business of supplying health-care services to patients for a profit - services heretofore provided by 
nonprofit institutions or individual practitioners" (Relman 1980:963). The MIC is composed of for-profit hospitals, health insurance companies, medical device manufacturers, the Pharmaceutical Research and Manufacturers Association, and longterm care facilities. Relman (1980:969) warned in 1980 that "[a] private health-care industry of huge proportions could be a powerful political force in the country and could exert considerable influence on national health policy." In the 30 years since his writing, the MIC has grown significantly and has influenced policy. This is worrisome, because Relman notes that the interests of the medical-industrial complex are at odds with the interests of patients and society. The MIC is mostly interested in selling services that are profitable and increasing its overall sales (Relman 1980). Patients, however, are interested only in the services they need and American society has an interest in controlling total expenditures for healthcare. Relman (1980:969) says “ ....the interests of patients and of society must be represented by the physician..." but the financial strength of the MIC coupled with oppositional interests to patients and society creates a formidable opponent.

Angell (1993) argued that because doctors have to represent patient and societal interests against the MIC, they are forced to take on a role as "double agents." It is the contradiction doctors experience negotiating the opposing practices of caring for patients while attempting to control costs. In response, "physicians feel an inherent conflict -either ethical or financial or both -- between patients' interests and those of the managed care system they represent as gatekeepers" (Waitzkin and Fishman 1997:140). Freidson (2001:187) details how this eroded physician autonomy: "Initially, physician and patient reimbursement claims were honored without serious question, but the extraordinary 
increase in costs that occurred during the 1970s led to increasingly stringent efforts to restrict coverage and, more importantly, to develop ostensibly objective medical criteria by which to appraise the propriety of paying claims." These efforts have resulted in the deprofessionalization of physicians.

Furthermore, "[t]he bureaucratic management of government agencies, private insurance companies, and investor-owned health service facilities came to mediate the relationship between doctor and patient. Although they did not necessarily employ doctors, they gained the power to determine how much the doctor would be paid and for which services" (Freidson 2001:187). The autonomy physicians gained early in the $20^{\text {th }}$ century has been infringed upon by the MIC due to its influence on how physicians practice and how they are paid.

Moreover, during the Golden Age, “...the pharmaceutical, medical technology, and hospital industries sought to persuade physicians to prescribe their products, use their technologies, and patronize their facilities" because physicians were the legal gatekeepers who controlled the consumption of medical products and use of facilities (Freidson 2001:188). However, "once these industries had gained state regulatory agency permission to do so, they began to advertise directly and aggressively to consumers, aiming at minimizing their dependence on physicians as gatekeepers by persuading patients to demand what they want from their physicians" (Freidson 2001:188). Hence, these industries were at one time the profession's allies, but have now found good economic and political reasons to adopt opposing positions which pad the bottom line at the expense of physician autonomy during the commercialized age (Freidson 2001). It 
represents a shift in the focus of medical work to securing profits instead of meeting patient needs, raising ethical concerns for physicians.

In the 2000s came renewed attention to healthcare reform at the federal level. Barack Obama was elected president in 2008 and made healthcare reform a cornerstone of his presidency. However, single-payer advocates were excluded from the debates that culminated in the Patient Protection and Affordable Care Act (ACA). The reforms sought to expand access to care which would be accomplished through expanding Medicaid eligibility (which, after a decision by the Supreme Court in 2012, was made an option states could choose to participate in or not) and through the provision of subsidies to individuals to help them afford private health insurance plans bought on "exchanges" or websites. In essence, the ACA strengthened the preeminent position of the medicalindustrial complex and health insurance companies in the commercialized age of medicine. It also made very clear to those hoping for universal healthcare that singlepayer would not be possible at the federal level and that pursuing single-payer would only be feasible at the state level.

\section{Consequences for Physicians: Deprofessionalization}

The decisive criterion of a profession is legitimate control over the content of work (Freidson 1988, 2001). In the last two decades, multiple physician surveys have documented physicians' declines in professional autonomy (discussed below). Details from the studies reveal that most of the grievances stem from oppressive oversight of private insurance companies and the infiltration of business motives into their domain. 
In an open letter to his colleagues in the medical profession, Relman describes the realities of practicing medicine in the era of commercialized US healthcare. He writes,

"Now you face a different climate that compromises your professional standards, constrains your decisions, makes it difficult to treat patients optimally, and sometimes even prevents you from seeing low-income patients who are in need of medical care. You will be increasingly controlled by the financial imperatives of competing organizations that use you to enhance their income. It is a trend that threatens not only the availability of affordable medical services, but your independence and the quality of your professional life" (Relman 2007:161).

The discontent and lamentation of lost autonomy is clear.

Insurance companies have gained power in the medical arena at the expense of physician autonomy. "The dominance of the insurance companies in the health care sector has meant that they, rather than the providers of care, are the ones who have a commanding voice in that sector. As a result, it is frequently not physicians and other health professionals who decide what their patients need; it is the insurance companies" (Navarro 1993:31). When doctors seek the pre-authorization required by many plans and are denied reimbursement for services the physician feels are necessary, it "underscores their powerlessness to use their training and judgment on their patient's behalf [and] is a key contributor to the decline of their profession" (The Physicians Foundation 2012:26). Birenbaum (2002:129) states that at the start of the $21^{\text {st }}$ century, “...the profession has not regained the power lost to managed care in the financing, organization, and delivery of health services. Physicians in the United States are finding their incomes and control over their work situations in decline."

When a doctor determines a test or treatment is necessary to resolve the patient's complaint, reimbursement for the service comes from the insurance company and if the 
insurance company denies reimbursement, the patient must pay for the service out-ofpocket. Freidson (2001:187) argues that “...in so far as some services, drugs, and procedures were banished to a "not covered" limbo requiring out-of-pocket payment, they [are] effectively discouraged." In a national survey of managed care physicians, 60 percent reported that external reviews and limitations on their clinical decisions interfered with their ability to practice medicine (Collins, Schoen, and Sandman 1997). These situations often lead to doctors and their staff spending valuable time attempting to acquire approval or obtain the service through some other means. Results from a recent national survey of physicians found that of the $84 \%$ of respondents who agreed that the "medical profession is in decline," a majority cited "too much regulation/paperwork" as the most important factor followed by "loss of clinical autonomy" (The Physicians Foundation 2012:27). In a multi-country study, $48 \%$ of US physicians said that the "amount of time physicians or staff spend getting patients needed drugs or treatments due to coverage restrictions is a "major problem,"” the highest rate of the 11 countries studied (Schoen et al. 2009). This situation reflects the erosion of physician autonomy in the commercialized age of medicine.

These difficult encounters with health insurance administrators seem to be increasing according to physicians. When a national sample of US physicians were asked in 2006 the extent to which they believed their costs of interacting with health plans had changed in the previous two years, $77 \%$ responded that they had increased in that time (Casalino et al. 2009). The burdens are greatest for physicians in small practices and for primary care physicians (Casalino et al. 2009). Extrapolating from their sample to all physicians in the US, Casalino and colleagues (2009) estimate the total costs to 
physicians from interacting with health plans is about $\$ 31$ billion per year. Morra and colleagues (2011) find that US physicians spend four times as much money interacting with payers than their Canadian counterparts who operate in a single-payer system. In this same study, the US physician's staff will spend 10 times as many hours per week interacting with health plans than their Canadian counterpart's staff (Morra et al. 2011). The loss of US physicians' professional sovereignty is represented in a reduction of "autonomy, control over clinical decision making, self-regulation, management of costs and finances, and control over the decision of medical labor" (Castellani and Wear 2000). Physicians experience this as a challenge to their power and to their medical ethics (Castellani and Wear 2000).

A survey of California physicians in the 1990s sought to measure how physicians' perceived autonomy was changing over time. Burdi and Baker (1999:141) found "[ $[$ the level of autonomy perceived by young California physicians declined markedly between 1991 and 1996." They find "[s]ome of the autonomy reductions observed are directly related to the freedom to make independent decisions about the care of patients" (Burdi and Baker 1999:141).

Their findings also show that fewer doctors have the freedom to care for patients who require heavy time and resource commitment. Eighty-three percent said they could do this in 1991 while $64 \%$ reported being able to do so in 1996 . "The decline in freedom to spend sufficient time with patients was particularly marked among primary care physicians" (Burdi and Baker 1999:141). The authors worry that it will become increasingly difficult to successfully operate "a healthcare system in which one of the most important groups is increasingly disgruntled" (Burdi and Baker 1999:143). In sum, 
the lost physician autonomy results in physicians having less time to dedicate to patients and less control over what remedies their patients receive.

Not all medical specialties experience the same intrusion of health insurance company oversight into their clinical decision-making. The limitations in place by insurance companies place greater burdens on primary care physicians, psychiatrists, and oncologists because they restrict treatment options as the physician develops a treatment plan the patient can afford and adhere to (Ackermann and Carroll 2003). Other medical specialties are less affected by insurance restrictions. These include physicians who practice in emergency rooms, surgeons, and anesthesiologists. Emergency room physicians are often allowed to order whatever tests or treatments they believe are necessary in order to diagnose and return the patient to a stable condition. When surgeons and anesthesiologists perform their work, they do whatever is necessary to perform a successful surgery and do not have to stop mid-surgery to get authorization from a payer. Therefore, the level of erosion of professional autonomy is linked to the medical specialty of the physician.

\section{Consequences for Patients: Increasing Barriers to Care}

The consequences for patients are likely to figure prominently in physician grievances, making it prudent to examine how patient experiences affect physician autonomy. Waitzkin (2012:3) believes the consequences for patients stem from the fact that "...the United States remains the only economically advanced country without a viable national program that ensures access to needed care for all. As a result health care — and health — remain a commodity for sale." Furthermore, the high price for health 
as a commodity is a consequence of experience rating, where individuals with greater medical needs are required to pay the highest prices for health insurance coverage (Bodenheimer and Grumbach 2009). The result is that those who need care the most experience the greatest difficulty accessing care.

Rising premiums have also effectively priced many out of the health insurance market (Hancock 2012). In fact, 49 million Americans under age 65 were uninsured in 2010 (US Census 2011). The implementation of early provisions in the Affordable Care Act caused this number to decline to 42 million in 2013 (US Census 2014). Uninsured patients must pay for all medical care out-of-pocket and often cannot afford to pay a doctor's bill in full. This limits the capacity for sick uninsured individuals to see a primary care physician leading them to sometimes visit emergency rooms for basic treatment with little continuity of care (Bodenheimer and Grumbach 2009). A large number of uninsured patients requiring charity care, coupled with physicians' reported difficulty providing charity care, could contribute to dissatisfaction among doctors with the current system.

While the Patient Protection and Affordable Care Act (ACA) passed in 2010 prohibits companies from denying coverage to people with preexisting conditions beginning in 2014, it does very little to control rising premiums. A report from the Commonwealth Fund (Schoen et al. 2012) that analyzed health insurance premiums over the period from 2003-2011, found that premiums in employer-sponsored plans rose $62 \%$ in those eight years. The cost of premiums rose three times as fast as wages did during this period (Schoen et al. 2012). The study authors further note that "[b]y 2011, there were 35 states in which the annual premium equaled 20 percent or more of income, 
compared with just one state in 2003" (Schoen et al. 2012:3-4). Combined with an erosion of benefits and worker wages that have failed to keep up with rises in the cost of living, the authors say these trends underscore the need for serious health system reform.

The ACA also does not reverse the disconcerting trend towards greater patient cost-sharing. Greater patient cost-sharing is a tactic used to shift financial risks onto patients. High-deductible plans are one way of doing this, where the patient must pay a large sum out of pocket before the insurance company contributes to payment for care. These plans have attracted the attention of large employers who are looking to reduce their costs associated with providing health coverage. This trend is worrisome because large employers like General Electric and Chrysler have switched, affecting thousands of workers and their families (Hancock 2012). Other "[b]ig companies that have shifted all or most employees to high-deductible coverage include financial firms Wells Fargo and American Express and grocer Whole Foods" (Hancock 2012:1). This is a national trend shifting greater responsibility of medical financing to individuals, increasing their burden and forcing many to forego coverage.

Studies have found that greater patient cost-sharing leads patients to skip needed care, preventive care, and cost-effective care (Bodenheimer and Grumbach 2009; Hoffman and Paradis 2008). A Kaiser Family Foundation (KFF 2012) report showed that $58 \%$ of respondents reported that they or a family member in their household reported foregoing or delaying medical care in the last 12 months due to cost. Even families with insurance often learn their coverage is inadequate and find it difficult or impossible to pay medical bills when they get sick. In a study of Americans who filed for bankruptcy due to medical bills, three-fourths had health insurance coverage at the onset of the 
illness (Himmelstein et al. 2005). For some people in the study, their sickness was severe enough to prevent them from working in their jobs, which then caused a loss of insurance coverage, exacerbating the financial pressures. Even for those who were continuously insured, high deductibles and co-pays proved to be financially ruinous (Himmelstein et al. 2005). The effect of shifting costs and risks onto patients is that they find it increasingly difficult to access care and when they do access care, the costs and limited reimbursement by insurance companies limit the range of treatment options available to physicians, reducing their professional autonomy.

For physicians who value autonomy and being able to care for a patient in the way they believe is best, operating in this system can lead to many negative emotions. Waitzkin (2001:83) describes common feelings doctors experience, which include “...guilt, anger that the system can lead to critical delays in patient care, sympathy for patients who have a difficult time getting what they need, annoyance in having to perform tasks that do not require clinical skills, irritation that financial considerations underlay all decisions, frustration that their experiences deviate from what they had expected to have in their medical careers, and sadness that communication is tainted by the nature and organization of medical care."

These negative emotions relating to patient issues contribute to frustration and low job satisfaction rates for physicians (The Physicians Foundation 2012).

In short, the reliance on private, for-profit financing of healthcare coupled with rising premiums and great patient cost-sharing have resulted in a crisis in American healthcare. America remains the only rich nation that leaves tens of millions of its citizens without reliable access to care and is the only nation when tens of thousands of citizens go bankrupt due to medical costs every year. Physicians find their clinical decision-making is frustrated by payer limitations, view their profession in a decline, and 
report compromises to their medical ethics. This situation has produced growing demand for altering the financing of healthcare in America to a non-profit, universal system.

\section{The Single-Payer Alternative: Growing Support for a Fair System}

A single-payer healthcare system can address the issues outlined above because it creates "...one publicly financed insurance fund that provides basic benefits to all citizens and pays providers under uniform mechanisms and rates" (Hsiao et al. 2011:1232). For patients, instead of paying premiums, co-pays, and deductibles, individuals would pay a progressive tax which would cover them for all medicallynecessary care, and care would likely be free at the point of service (Oregon State Legislature 2013). This would reduce financial barriers to care and make it easier for individuals to care medically-necessary care.

In the first half of the $20^{\text {th }}$ century, physicians opposed single-payer health insurance because they feared government financing would control medicine and "they mobilized against this perceived threat to their professional sovereignty" (Quadagno 2004:39). But in the age of commercialized medicine, "physician autonomy is threatened more by private insurance than by government interference" which one reasonably expects would reduce the profession's opposition to national health insurance (Hoffman 2001:186).

In fact, surveys show that support for single-payer is high among physicians today. A 2004 survey of Massachusetts physicians found that nearly two-thirds of respondents favored a single-payer system over managed care or fee-for-service (McCormick et al. 2004). The authors note that Massachusetts is a state with a high 
prevalence of managed care and the administrative oversight associated with managed care systems could contribute to their dissatisfaction with the current system. Only $6.8 \%$ of respondents in their survey felt strongly that private health insurance companies should continue to play a major role in the delivery of healthcare (McCormick et al. 2004). They also found women (70\%) were slightly more likely to prefer single-payer over men (61\%) and that non-AMA members (67\%) were more like to favor single-payer over AMA members (56\%) (McCormick et al 2004). A particularly intriguing finding from this study is that $64 \%$ of all physicians in their sample choose single-payer as the best alternative to provide care, yet when asked what their colleagues thought, only $52 \%$ believed their colleagues would also choose the single-payer system as the best alternative (McCormick 2004). This suggests a discrepancy between actual support for single-payer and perceived support, with actual support being greater.

National studies have illuminated what factors contribute to a physician's decision to support policies establishing a single-payer system. A 2003 national survey of US physicians revealed $49 \%$ support legislation to enact single-payer health system (Ackermann and Carroll 2003). Doctors who had a higher percentage of uninsured patients and patients using Medicaid expressed greater support for establishing a singlepayer system in the United States (Ackermann and Carroll 2003). Other characteristics correlated with increased support for single-payer include working in an urban area, working in a private practice, and being a primary care physician (Ackermann and Carroll 2003). Physicians in these settings and whose clientele include the uninsured or Medicaid recipients may experience greater restrictions on their ability to care for their patients. The uninsured and Medicaid recipients often lack sufficient financial resources 
that would allow them to complete recommended tests or treatments and are more likely to forgo recommended care. It is also this population of patients that require physicians and their staff to dedicate substantial time trying to acquire the needed service or medicine through other channels, which likely lead to their greater support for universal healthcare.

Carroll and Ackermann (2008) did a second wave of their survey five years later and found that national support among physicians for single-payer legislation had increased in that time. Support to establish single-payer healthcare increased to $59 \%$ in their national sample (Carroll and Ackermann 2008). Only 17\% of surveyed physicians strongly opposed single-payer healthcare for America (Carroll and Ackermann 2008).

Sometimes physicians feel the need to assert their perspective. In 2013, in the Journal of Oncology and Practice, an article was published detailing why oncologists support a single-payer, national health insurance system (Drasga and Einhorn 2013). The authors discuss how the current multi-payer system makes it difficult to appropriately care for patients. They describe how patients delay seeking care due to being under- or uninsured and experience difficulty affording their cancer medications. Additionally, the myriad insurance plans have varying benefits, which complicate and frustrate the development of appropriate treatment plans. It is interesting that even though the majority of their argument focuses on the fiscal and pragmatic benefits of single-payer financing, Drasga and Einhorn (2013:4) end by saying, "It is our moral and ethical obligation as physicians to advocate for universal access to health care." Physicians support singlepayer for economic, professional, and moral reasons. 
Waitzkin (2001:169) believes that under single-payer national health insurance, "[d]octors would most likely experience greater clinical freedom and less intrusive micromanagement by administrators." He does not anticipate much change in physician incomes except that “...primary care specialties could anticipate equal or somewhat greater earnings than previously, and only the highest paid surgical subspecialists could expect to see a fall in income" (Waitzkin 2001:169). A reduction in the pay inequities between generalists and specialists could ameliorate the dearth of primary care physicians in the United States. And primary care physicians are on the front lines of medicine, often the first to diagnose depression and help correct patients' lives to prevent future illness (Hoff 2010). Rectifying the disparity in number and in salary between specialists and generalists is expected to improve the overall functioning of the healthcare system (Bodenheimer and Grumbach 2009).

A major benefit expected to come with a single-payer system is restored professional autonomy for physicians. Geyman (2005:3) agrees that under a single-payer system, “[p]hysicians and other health professionals would be freed from much of today's cumbersome bureaucracy; they would find the billing process simplified and their overhead lower, which would leave them more time to devote to direct patient care." Lundberg (2002), a physician, says a single-payer system would address a common source of patient distrust and resentment - undiscussed charges. Since under the current system, treatment costs are neither transparent nor readily ascertainable, Lundberg (2002:288) says, “[m]ore resentment than physicians can imagine results from undiscussed charges." He says patients pay ruefully and that "[n]o explanations [of the bill] are provided, no discussion is encouraged, and no recourse from the final bill is 
offered" (Lundberg 2002:288). He believes the current billing and charging weakens patient trust in physicians and fosters resentment among patients. Under a single-payer system, the pernicious final bill will be eliminated serving to restore dignity to the physician-patient relationship.

In essence, the US healthcare system has lurched to a crisis point creating contradictions for physicians as they care for patients. Many physicians lament their lost professional autonomy and resent the limitations on their clinical decision-making. The trends of cost-sharing make it difficult for patients to access care and to adhere to treatments. Physicians' perception of the decline of their profession and the rising costs of care that limit patient access has created the conditions for a critique and countermovement of for-profit care. The way physicians discuss these issues will reveal what guides their motivations for engaging in collective action.

\section{Political Difficulties Achieving Single-payer Healthcare at the National Level}

Several factors combine to limit the feasibility of passing single-payer healthcare. First, incremental reforms are more politically viable than comprehensive reforms which make single-payer legislation unattractive to policymakers (Oberlander 2003). Second, the opposition to single-payer healthcare, represented by the Medical-industrial Complex is very well funded and organized (Potter 2010). Last, American culture typically promotes individualism and a distrust of government, holding individuals responsible for their fate (Wright and Rogers 2011). In fact, the passage of the ACA created enormous backlash from Americans who felt the legislation violated American ideals. This colored the context in which I conducted my interviews. 
In Washington, health reforms have been incremental; offering small changes rather than drastic change (Marmor and Hamburger 1994). Oberlander (2003:W3-403) argues that "[o]ver the long run, incremental reforms may not be sustainable precisely for the same reason they are enacted: Their acceptance of the status quo guarantees that they will fail to control costs or assure universal coverage." Legislation to enact a single-payer healthcare system is a revolutionary overhaul and is treated with suspicion by politicians because it would dismantle the status quo. The feasibility of single-payer is reduced by a political process discourages full debate and politicians who "... are terrified by the anger that would result from putting health insurers out of business" (Marmor and Hamburger 1994:161).

Marmor and Oberlander (2004:211) further explain that the opponents of fundamental change (i.e., the groups subsumed under the medical-industrial complex) are well-organized, well-funded, and are willing and able to take advantage of the media to "block legislation deemed hostile to their interests." Meanwhile, the 43 million uninsured Americans who would benefit substantially from single-payer healthcare, are “...a diverse group politically, geographically, and ethnically, they have no organization, few financial resources, and little political clout" (Marmor and Oberlander 2004:211).

The imbalance of resources is critical. For example, it is estimated that opponents of NHI spent over $\$ 100$ million to defeat the Clinton bill for universal insurance while its supporters raised only \$15 million (Quadagno 2003). The formidable resources that the medical-industrial complex generates from the status quo are used to ensure that no fundamental changes are enacted. It would seem that only a well-organized and 
mobilized proponent group, with the leadership of physicians, could create a political atmosphere in which politicians feel comfortable supporting a single-payer plan.

Another obstacle to national health insurance is Americans' distrust of government. Single-payer insurance would be publicly-funded and require the government or a non-profit organization to manage the funds. Skocpol (1996) has detailed how the failure of the Clinton health plan in the 1990s was linked to the opposition playing on public fears of "big government." The opposition was able to arouse fears about government intrusion into citizens' personal lives. The opposition's discourse in the media revolved around "meddlesome government bureaucracy." They said national health insurance would be another "billion dollar bureaucracy" with the "compassion of the IRS and the efficiency of the Post Office" (Skocpol 1996). This rhetoric, combined with less than one-fifth of Americans in 1993 trusting the government to do what is right either "always" or "most of the time," stalled progress. Trust in government has not improved in 20 years. A report from the Pew Research Center (2013) shows that in October of 2013, this number remained the same, at $19 \%$. This ideological distrust of government prevalent among Americans proves to be its own obstacle to passing well-meaning reform.

American culture is also highly focused on the individual and the Protestant Work Ethic remains strong in the $21^{\text {st }}$ century. A key characteristic of the Protestant Work Ethic includes the idea that hard work is a calling or duty from God and in order to join God in Heaven in the afterlife, one must fulfill this calling by working hard (Weber 2002[1920]). It is seen as a sin to not work hard and if someone is not working hard then they deserve the negative repercussions in life. This is manifest in the belief of the American Dream 
that every individual can achieve success if only they work hard and make good choices. It is seen as unfair for the government to provide services to disadvantaged individuals because the situation those people are in is due to their own poor choices and not working hard enough.

Single-payer healthcare is antithetical to the Protestant Work Ethic and value of individualism in American culture because healthcare would function as a public good and be available to all, whether individuals work hard or not. In fact, the opposition to the national health insurance plan proposed by the Clintons was attacked because it would charge the same rates to smokers and joggers. Many Americans viewed this unethical and unfair because it violated their values of individualism and the Protestant Work Ethic. Americans' distrust of government and belief that individuals should not get undeserving entitlements helped kill national health reform in the 1990s. Given the equally low number of Americans who trust the government in 2013, this could prove to be influential in shaping physicians' perceptions of the feasibility of single-payer.

\section{Health Reform in Oregon: Failure to Achieve Universal Coverage}

What follows is a brief history of healthcare reform experiments in Oregon since the 1980s. The single-payer movement examined in this dissertation should be understood in the context of a state that has had elite political leadership by a physician (John Kitzhaber) and has attempted to enact universal healthcare multiple times. Hence, Oregon is a state that has repeatedly had healthcare at the top of its agenda and has substantial experience with healthcare policy reforms. 
Oregon is known nationally as a health care innovator. Some of what Oregon has done in the last 30 years has been viewed as lessons that other states could learn from (Bodenheimer 1997). Oregon has engaged in four healthcare experiments with its Medicaid population that garnered national and international attention in recent decades.

The first, in the 1980s, called Oregon Health Decisions, was innovative because it solicited and incorporated public input into what services should be covered. The second, in the early 1990s, sought to achieve universal coverage in the state and established the Oregon Health Plan (OHP). The third, in the 2000s, was a natural experiment due to a lottery in which some individuals gained coverage and some did not. The fourth experiment, in the 2010s, involves Oregon's Coordinated Care Organizations and a flexible budget to address social causes of illness in hopes of reducing the rate of growth of Medicaid spending.

A primary reason why Oregon has embarked on quests to reform healthcare is because of the leadership of John Kitzhaber, a former emergency room physician. He was first elected to the Oregon legislature in 1978 and was instrumental in shaping and implementing health reforms. He went on to become Oregon Senate President from 1985-1993 and has served three terms as Governor of Oregon: 1995-2003 and 20112014. Healthcare reforms have been a part of his platform since early on in his public service. Kitzhaber has drawn substantial attention for his leadership success in guiding Oregon's health reforms. So much so, that an unscientific poll completed in 2013 by Modern Healthcare ranks Kitzhaber as the second most influential person in healthcare; behind Kathleen Sebelius, then Secretary of Health and Human Services, and ahead of then President Barack Obama (Modern Healthcare 2013). 
Single-payer supporters have viewed the incremental changes by the legislature as largely ineffective (Oberlander and Lyons 2009; McCanne 2003). While some experiments have expanded access to care, none of them have achieved universal coverage. Additionally, the experiments have largely addressed which services are covered and the delivery of care, while ignoring the large amount of funds that go to administrative costs in the private insurance system. Single-payer activists have often been mobilizing as these state reforms were taking place and will be discussed after the next section.

Oregon's first novel healthcare experiment began in the 1980s as many states were struggling financially to ensure their citizens had access to healthcare. The inflation of medical prices and increased cost-sharing resulted in medical care being inaccessible for many. What Oregon did differently than other states was involve the medical and public community to incorporate their input and increase transparency in decisionmaking processes. This first innovation created a task force called Oregon Health Decisions which held over 300 community meetings to explore "public values about ethical dilemmas in health care" (Conviser 1990). Among other things, this led to increased planning for end of life care and an increase in the number of Oregonians with living wills.

In 1987 the legislature made a decision to "stop paying for organ transplants, except for kidney and cornea transplants, for Medicaid clients" and use the money to cover prenatal care instead (Conviser 1990). Following a widely-publicized case of a denial of a bone marrow transplant for a nine-year-old boy, Kitzhaber, a state senator at the time, initiated a priority setting project. This case and the project “...helped to focus 
public attention on the more basic issue of what health care services should be guaranteed to all Oregonians, regardless of their insurance coverage or income" (Conviser 1990).

The second experiment began in 1989 when legislation was passed creating the Oregon Health Plan (OHP) and the Health Services Commission. In the priority-setting project, the commission was charged with developing a list of covered health services for the Medicaid population (OHP patients) prioritized from most important to least important. The commission included five physicians, one public health nurse, and one social worker with the remaining four positions representing purchasers and consumers of health care (DiPrete and Coffman 2007). The commission considered clinical effectiveness in its decisions but also integrated social values into the priority list through public involvement (Kitzhaber 1993). This created an environment in which public input on health policy reform was valued and utilized.

Trained staff members collected this public input on social values by engaging in community meetings and focus groups. The public placed a high value on preventive services, particularly for pregnant women and children (Kitzhaber 1993). Community members placed a low value on services that had little to no effect on health status. This process was noteworthy because of the public involvement and collaboration with the medical community to work for the common good. The list of prioritized services for Medicaid patients was finalized in 1993 and is updated every two years (DiPrete and Coffman 2007).

While the prioritized list was targeted at the Medicaid population, another part of this second effort came in 1990 with the goal of establishing universal coverage in the state. Universal coverage would be achieved by altering the requirements for Medicaid 
eligibility to include more adults and an employer mandate. The employer mandate provision was “... beset by business opposition and hampered by the election of a conservative Republican legislative majority in 1994" (Oberlander, Marmor, and Jacobs 2001:1584). The state did succeed in expanding Medicaid coverage to all individuals whose incomes were below $100 \%$ of the federal poverty level with the passage SB27 (previously eligibility was limited to those making $58 \%$ of the federal poverty level).

Oberlander, Marmor, and Jacobs (2001) say that this strategy did not result in substantial cost savings, but it did reduce Oregon's uninsured rate from 17\% in 1992 to $11 \%$ in 1997 while the national average was $16 \%$ in 1998 . They say the explicit rationing and attempts to expand coverage are not new, but "the real innovation in Oregon has been drawing on public participation to build public support and raising revenues for expanding insurance for the poor" (Oberlander, Marmor, and Jacobs 2001:1586). The transparency, public involvement, and collaboration with medical professionals was praised and considered fundamental to the success of the health reform strategy (Fox and Leichter 1991). The OHP program utilizing the prioritized list was well-supported from 1994-2000 due to a strong economy and a sufficient tax base, but a budget shortfall in 2001 ushered in changes (Hrinda 2007).

The third experiment began in 2002 when Kitzhaber, then in his second term as governor, was still keen to expand coverage. In the face of budget constraints, he instated new cost-sharing and premium stipulations to redirect funds from existing policies in order to cover more people. Medicaid eligibility would be expanded to people earning $185 \%$ of the federal poverty limit and would be financed by dividing OHP enrollees into two plans (OHP2): OHP Standard and OHP Plus (Oberlander 2007). 
OHP Plus would cover the population traditionally eligible for Medicaid while OHP Standard would cover the newly-added expanded population. OHP Plus remained largely unchanged while OHP Standard included increased premiums, reduced benefits (excluding dental, vision, and behavioral health services among other cuts), and a six month lockout for members who missed a monthly premium payment (Carlson, DeVoe, and Wright 2006). Additionally, OHP was closed to new enrollees between 2004 and 2008.

"This strategy represented the fiscal pragmatism and progressivism dominant in Oregon politics, specifically the application of conservative means to achieve liberal ends" (Hrinda 2007:16). The goal liberals sought was expanding the number of people on Medicaid and the conservative means to achieve it included regulations that emphasized personal responsibility by increasing cost-sharing and assessing penalties for failure to pay. Hence, this plan had bipartisan support.

Implemented in 2003, the increased cost-sharing associated with OHP Standard was an insurmountable barrier for many and resulted in unintended consequences (Wright et al. 2005). Oberlander (2007:w99) reports that “[i]n the year following OHP2's implementation, enrollment of the Medicaid-expansion population in the health plan fell 53 percent, dropping from 104,000 in January 2003 to 49,000 in December 2003. And in the ensuing eighteen months, OHP Standard enrollment fell by another 50 percent." Suddenly, thousands of low-income Oregonians had lost health insurance coverage due to the increased cost-sharing and the immediate loss of coverage for missing a premium payment. 
Utilizing a cohort analysis over three years, Carlson, DeVoe, and Wright (2006) examined how these changes affected individuals who maintained steady coverage, those that lost coverage, and those that had a gap in coverage. They found that compared to those who had steady coverage, those with disrupted or no coverage had greater unmet medical need and greater medical debt three years after the changes (Carlson, DeVoe, and Wright 2006). They found no effects of the coverage changes on emergency department utilization.

While the cost-sharing component of this plan contributed to its successful passage by appealing to conservatives, it highlights that even modest cost-sharing can have negative health consequences for adults. This case provides "...a cautionary tale for states enamored with consumerism and the prospect of having Medicaid recipients put more "skin in the game" through added cost sharing" (Oberlander 2007:w100). In drafting a single-payer bill for Oregon, activists remembered these unintended effects and minimized cost-sharing in their proposal.

Since OHP was closed to new enrollees and many lost coverage due to lapses in premium payments, this generated a substantial waiting list. In yet another effort to expand access to care, the state "established a new funding source for OHP Standard—a tax on hospitals and health plans - thereby permitting the state to build membership back to 24,000" (Commonwealth Fund 2008). The program could expand to cover 24,000 and had enrollment at the time at 17,000 leaving room for only 7,000 additional enrollees (Yardley 2008). Ninety-one thousand Oregonians signed up to be considered for the latest Medicaid expansion (Yardley 2008). 
Out of this situation emerged the third Medicaid experiment, formally called the “Oregon Health Insurance Experiment." Officials decided the fairest way to select individuals for OHP coverage was a lottery. This lottery selection generated a random control experiment which is rare in the social sciences. This situation allowed for the evaluation of the impact of Medicaid coverage on adult health. This again drew national attention to healthcare reform in Oregon.

Studies following individuals who gained coverage and those who did not had mixed results. On the one hand, results from two years after the lottery “...confirm that Medicaid coverage increased overall health care utilization, improved self-reported health, and reduced financial strain..." as well as "...a substantial reduction in the risk of a positive screening result for depression" (Baicker et al. 2013:1718-1719). These benefits were offset by two findings: that emergency department utilization increased about $35 \%$ among the population that received Medicaid eligibility relative to the control group and that there were no statistically significant physical health differences (measured by blood pressure, cholesterol or blood sugar) between the Medicaid group and the control group (Baicker et al. 2013).

The fact that this study found that emergency department utilization increased among Medicaid recipients has been used as an argument against the Medicaid expansion under the Affordable Care Act. A cornerstone argument for the Medicaid expansion under the ACA was that by providing access to primary and routine care, this would reduce emergency department (ED) use, which is more expensive than regular office care. It is possible that the increase in ED use is due to pent-up demand caused by the prior lack of access and the short timeline of the study was unable to demonstrate the 
longer-term savings generated by increased access to preventative and primary care. Others say that these mixed results should place more emphasis a single-payer system because expanding access to Medicaid did not result in significant benefits (McCanne 2014).

The fourth experiment came after the mixed results from the Oregon Health Insurance Experiment. Kitzhaber, in his third term as Oregon Governor, wanted to try something new. Instead of expanding or reducing access to care, he would make high quality care less costly. In 2012, Kitzhaber struck a deal with the federal government. In exchange for $\$ 1.9$ billion from the federal government over five years, Oregon would slow its per capita rate of growth for Medicaid spending by 2\% (Stecker 2013). This money would be invested in Oregon's Coordinated Care Organizations (CCOs), which function like the Accountable Care Organizations outlined in the Affordable Care Act. This is the fourth Medicaid experiment. This experiment will include a growing number of Oregonians. In fact, out of the states that chose to expand Medicaid under the ACA, Oregon was the state that saw the largest increase in its Medicaid population; the number of adults on Medicaid increased by 34.8\% in the early months of 2014 (Luhby 2014). The figure for all states that expanded Medicaid was an average increase of $8.3 \%$, compared to a $1.6 \%$ increase in states choosing to not expand Medicaid (Luhby 2014).

The CCOs coordinate medical and behavioral care and focus on social determinants of health by connecting social workers with Medicaid patients (Klein 2013). The deal gives Oregon flexibility in what it can spend its Medicaid dollars on. For example, an oft-repeated story is that under the new program, Medicaid dollars can be spent on a $\$ 200$ air conditioner in order to avoid $\$ 50,000$ hospitalizations for an elderly 
woman with heart disease (Klein 2013). Since social conditions strongly determine health conditions, utilizing Medicaid funds to address the social determinants of health is expected to generate substantial cost savings down the line. If Oregon is unable to achieve a lowered Medicaid spending rate, it will lose future funds. As of summer 2014, it is still too early to determine if the CCOs are on track to generate the predicted savings.

For the last 30 years, Oregon has been engaging in innovative health experiments designed to expand access to care and improve the health of its population. Engaging the public and medical community to inform the prioritization of health services was praised and contributed to the success of the OHP (Fox and Leichter 1991). The greater costsharing approach utilized in OHP2 yielded important lessons. Even modest cost-sharing caused low-income individuals to lose coverage and that loss of coverage came with increased unmet medical need and medical debt (Wright et al. 2005; Carlson, DeVoe, and Wright 2006). Lately, Oregon is engaging a new gamble, hoping that coordinating care and adding flexibility in its Medicaid spending will yield savings in the future.

The history of health policy innovation in Oregon may have influenced the development of the single-payer movement in that state. On the one hand, continued attention to healthcare policy reform may have created the fertile soil for the single-payer movement to take hold. After all, Oregon purposively involved lay citizens in the decision-making process. Oregon has also had a physician in a prominent leadership position, perhaps encouraging political involvement among physicians. Also, since policymakers and medical professionals in Oregon have grown accustomed to trying new strategies in health policy, perhaps Oregon is a location where a "radical" idea like 
single-payer can succeed. Kitzhaber has been indifferent about single-payer, choosing to focus on reforming delivery of medical care instead of reforming financing.

Time and time again, Oregon put substantial effort toward expanding access to care, but the percentage of uninsured in Oregon has never dropped below $11 \%$ and was at 15\% in 2012 and 2013 (Oregon Health Authority 2014; Oregon Health Policy and Research 2011). Yet, as mentioned above, problems are not limited to the uninsured. Patients with private health insurance coverage still find that many of their needs are unmet when they use their coverage and tens of thousands still go bankrupt due to medical bills each year (Himmelstein et al. 2005). Ultimately, I believe Oregon's experiments only served to strengthen the conviction among single-payer supporters that making the financing of healthcare non-profit is the only fiscally-prudent way to achieve universal coverage in the state.

\section{Successful Single-payer Campaign in Vermont Inspired Oregon}

Vermont is hailed as the first state to enact legislation that creates a single-payer, universal healthcare system for its citizens. Act 48, enacted in 2011, establishes the path Vermont will take toward a single-payer system to be implemented in 2017. In the years leading up to 2017,the first year states can opt out of the ACA, Vermont will establish a board that designs a financing plan and a basic benefits package for all Vermonters. This was achieved through a grassroots social movement, very similar to the movement underway in Oregon. Examining the path that led Vermont to successfully pass its singlepayer legislation can inform the context in which Oregon physicians make their decision to engage in such activism. 
Unfortunately, there is little scholarly work published on the single-payer campaign in Vermont. Many of the sources pertaining to Vermont's single-payer movement describe the legislation and not the social movement organizing that made the legislation possible. Due to this, I drew information from nearly all relevant sources I could find that describe the struggle to achieve single-payer in Vermont. I feel comfortable utilizing the information I gathered because there was no contradictory information among the sources. The sources utilized included things like newspaper articles, Vermont politicians' websites, stories written by activists in the movement, and my fieldnotes taken at the presentation by Vermont activists.

Vermont, similar to Oregon, had a physician governor with healthcare reform as a centerpiece of his agenda preceding the single-payer campaign. Howard Dean was Vermont's governor from 1991-2003 and used his position to expand medical coverage to vulnerable populations in his state. His is perhaps best known for his Dr. Dynasaur program. The program expanded Medicaid to achieve near-universal medical coverage for children and pregnant women which helped to reduce the uninsured rate in Vermont. Yet, this incremental reform still meant that many citizens were uninsured or vulnerable to medical costs, so single-payer advocates began mobilizing for comprehensive reform.

The single-payer victory in Vermont was long in coming. "Single payer bills were introduced in Vermont for more than 25 years, but were unable to get legislative approval until a widespread public education campaign around the theme of health care as a human right raised enough public interest that voters put pressure on legislators to pass the bill" (McCurdy 2012:1) It was a hard-fought battle and required over a decade of grassroots 
organizing to make it happen. Several factors led to its success; factors which activists in other states, like Oregon, are trying to re-create.

First, Vermont had an indefatigable physician advocate in Deb Richter. Frustrated with lack of access to her politicians in New York, she moved to Vermont in 1999. In that year she assembled an ad hoc group called Vermont Health Care for All (Wright 2013). She proposed that Vermont amend the state constitution to declare access to medical care as a human right. This was not successful, but Dr. Richter did not abandon her efforts and gave hundreds of talks to business groups and others between 1999 and 2003. It is estimated that by 2011 , she gave over 500 talks just to medical providers which convinced many to support the single-payer legislation in Vermont (McGill 2012).

In 2001, the state commissioned a study to examine healthcare financing options. The state-commissioned Lewin Report determined single-payer to be the best option, saving an estimated \$118 million annually (Wright 2013). In 2005, a single-payer bill was introduced and passed the legislature, but was vetoed by Governor Jim Douglas (McGill 2012; Wright 2013). Next, in 2006, the state commissioned another economic study by Ken Thorpe to evaluate which type of healthcare system would be the most fiscally responsible. The study concluded that a single-payer system would provide the greatest savings, echoing the findings from the previous study.

A second factor contributing to the successful campaign appeared in the mid2000s; Vermont Healthcare for All began collaboration with the Vermont Workers Center. The latter group, representing unions and the working class, supported universal healthcare because so much time during contract negotiations was spent on healthcare coverage. With universal healthcare, the union advocates could focus on other important 
labor issues. The Vermont Workers Center was not an expert on healthcare, but did have substantial experience mobilizing grassroots supporters. This group was able to reach into communities by going door-to-door to get in touch with individuals, inform them about single-payer, and build the movement (McGill 2012).

However, even with the grassroots mobilization, the Vermont single-payer movement was frustrated by the fact that many politicians said the single-payer plans made sense, but weren't politically feasible (McGill 2012). Activists and the Vermont Workers Center knew that in order to be successful, they had to make single-payer viable politically. Since politicians depend upon votes to be elected, the campaign sought to make sure politicians knew that thousands of voters would only vote for them if they supported healthcare for all. They accomplished recruitment through staffing tables at grocery stores and farmers markets, writing letters to the editor, marching in local parades, and building alliances with religious groups and local businesses (McGill 2012). Activists from the Vermont Workers Center reported that being able to demonstrate widespread support was fundamental to their success. The group was so successful in getting a majority of voters to understand and support single-payer, that politicians had to publicly support it if they wanted to be elected or re-elected. Showcasing the reach of their efforts, the Healthcare as a Human Right campaign held a rally at the Vermont Capitol in 2009 with over 1000 attendees.

Another factor that was instrumental in the passage of single-payer legislation in Vermont was the leadership of Peter Shumlin. Shumlin was rising in the state senate and said the following regarding healthcare: "They are not going to solve this in Washington. They are not going to come up with a solution, and we'll have to do it here in Vermont" 
(Wright 2013:np). The single-payer campaign supported and campaigned for Shumlin since he advocated for single-payer.

In fact, Shumlin credits his being elected as governor to the grassroots organizing. He supported single-payer healthcare and believes he would not have been elected if it were not for the activists informing people about single-payer healthcare. Shumlin stated, "The grassroots support I got from single-payer advocates made it possible for me to be governor. They knocked on doors. They poured their hearts out. They saw an opportunity, and I would not be here without them" (Wright 2013:np).

In March, 2010, the state commissioned a third economic study of healthcare systems in Vermont. This time, William Hsiao of Harvard led a study that “...concluded that the most effective way to achieve Vermont's stated reform goals of universal coverage and cost containment would be a program that retained the fundamental concepts of a single-payer system" (Hsiao et al. 2011:1233). Unlike previous studies which only looked at economic aspects, Hsiao’s study “...explicitly considered the political landscape and the fiscal, legal, and institutional constrains on reform" (Hsiao et al. 2011:1233).

2010 was also the year Shumlin was elected to governor. In 2011, Shumlin signed Act 48 into law which creates a universal health system in Vermont. The state is currently complying with stipulations under the Affordable Care Act and is laying the groundwork to establish its universal health system in 2017 , which is the first year states may deviate from the Affordable Care Act.

The factors that contributed to success in Vermont included vocal medical provider advocates, economic feasibility studies, a visible political leader, and grassroots 
organizing that ensured candidates supporting single-payer were not committing political suicide. The factors that led to success in Vermont can inform strategies in other states seeking a similar goal.

\section{Oregon Single-payer Campaign}

Oregon activists are hoping to learn from Vermont and emulate its success. While Kitzhaber and the Oregon legislature tinkered with the Medicaid program, single-payer advocates have been on the sidelines, fighting for their chance to establish an affordable, universal, and quality healthcare system. Like the single-payer movement in Vermont, the Oregon movement has had very little published about it. The sources I used to trace the Oregon campaign include my fieldnotes, newspaper articles, and the website for the Oregon single-payer movement.

The modern campaign to establish single-payer healthcare in Oregon has occurred in two phases. Phase one occurred between 1993 and 2002; phase two began in 2008 and continues today. The first campaign crystallized with the introduction of SB707 into the Oregon Legislature in 1993. The bill would have established a single-payer system of universal health insurance in Oregon. It was sponsored by Senator Frank Roberts and had the support of 100 organizations. The bill failed, but single-payer advocates were undeterred.

In 1995, the Oregon Health Action Campaign spearheaded the submission of SB1066 which would have also created a single-payer healthcare system at the state level. The bill received a hearing, but did not succeed (Huntington 2014). After its defeat, activists backed off to reconsider their strategy. In 1999, after deciding to launch another 
single-payer campaign, activists founded Healthcare for All Oregon (HCAO), an independent 501(c)4 organization.

"From 1999 through 2001, a broad-based group of citizen activists in HCAO spent years writing the initiative language and getting feedback on the measure from other groups around the state" (Huntington 2014). In 2002, HCAO filed ballot measure 23 titled the "Oregon Comprehensive Health Care Finance Plan." Opponents outspent supporters by a measure of 50 to one and the bill garnered only $21 \%$ of the vote (Huntington 2014). After this point, there was a lull in the Oregon single-payer movement for a few years. This dearth of activism and outreach for single-payer healthcare between 2002 and 2008 is what I consider the break between the first and second phases of the Oregon campaign for single-payer.

In 2008, emergency medicine physician Paul Hochfeld in Corvallis debuted a movie he made called Health, Money, and Fear. The movie details numerous issues with the multi-payer arrangement of US healthcare and promotes single-payer healthcare as an alternative. Hochfeld made the movie, but experienced difficulty finding an audience for it. A potential solution came in 2009 when he was approached by Adam Klugman, Creative Director/Owner of Progressive Media Agency, and Gary Jelinek, a political organizer, and asked to start a group called Mad as Hell Doctors (MAHD).

Hochfeld and his physician friend Mike Huntington deliberated over whether they were truly "mad" enough to start a physician advocate group for single-payer. Eventually the two agreed they were sufficiently angered by the performance of the health system and by the avoidance of single-payer in national health reform talks to lead the group. Six physicians embarked on a cross-country tour from Oregon to Washington D.C., stopping 
in 30 towns along the way to speak about healthcare dysfunction and the potential of single-payer financing (Graves 2009). In 2010, the group would tour across California, spreading a pro-single-payer message. In 2011, MAHD did a tour around the state of Oregon. These tours were one way for Hochfeld to promote his movie and educate the public about single-payer healthcare.

The year 2011 was a watershed year for the single-payer movement in Oregon. In January, 500 people attended a conference to hear US Representative John Conyers speak about his national single-payer bill, HB676. The same year, the single-payer campaign supported Representative Michael Dembrow in submitting HB3510 into the Oregon state legislature. Dembrow experienced single-payer healthcare firsthand in France with the birth of his first child and compared that experience to the birth of his second child in the US. The financial burdens for his family in the US resulting from the hospital stay compared to no financial burden in France led him to want to fight to bring affordable, quality healthcare to Oregonians. House Bill 3510 would set up a state-level single-payer health system and is called the "Affordable Healthcare for All Oregon Plan." The bill was still under consideration by the Ways and Means Committee when the committee adjourned, effectively killing the bill.

In December 2011, two Portland-based progressive organizations Jobs with Justice and Alliance for Democracy brought employees from the Vermont Workers Center to Oregon to do a tour around the state explaining how it successfully passed the single-payer bill in Vermont. An estimated 350 people attended the Portland presentation. The tour and talks by the Vermont Workers Center energized and brought renewed vigor 
into the Oregon single-payer movement. Oregon activists planned to adopt the strategies that proved successful in Vermont.

In January 2012, representatives from twenty-eight organizations, including unions, community organizations, immigrant rights groups, faith groups, and health care advocates met to form a new statewide coalition for single-payer. This new coalition of single-payer activists received formal permission from the first wave of activists to use the group name Healthcare for All Oregon (HCAO) to represent their coalition. In 2012, HCAO mobilized supporters around the state and in February 2013 the group held a rally on the Capitol steps that drew nearly 1000 single-payer advocates (Hall 2013).

At this point, Oregon had many of the pieces in place that led to success in Vermont. Oregon had a vocal medical provider community active in advocating for single-payer healthcare. It developed an alliance with the group Jobs with Justice which assisted with the grassroots organizing. HCAO itself also worked to establish networks in all areas of the state and mobilized grassroots support by county and legislative district. Oregon even had its political leader, Dembrow, willing to spearhead the campaign. What Oregon lacked though, was an economic feasibility study. Activists felt it was imperative to have an economic study to convince politicians that single-payer financing would be in the economic interests of the state. Without a study demonstrating the potential efficacy of single-payer, many of the politicians' questions would remain unanswered. Table 3.1 below compares the important factors between the two states. A plus sign indicates the factor's presence and a minus sign indicates its absence. 
Table 3.1: Factors Affecting Vermont and Oregon's Single-payer Campaigns

\begin{tabular}{|l|c|c|}
\hline \multicolumn{1}{|c|}{ Factor } & Vermont & Oregon \\
\hline Vocal Medical Providers & + & + \\
\hline Political Leadership & + & + \\
\hline Grassroots Organizing & + & + \\
\hline Economic Study Bill & + & - \\
\hline
\end{tabular}

A Study Bill (House Bill 3260) was introduced in the Oregon legislature in 2013 and passed. The study is to examine the economic impact of four different health system arrangements. The four options for financing healthcare to be studied under the bill include (1) the status quo (i.e., continuing with ACA reforms); (2) ACA reforms plus a public option; (3) a publicly-financed and privately-delivered single-payer system; and (4) an "essential health benefits" plan using private health insurance.

If the study is done, single-payer advocates are confident that the results will be similar to Vermont's economic studies and demonstrate that single-payer healthcare is the most economically-effective way to achieve universal healthcare. However, in designing the bill, activists judged that it would not pass if funding was requested from state coffers. So, the bill stipulated that funding for the study would come from private sources. As I write in fall 2014, this bill has not garnered sufficient funding, threatening to leave the movement without the hard data that was influential in Vermont (Gray 2014).

While Oregon copies the Vermont strategy, it is important to note some differences between that states that might bear on the influence of collective action. First, Oregon is much larger than Vermont in both population size and geography. Oregon's 2013 population of 3.93 million is six times as large as Vermont's 2013 population of 626,000 . This means Oregon activists will have to educate a much larger number of voters if political reforms are to be viable. Additionally, this larger population is spread 
out over a much greater area. At 97,052 square miles, Oregon is about 10 times the size of Vermont (9,615 square miles). This may present strategic and logistical challenges for movement activists to ensure all areas of the state are included in movement organizing.

Second, Vermont has a history of progressive politics. It was the first state to partially-outlaw slavery in its constitution and the first to allow civil unions for same-sex marriages (Ollove 2014). Also, the longest-running independent in the federal Senate, Bernie Sanders, represents Vermont. He is a self-described socialist and supported Vermont's experiment with single-payer healthcare. Further, during consideration of Act 48 in Vermont, both legislative chambers held democratic super majorities, helping to ensure its passage (Ollove 2014).

Oregon has traditionally been a democratic state and also has passed progressive legislation. For instance, Oregon was the first state to pass physician-assisted suicide. But Oregon's House of Representatives and state Senate are more evenly divided than Vermont's, as Democrats only slightly outnumber Republicans in both chambers. These factors may influence the perceived feasibility of passing single-payer legislation in the state, which could influence the choice to engage in activism.

\section{Summary}

The failed attempts to enact a universal, national health insurance system in the United States led to the complex multi-payer arrangement that characterizes our system. The ascension of the medical-industrial complex in the commercialized age has reduced the professional autonomy and decision-making capacities of physicians. This is worrisome because it gives the Medical-industrial Complex power to enforce its interests, 
which are opposed to the interests of individuals and society (Relman 1980). Moreover, cost-sharing trends have shifted more of the financial burden onto patients, resulting in increased barriers to care. The resulting frustration for doctors and patients has produced a situation ripe for a critique of the for-profit financing of healthcare in America.

This situation reached a crisis point as states needed to confront thousands of citizens without access to care. Oregon has explored various alternatives to expand coverage in the state, many of which were led by Kitzhaber. However, none of them succeeded in achieving universal coverage. Over the last twenty years, single-payer advocates in Oregon have struggled to realize their goals, but are hoping to emulate the recent success in Vermont. Oregon has its grassroots organization, Healthcare for All Oregon and its political leader, Dembrow, championing the cause. Oregon also has a vocal and active medical provider community increasing awareness of single-payer healthcare in the state. The single-payer campaign is waiting to learn if the money to fund the Study Bill will be acquired. The findings from this study will highlight the most economically effective ways of financing healthcare in the state.

The Vermont campaign provides an example of a successful single-payer movement that confers valuable experience and guidance for activists hoping to achieve similar legislation in other states. In particular, the Vermont case demonstrated that democracy is still alive in America and social movements can utilize the political system to achieve progressive social policy changes. Since Oregon has many of the pieces in place that Vermont did during its successful campaign, it gives a sense of optimism and feasibility to the Oregon advocates which encourages their participation in collective 
action. The next chapter will discuss the research design of this project as it examines physician activism in the Oregon movement for single-payer healthcare. 


\section{CHATPER FOUR: RESEARCH DESIGN}

The purpose of this study is to examine the determinants of physician activism for single-payer healthcare in Oregon. This chapter describes the specific research questions, the study design, the process of data collection, and the analytic strategy pursued.

\section{Research Questions}

This study seeks to answer two research questions pertaining to physician activism in the movement for single-payer healthcare in Oregon. The two research questions are:

RQ1. Among Oregon physicians who state they support enacting a non-profit, single-payer system, what accounts for mobilization and collective action regarding single-payer healthcare?

RQ2. For those Oregon physicians who do choose to engage in reform efforts, what activities are they involved in and what shapes their choices to engage in these activities?

\section{Study Design}

In order to answer these questions, this study combines semi-structured interview data with participant observation data. Most data comes from physician interviews, but it is supplemented by participant observation data acquired by the researcher as she engaged and witnessed physician mobilization in the Oregon single-payer movement. All respondents in the study agreed to supporting single-payer in principle, but differed on their levels of activism. This approach allows for comparison to illuminate factors that are unique or more determinative among single-payer activists and others common among both groups (Weiss 1994). A semi-structured interview guide and a questionnaire 
were developed to converse with respondents (see Appendix A and B). The semistructured nature of the interview guide allowed for flexibility to follow promising leads that emerge in the course of the conversation (Weiss 1994). The interview questions covered the experiences of physicians as they practice medicine today, their level of involvement in pro-single-payer activities, and their personal background and beliefs. The questionnaire asked about professional characteristics including the year in which the respondent graduated from medical school, their medical specialty, and the settings in which the respondent has practiced medicine.

\section{Sampling and Data Collection}

Participant observation data came from participation in aspects of the Oregon single-payer movement. I attended conferences organized by the physician-activists, regular meetings, rallies, and education talks that were part of the single-payer movement. I took notes on the framing discourse the presenters used at these events to better understand their arguments and motivations guiding their struggle for single-payer healthcare.

Respondents participating in the interview portion of the study were eligible if they had a Doctor of Medicine (MD) degree, practiced medicine in Oregon, and supported the idea of single-payer healthcare in principle. While these criteria were the same for all respondents, the physicians differed in other ways, like gender, medical specialty, age, and most important, level of activism. Initial respondents were identified based on their participation in single-payer organizations, contacted via email, and invited to participate. Interviews were conducted in-person and over the phone between 
July and November 2013. In-person interviews were conducted at a variety of locations, including public places like coffee shops or private locations like the respondent's home. Telephone interviews were done with respondents who lived around the state or with respondents whose schedules did not permit in-person interviews. Eight interviews were conducted over the phone and the remaining 13 were conducted in person. Respondents were informed of the purpose of the study, notified that the conversation was being recorded, that their participation was voluntary, and that their answers were confidential.

After each interview, respondents were asked to refer other physicians who might be interested in participating in the study. This snowball strategy led to an abundance of highly-active physicians in my sample. In order to increase the diversity amongst respondents, targeted sampling techniques were utilized, in which respondents are purposively recruited to ensure adequate representation of different groups in the sample (Weiss 1994). Respondents were asked to refer physicians who believed in single-payer, but were not active in the movement. Implementing the targeted sampling strategy yielded an even distribution of low-level activists (6), high-level activists (8), and nonactivists (7). Sampling continued until saturation was reached. Saturation is reached when new interviews are yielding redundant information. When the researcher is no longer learning new information in the interviews, the researcher has pursued all of the variance that exists in the sample population and it is considered appropriate to stop data collection (Thorne 2008).

The final sample included 21 respondents from around the state of Oregon that differed on their level of activism, gender, medical specialty, and age (see Table 4.1 on page 91). The medical specialties included family medicine, internal medicine, 
psychiatry, emergency medicine, obstetrics, cardiology, oncology, neurosurgery, endocrinology, radiology, and anesthesiology. The sample also reported various work settings. A few reported having worked their entire careers in one setting such as a large group practice like Kaiser or a single-payer system like the Veteran's Administration. More commonly, the sample reported practicing at more than one location over their career working in a combination of settings including community health clinics, university student health centers, academic medical centers, small-group practices (less than five physicians), a group practice with 6-20 physicians, and health maintenance organizations (HMOs).

Twelve respondents (57\%) are currently practicing medicine whereas nine respondents (43\%) have retired from active clinical practice. Two-thirds of respondents were male and one-third were female. This gender breakdown is representative of the practicing population of physicians in Oregon (Oregon Department of Human Services 2010).

Physicians fell into three categories of activism: high, low, and none. There were seven non-activists in the study. Respondents were placed into this category if they do no activism for single-payer or if their activism was extremely limited. For example, one woman was not part of an organization and did not participate in any formal activities, but she said she was willing to talk with other individuals when they brought up the topic. She was placed in the non-activist category because she does not instigate activities, does not engage in activities in an ongoing manner, and does not participate in collective action. 
Of the 14 activists that reported engaging in collective action, six had low-level activism and eight had high levels of reported activism. Activists were considered highlevel if they engaged in activities that required substantial personal effort, through the investment of time and talent, coordination, and planning. Some activities high-level activists engage in include planning single-payer conferences, drafting single-payer legislation, holding leadership positions in the movement, hosting a radio show discussing single-payer, and doing cross-country tours to speak about single-payer. Highlevel activists were also identified based on their ongoing support; they engage in activities over months and years. These individuals absorb high costs associated with their activism like mental focus, time, energy, cooperation with and coordination of others, as well as opportunity costs.

The low-level activists were identified by their limited, but committed engagement in the movement. Low-level activists engaged in activities that do not require substantial investments of time or resources. These respondents engaged in activities like posting on social media or commenting on Internet blogs with a pro-singlepayer message, manning a booth at an event to collect signatures, signing petitions, paying member dues to a single-payer organization, or occasionally attending meetings of a single-payer group. Oftentimes the high-level activists engaged in lower-level activities, but were distinguished by their sustained and ongoing participation in high-effort activities that occurred in addition to the low-level activities. The low-level activists do not shoulder as much of the costs associated with activism as the high-level activists, but still experience some costs as their activities still involve some time and effort. 
Table 4.1: Sample Characteristics

\begin{tabular}{|c|c|c|}
\hline \multicolumn{1}{|c}{ Variable } & $\begin{array}{c}\text { Non- } \\
\text { Activists (7) }\end{array}$ & Activists (14) \\
\hline Activism Level & & \\
\hline None & $\mathbf{1 0 0 \%}$ & N/A \\
& $(7 / 7)$ & \\
\hline Now & N/A & $\begin{array}{c}\mathbf{4 7 \%} \\
(6 / 14)\end{array}$ \\
\hline High & $\mathbf{5 7 \%}$ & $(8 / 14)$ \\
\hline Gender & & \\
\hline Male & $\mathbf{4 3 \%}$ & $\mathbf{7 9 \%}$ \\
& $(3 / 7)$ & $(11 / 14)$ \\
\hline Female & $\mathbf{5 7 \%}$ & $\mathbf{2 1 \%}$ \\
& $(4 / 7)$ & $(3 / 14)$ \\
\hline Practicing & & \\
\hline \multirow{2}{*}{ Practicing } & $\mathbf{4 3 \%}$ & $\mathbf{6 3 \%}$ \\
& $(3 / 7)$ & $(9 / 14)$ \\
\hline Retired & $\mathbf{5 7 \%}$ & $\mathbf{3 6 \%}$ \\
& $(4 / 7)$ & $(5 / 14)$ \\
\hline
\end{tabular}

Data Analysis

The audio-recorded semi-structured interviews were transcribed by the researcher during and after data collection. The transcriptions were imported to Dedoose, a qualitative data analysis program. Analysis began with an open coding process. At this stage, the researcher read through the transcript, at each point attaching a new code to each sentence each respondent said. Codes are "...the labels we use to classify items of information as pertinent to a topic, question, [or] answer..." (Lofland et al. 2006:200). The early coding process helps the researcher "....select, separate, and sort data to begin an analytic accounting of them" (Charmaz 2006:43).

Next, analysis progressed to focused coding. In this step, the researcher reduced the number of codes by combining similar codes, rephrasing codes, or dropping codes that upon reflection, seemed unimportant to the larger project. The reduced number of 
codes permits the identification of emerging themes and patterns (Weiss 1994). At times "in vivo" codes were used. In vivo codes use the respondent's language as the code label which helps to preserve the respondents' actions and views as they understand them (Charmaz 2006). A final codebook was developed which included 35 codes.

Autonomy was the only code assigned numerical weighting ranging from negative one to positive one. If a doctor said that their autonomy was unjustly infringed upon, the passage received an autonomy score of negative one. If a doctor mentioned that their autonomy was appropriate (i.e., controls on their freedom were prudent and reasonable) the passage was given a score of zero. Passages from respondents who felt that doctors have too much autonomy and freedom were assigned a score of 1 . This was done to capture the different contexts in which the issue of autonomy was discussed and to measure levels of experienced and perceived deprofessionalization.

Throughout the coding process, I kept a list of analytic memos in the form of early interpretations and reflective insights (Marshall and Rossman 2006). These memos include tentative connections among codes and conjectures about preliminary findings (Charmaz 2006). These were kept in a separate file and updated throughout the analysis period as I interacted with the data.

Once all codes had been refined and attached to quotes, functions in the Dedoose program were used to systematically analyze the codes. One strategy pursued was to examine the co-occurrence of codes to see where respondents talked about more than one issue in the same story or context. For example, codes about infringement on professional autonomy often co-occurred with codes about insurance policies. Additionally, analysis was conducted to examine codes had a gradient or the frequency in which codes were 
reported by high-level activists, low-level activists, and non-activists. For example, codes about social justice were most common among high-level activists and least common among non-activists, with low-level activists in the middle. Codes for American culture as a barrier to single-payer had a gradient, but reversed (most common among nonactivists and least common among high-level activists). The researcher also chose to focus on topics that were common to a majority of respondents in that category.

After this step, I was able to identify patterns amongst respondents in relation to the research questions. Analysis then progressed to the developing of themes in order to succinctly describe the motivations, barriers, and activities physicians experience with single-payer activism. The process of generating themes raises the descriptive codes to a "conceptual category" by continual questioning and interaction with the data (Charmaz 1990). If a code has been elevated to the conceptual category of a theme, it means that it reflects a significant process or issue in the study and has connections to other themes (Charmaz 1990). The themes served to expose important commonalities among the activists as well as the components of the collective identity produced and sustained among the activists.

Chapter Five reviews findings about physician mobilization for single-payer. I trace common background characteristics of activists, work experiences, motivations for activism, and justifications for advocating single-payer as the best solution to the healthcare crisis. I find that the activists share a collective identity that encourages political and grassroots activism to switch the financing of healthcare in Oregon to a single-payer system. I also detail what activities the physician-activists engage, how they choose their activities, as well as considerations around barriers and burnout. 


\section{CHAPTER FIVE: PHSYICIAN ACTIVISTS}

This chapter utilizes an empirical case study of physician activism surrounding single-payer healthcare in Oregon. To date, no scholars have systematically explored physician mobilization around single-payer, universal health care in the United States. In this chapter, I aim to show how the physician activists engaging in the Oregon movement for single-payer collectively produced and shared a collective identity that facilitates engagement in a wide range of social and political actions that challenge the way healthcare is financed. This chapter will discuss why physicians are motivated to engage in activism for single-payer, how they mobilize, and what physician activism for singlepayer looks like.

Drawing from social movement theories, in particular collective identity theory, I find that physicians develop a collective identity centered on single-payer financing of healthcare being the only way to solve the problems in our healthcare system (i.e., achieving universal access to care without increasing spending). Physician mobilization for single-payer healthcare in Oregon includes motivations that derive from a reaction to state policies that are inconsistent with internally-held values. I find that physicianactivists are inclined to act due to their interpersonal values that make them want to help others coupled with a work experience colored by national policies that promote medicine as a business.

The collective identity produced through interaction among physicians who support universal healthcare has five main beliefs: (1) a value system that promotes social justice, equality, and fairness; (2) a frustrating experience of deprofessionalization that 
compromises medical ethics; (3) a sense of duty to help the less fortunate; (4) a belief that healthcare reform must prioritize changing the financing of healthcare instead of continuing with delivery reforms; and (5) a perception that political opportunities for single-payer are achievable at the state level. The first two factors predate the respondent becoming a physician and incline them to act whereas the other factors are sociallyproduced and reinforced in physician networks. These five beliefs serve to create the boundaries that define membership in the group.

Most physicians in my sample came to join the movement after becoming dissatisfied in their practice and seeking solutions on the Internet. From there, physicians learn about how other countries finance care and seek local chapters of single-payer physician organizations. In these groups the collective identity is formulated through framing discourses and adopted. It provides the rationale for action and awareness of opportunities to participate in outreach activities. Physicians tend to participate in activities they enjoy or fit with their skill set, while the constraints of availability condition their level of involvement.

Five Main Beliefs of the Collective Identity

The physician activists working for single-payer healthcare are inclined to act because they witness the violation of their interpersonal values of social justice in their work settings. The inter-personal values of justice, equality, and fairness compose the first piece of the collective identity and influenced their choice to become a doctor and their practice location. Once practicing, physicians realized they were in a broken system that does not meet patient needs. This is a result of the trends in the commercialized age 
of medicine that have turned medicine into business and caused insurance companies to dominate the medical arena. Physicians who desire to put patients ahead of profit describe the system as "hostile" to them and this situation produces emotions such as anger, frustration, and outrage.

The second piece of collective identity results from these experiences: the belief that anger-inducing issues resulting from deprofessionalization would be ameliorated in a single-payer system. The third belief is desire to help others and stems from a sense of a social, professional, or religious duty to help the disadvantaged. The activists recognize the need for collective action to make that happen. The fourth belief centers on the prognostic frame and emphasizes that changes to the financing of healthcare must happen before more delivery changes. The last belief of the collective identity produced by the activists is that single-payer is achievable at the state level. Each of these five beliefs will be substantiated below.

\section{Interpersonal Values of Equality and Justice}

The physicians who engage in activism for single-payer healthcare all express a strong commitment to interpersonal values of social justice instilled during childhood. These values derived from parental or religious teachings and focus on the notions of social justice, fairness, equality, and helping the less fortunate. For many, this guided their choice to become a physician as well as their practice location, choosing to practice in underserved areas.

I find that these values form an important part of the foundation of the collective identity of the physician-activists. Belief in and commitment to these values serve to 
distinguish insiders from outsiders. All activists felt strongly that medical care should be a public good to which everyone should have access and if this belief is not met, then one does not belong in the group of single-payer activists.

For example, a male practicing in internal medicine describes his motivations for engaging in single-payer activism this way: "If someone's suffering and dying and you can help them, then you should. It's kind of a simple moral idea." He knows that people can be helped because of the economic studies demonstrating that rearranging the financing of healthcare would allow everyone to access needed care without spending more money. Hence, we have the money to ensure everyone has access; so if we can help people, we should.

He goes on to say that his morality derived from Catholic teachings during childhood. He is no longer a practicing Catholic, but he carried the basic moral principles with him through life. He says,

"I certainly think the values that I have preceded my activism for universal healthcare and I also frankly precede my being a doctor. So yeah, notions of social justice and some of that comes from, I think a principled sense of social justice which you could say is grounded in faith. So I was raised in a Catholic faith, although I'm not a practicing Catholic, there's a saying or statement in the Christian bible that says, 'whatever you do to the least of your brothers, you do to me'. [...] I think there's social justice and that kind of captures it."

He describes how early Catholic teachings influenced the importance he places on social justice values and helping others.

Echoing this sentiment, a female, low-level activist practicing in internal medicine in a hospital describes the connection between her support for single-payer healthcare and parental teachings: "I think everybody should have good healthcare. That's kind of a 
moral imperative to me and I'm sure that has to do with how I was raised - you know, everybody's equal, everybody should be treated fairly." For her, since everyone should be treated fairly, everyone should have the same type of access to needed medical care. This is a value that guides her thinking and leads her to support single-payer, universal healthcare.

A different female low-level activist also recognizes how her parents and upbringing influence her thinking:

"My parents were pretty much children of the sixties. Very active politically. So we had values of justice, equal rights. So I think I was just ingrained from a very young age. So that's why I've worked for such a long time with community health clinics. I continue to feel very strongly that having access to care is important."

She describes how these have been strong values she has carried with her since childhood and how they guided her choice of workplace. For her, practicing medicine in underserved areas is one way of upholding her values, striving to ensure all people have access to high-quality care.

Similarly, a retired male physician who saw his father assist people as a pharmacist describes its influence on him: "Watching my dad and how compassion was part of his life, made that important to me so I went into medicine. So that element made it easy to support a movement that has compassion written all over it." Since a young age, he valued compassion for others and his belief that everyone should have access to medically-necessary care is one way of demonstrating his compassion for others.

The next two quotes illustrate the link between these deeply-held values and the physician-activists' desire to change the system. A retired male radiation oncologist who is a high level activist talks about how his values color his interpretation of what he's 
seen in the system: "You just don't want to let people die, [or] suffer unnecessarily. And we think this is unnecessary. We have a system that's unnecessarily cruel, so let's do something about it." These physicians witness the violation of their values in an "unnecessarily cruel" system and desire reforms that would bring the system more in line with their values.

Another oncologist, a practicing female articulates the connection between her values and her engagement in single-payer activism:

"The values I was raised with were to 'treat others as you want to be treated' and to 'always do the right thing' and 'tell the truth' and these kinds of things. And I'm trying to rebel against what I see as politics that don't necessarily support the values that I was taught."

She reports that the facility she worked at and her supervisors were preoccupied with generating revenue and profits which she believed was to the detriment of patient care. She wanted to change policies so that doctors can uphold their values of 'doing the right thing' instead of doing what makes profits.

Additionally, the physician activists discussed social compacts and how we should be caring for one another. A low-level male family medicine doctor and selfdescribed socialist discussed single-payer in the following way:

"It's moral, ethical thing we should be doing. I think there is an ethical point to be made that we should be doing this because it leads to better outcomes for the population and everybody does better, we all win."

He is looking beyond the individual to moral action aimed at ensuring a community is filled with happy and healthy members. He believes people do better and the community does better when everyone can access necessary medical care. He wants the collective to be strong, not just a portion of the community. 
In a similar vein, another physician expresses his confusion over the negative connotation associated with social programs and helping one another. The low-level activist male who retired from family medicine said,

"They [the opposition] make it look like it's an evil bad thing, they make it look like it's socialism if you are reaching out. And you look up the word 'socialism,' it means taking care of one another, in a social way. So, why does socialism have a bad connotation? Why can't we help one another? To take care of one another, that's great; the one thing that really matters in life."

I find that these interpersonal values play an important role in the story of how this sample of physicians became activists and came to form an important part of the collective identity. Whether the values were secular or religious in nature, all respondents felt it was important that all people be treated equally and to help others if you can. A genuine belief in and commitment to these social justice values came to define membership in the group and serves to delimit insiders from outsiders.

In the next section, I review how the healthcare system violates these values as the physicians practice medicine and try to care for their patients.

\section{Frustrating Work Experiences Cause Emotional Reactions}

The work experiences of physicians colored their view of the medical system. This section chronicles the frustrating work experiences reported by physicians and their belief that under a single-payer system, these issues would be eliminated or mitigated. All physicians in the study lamented how "medicine has been turned into a business" and how they are pressured to earn money for their institution, even if might compromise patient care. Physician-activists tended to prioritize patient care above profit-making for 
their institution. The physicians identified insurance companies as having an undue amount of control over how they perform their work. Physicians report they feel they have been turned into mercenaries, forced to sacrifice their medical ethics in the pursuit of profit.

Related to the rising prominence of business in medicine is the "double agent" term from the literature (Angell 1993). A hallmark of the double agent role is the need to be paying attention to more than just "what is best for the patient"; physicians must also pay attention to financial aspects of care. The double agent contradiction from the literature took a new twist in this study. The term was first used in relation to managed care where there was a pressure to control or limit costs due to a capitated budget.

In this study, most of the doctors were working on a fee-for-service basis and experienced the double agent role in a different way. Respondents in this study felt pressured to increase the amount of money they could charge for the appointment and procedures. This pressure generated an uncomfortable conflict for many doctors, acting as a motivator to change the system. Unhappiness with the double agent tension was mentioned most often by high-level activists $(85 \%)$ with the remaining occurrences of this topic linked to low-level activists.

A male physician working in internal medicine describes how he believes the business pressures have turned physicians into mercenaries:

"You have to be thinking about generating revenue. At the big level, like people who work for large organizations like this [Academic Medical Center] are often paid on the basis of productivity. The more widgets you process, the more pay you get. And you can't help but be thinking about that and that makes doctors spend less time with people. There's been a real shift to where it's much more, "I do what I get paid for and I don't do other stuff" so we've been turned into more mercenaries." 
This feeling comes from the tension between wanting to do what's best for the patient, which may not be the most profitable or the most efficient, and doing what will generate the most revenue for the practice. Activist physicians did not want to put the business' priorities above patients, but those were the demands from their superiors which created an uncomfortable position.

Six activist doctors reported increasing pressure to see more and more patients. This experience is related to medical specialty and explains why not every activist experienced this. Physicians in the lower-paid specialties like family medicine and psychiatry felt this pressure more than doctors in other specialties. As a high-level activist stated: "Our healthcare system reflects a disdain, both in reimbursement and respect, for primary care physicians. This is uniquely American." In other countries, the foundation of the healthcare system is primary care, whereas in the US healthcare system, higher payments flow to specialists than generalists, causing a crisis in primary care (Mechanic 2006). The underpayment of generalists in the US has caused difficulty for primary care doctors to take good care of their patients.

A high-level activist retired from an internal medicine practice explains:

"I think the main dilemma facing physicians today is how to take good care of patients when there's also pressures from insurance companies and practices to make it hard for them to take good care of patients. For instance, the work schedule where you don't have enough time to see patients. The pressures especially with the electronic medical record to spend so much time taking care of your chart notes rather than the patient. You know, all these authorizations you have to do, all the paperwork you have to do. And I guess, all the things that get in between you and your patient, that prevent you from taking good care of your patient. I mean, ideally, you would like to spend as much time seeing your patient as you need to and you would be paid appropriately. [...]I think if we eliminate the insurance companies, it puts the incentives back where it should be. 
We're [most doctors] not motivated by profit, we're motivated by caring for patients."

The mercenary position and focus on business does not appeal to the doctors who entered medicine with altruistic motives. For them, their priority is their patient, not the business. Yet, they understand the exigencies of keeping a business running which puts them in an uncomfortable position as they perform patient care.

The same male retired from an internal medicine practice describes how 'medicine being turned into a business' is what finally drove him to exit medicine. He says, "I was constantly pressured to do things, see more patients, do things that really were irrelevant to patient care." To explain further, he describes his middle-level position in his medical group. He says,

"I was caught in the middle between the doctors and the management. You know, the doctors would say, "We can't see more patients, we need more time." And from above it'd become, "You guys aren't producing. Look at some of our other guys are producing more work than you. You gotta crack the whip." And I just said, "That's enough. I did not go into medicine to be a businessman. I went into medicine to take care of patients." And I finally decided "That's it. I can't do it anymore. I'm done." And I got out."

He says it was a huge relief for him to leave medicine and not be put in a precarious ethical position on a daily basis anymore. The lamentation of business factors being prioritized over patient welfare was prominent for respondents in this study and acted as a strong motivator to change the system.

A male practicing family medicine explains his thought process when forced to act as a double agent. He says,

"You're always under a dilemma. [I ask myself] "do I order a test for this patient? I really don't think they have this disorder that's causing this particular symptom. I think they should get a CT scan of the head, but if 
they go get the scan of the head and it's normal, great for us that they don't have this disorder we're worried about, but then they have to pay the bill for six months or a year that they can't afford. But if I don't order the test and it is the one in a 100 cases where it is something happening inside the CT scan, then you're waiting longer or potentially causing them to have a much worse outcome. So it's a big dilemma in terms of the payment issues and people not getting adequate care based on simply our healthcare system not based on the medical system or the medical care itself."

The last sentence describes poignantly how the arrangement and financing of our healthcare system is not based on ensuring patients have their health needs met. It tells how both the patient and the physician are put in a stressful situation because of the extreme cost-sharing that is common in our multi-payer system. No matter what the doctor chooses, he is potentially inflicting harm on his patient; financial harm if he chooses to order the test or potential physical harm if the patient has the condition and he does not order the test. He resents this situation and believes that in a single-payer system these considerations would not taint his medical decision-making.

The next quote comes from a female practicing oncology. In it, she describes how it makes her feel uncomfortable that our medical system is intensely preoccupied with making a profit instead of trying to cure illness. She begins by talking about medical care:

"To me, it's a basic human need, just like air, water, and food, love and connections. And so to make it into a business commodity, to me, I think on the deepest level, it feels wrong to me. It feels just, wrong. It feels wrong that there are factions of businesses and individuals who want to make a whole bunch of money on illness."

Her morals and values are clear in this statement. She believes medical care should be a public good, one in which everyone has access to. And given that everyone will need to access medical care, she feels it is wrong for people to profit off of other people's 
suffering. Saying that this is wrong on "the deepest level" demonstrates how serious these values are to her.

The following quotes describe how physicians feel restrained as they attempt to perform their job because of the constraints of the system. A male working in musculoskeletal radiology, when asked why he thinks physicians become involved in single-payer activism said,

"From what I've heard, most people, it has to do with feeling bad for patients I think. Seeing people not being able to afford care, being denied care, and suffering. Or dying because of that. So it's a frustration of not being able to do your job."

He feels his job is to treat people's medical ailments and alleviate their pain. The current financing arrangement prevents him from being able to do his job in a satisfactory manner and it is the patients who suffer needlessly because of the unjust system.

A high-level activist male working in family medicine adds,

"There's so many variations of the same story, but the bottom line is you're trying to get a work-up or a treatment done and the healthcare system is preventing it, usually because of monetary problems and usually the onus is on the patient. And that's not even talking about the people with no insurance. How do you treat them?"

In both quotes, the doctors are drawing attention to how the arrangement of the US healthcare system makes it difficult for them to adequately care for patients, evoking frustration. And, this quote brings to light how activists are not only concerned about their patients, but about the people in their communities that can't access physicians due to being uninsured or underinsured.

A male who has retired from psychiatry comments on how the limitations of insurance companies make it difficult to do what's right for the patient. He may know 
that something is the right treatment, but if the insurance company will not authorize it, then this puts the physician in a difficult position. He says, "If you're in a private system, then you're fighting the insurance agencies. And there's a conflict between getting paid and doing the right thing for the patient. And that's just built into the system." Again, this is built into the system because in the commercialized age of medicine, the interests of the medical-industrial complex are promoted above those of the patient or society. The focus on business and profits manifests as physicians' ability to make decisions over treatment options is curtailed, which evokes frustration from activist-physicians.

This tension between getting reimbursed by an insurance company and doing what's best for the patient is explained by a male working in anesthesiology:

“There's a deep conflict there. Then these physicians are put in the position of doing either what's best for the patient by providing free, uncompensated care that consumes a lot of time or what's in the physician's financial interest. It's an example of being caught up in the financial interest of providers and payers being 180 degrees away from what's in the medical interest of patients."

Many respondents mentioned that they feel pressure to what's best for the business instead of what's best for the patient which was uncomfortable for them. The activist physicians genuinely care about their patients and the people left out of the healthcare system who are not their patients. They want the focus of the healthcare system to be on meeting the health needs of the population instead of a focus on making the greatest profits. They agree with Geyman (2005) that in a single-payer system, the pressures to generate revenue and profit would be greatly decreased, allowing them to focus on patient needs, which is one driver of their engagement in single-payer activism.

A female practicing obstetrics echoes this dilemma. She details, 
"I guess, more and more, health insurance is creating a barrier where they're saying, "This and that's not covered" so it leaves it more to the physician if they're willing to fight for their patients to get those services that they think they require. And physicians who are overworked or overwhelmed might not be able to be advocates for their patients."

Again, there is a palpable tension for doctors in choosing to do what they will get paid for or what is in the best interest of the patient. In order for physicians to do what's best for the patient, they must "fight" insurance companies and the business pressures coming from their superiors. They way the system is financed forces them to struggle and put in extra effort simply to make sure their patients are being cared for properly, which upsets them.

Additionally, physician-activists highlight the role that insurance companies play in their deprofessionalization and reduced professional autonomy. A male working in internal medicine explains, "I guess the simplest way to put it, is that instead of sitting down with my colleagues and saying, "what's best?" The reality is that we have to start with what's covered [by the patient's insurance plan]." He says that this results in a "huge amount of work away from the bedside that has mostly to do with the fact that all of them have different rules. And they change them all the time. [...] The amount of paperwork we do is just mind-boggling." This physician dislikes the complexity added to patient care by insurance companies and their continually changing rules about what is and is not covered, which leads to less time to interact with the patient.

A male retired from psychiatry adds that insurance restrictions create a burden for doctors as they try to care for their patients. When asked to elaborate on how they cause a burden, he explains "A burden in time, a burden in making doing clinical work much more cumbersome and tedious. And I think it may have limited the kinds of options you 
would have preferred to have had in making choices about treatment." Instead of simply thinking about what is best for the patient, he is forced to think about what will be approved by this patient's insurance plan which makes work more complicated than it would be otherwise and means the patient may not be getting optimal treatment. A male retired from internal medicine reflects upon how this manifested in his work. He said,

"Well, a lot of what we had to do was figure out what the insurance companies would cover and what they didn't. It was extremely annoying to have to not be able to just make a clinical decision. I had to decide what the insurance company would pay for. There were a lot of these "mother may I" [requests] where basically every time you want to order a test you had to call mother and say, "may I get a CT scan on this patient?", "may I refer the patient to the specialist?"”

This physician felt that he had a demonstrated history of making cost-effective decisions and loathed the extra layer of bureaucratic control over him. He said dealing with this on a regular basis “...pissed me off. It made me angry. Like I said, it's insulting to me and there's a total absence of trust." He felt personally offended by this oversight and the intrusion of insurance restrictions led to a work environment that was not appealing to him. He wanted to focus on caring for the patient but the system made it hard for him to do this.

A male working in family medicine explains how he feels when insurance companies have more control than he does over whether a patient receives a particular treatment:

"It's really frustrating because I just think that... I mean, I went to undergrad, went to med school, went to residency, practiced on my own, you know, have enough knowledge to know when a patient has a particular situation [or] they need this particular treatment modality. And I don't really understand why people who don't have any sort of medical 
training are having decision-making capacity over the patients that really need the thing."

He wishes that his training and experience were enough to give him the authority to decide what the best treatment is for his patient. In the end, he is not always the one who makes the final decision; it is the insurance company, which is experienced as an erosion of autonomy.

A male working in internal medicine describes how he feels "frustrated, angry, [and] powerless" when the insurance companies have so much control in dictating what happens to a patient. In the following quote, he talks about the phenomenon of preauthorization. Often, before a patient can be admitted to a hospital, the insurance company must authorize that. Here, the doctor describes a situation involving preauthorization from an insurance company:

"So, a patient of mine had a heart attack and normally you go to the hospital for these things when it happens. [laughs] So he has a heart attack and I have him in the hospital, and the insurance company calls after the weekend and this person says, kind of indignant, this woman on the phone, she was very indignant that I had admitted the patient without preauthorization. And I said, you know, it's a myocardial infarction, you don't plan those. And she says, "could you spell that" [look of disbelief]. And I thought, here we are where the person who's got to approve that I admit the patient for a myocardial infarction, can't spell it."

Like the family medicine doctor, these physicians are very frustrated that their clinical decision-making is being superseded by an employee of the insurance company with no medical training, particularly when their decision conflicts with the decision of the doctor to do what $\mathrm{s} /$ he feels is best for the patient.

The quotes from this section highlight how another aspect of the collective identity that is formed among physician-activists is how the insurance companies and the 
focus on profits undermine their medical ethics. The double agent/mercenary aspect of modern US medicine forces physicians to continually consider financial aspects when making treatment decisions. They experience a tension between getting paid and adhering to medical ethics by doing what they believe is best for the patient. Activists have strong moral agendas and place patient care ahead of making large profits, but their quotes illuminate the difficulty in escaping the influence of business and profit in the US healthcare system.

The activists also complained about the oversight of insurance companies as they carry out their work, illustrating what Navarro (1993) highlighted when he said that in our commercialized age, insurance companies have more power to determine what patients need than doctors. Oftentimes, the physicians cannot simply make clinical decisions; they have to first find out what is covered by the insurance plan before weighing options. This increases the work physicians do in terms of making phone calls and filling out paperwork to authorize treatments. And physicians feel very frustrated when the people they are seeking permission from have no medical training. These extra bureaucratic steps make their work more complicated and burdensome.

The physician-activists came to believe that under a single-payer arrangement, the simplified administrative requirements for treatment and reimbursement would lead doctors to have greater time to devote to patient care (as Geyman 2005 believes). It is worth highlighting that when physicians discuss the erosion of their professional autonomy, it is almost always discussed with the patient at the forefront. The physicians resented the deprofessionalization because it means they cannot always do what they feel is in the best interests of the patient. So, physician-activists anticipate that many of the 
mercenary and deprofessionalization issues would be ameliorated under a single-payer system.

\section{Desire to Help Others and the Need for Collective Action}

Another piece of the collective identity produced by single-payer physicianactivists is the willingness to help others and the recognition that the doctor cannot do it by themselves in their own practice. All of the activism done by the physicians in this study was collective in nature, linked to the tactics of the larger single-payer movement in Oregon. I assert that simply being dissatisfied with the system and believing singlepayer is superior is not sufficient to cause activism. A willingness and desire to help the less fortunate are also necessary pieces of the collective identity. For many physicians, this only came to fruition after years of practicing.

This family practice male physician says that what mostly influenced him to engage in single-payer activism was practicing in a system that was not meeting patients' needs. He links his frustration from witnessing patients not getting the care he needs to the values he learned during childhood:

I think once you're out practicing, actually practicing medicine, then you really get a flavor for whether the system works or not. And I ended up practicing in Oregon. And the system wasn't working at all. So for me it was, just seeing patient after patient dealing with those issues of getting caught in the middle of a healthcare system that doesn't work. Not really anything personal. You know in terms of politics, I've always kind of favored more progressive politics and that's probably been in my family as well. So I think my upbringing is where I get some of these ideas about fairness and not wanting people to be taken advantage of. 
He ties his grievance to the system and recognizes that in his practice, he has very little ability to make the changes needed to ensure patients receive needed care. This caused him to go online and seek solutions.

Another physician grew up with a conservative family, but when his sister attended the University of California Berkeley, she told him about the struggles people with limited resources encounter. He says,

"I became a convert from hearing about how people exist through my sister and her circle of friends. And then I saw it with my own eyes during my 35 years [practicing]. This doesn't work for a lot of people. This capitalism, or at least this free enterprise in healthcare doesn't work."

He is concerned about how the dynamics in treating medical care as a private good have limited access to care. He recognized that the profit incentives inherent in the for-profit medical arena function in a way that make some people suffer unnecessarily and he wants to change the system to help others; to ensure medical care is a public good and people get the care they need.

This retired male oncologist recounted how he felt upset about what he witnessed in his practice:

"As I saw these patients come in with advance cancers because they couldn't afford healthcare and they let symptoms go for two or three years, I was very upset that this was happening in our country. I felt badly for the patient, the family, myself, but our nation that we had a situation where patients are afraid to go in for care when they have serious symptoms."

He said that it was only after "probably five to 10 years of angst about, 'this shouldn't happen"" that he became involved in healthcare reform. Like the other activists, he recognized that the nature of the problems was systemic and not something that an individual practitioner could solve at his clinic through changing his clinical behavior. To 
change the system, it would require collective action outside of the clinic. He was recruited by a long-time activist and only after he began seeking solutions, did he learn about single-payer healthcare, when another doctor told him that single-payer healthcare is the solution that they should look into.

For many of the physicians, it wasn't just witnessing the violation of their social justice values that made them angry and want to support single-payer; they also had a sense that they were privileged and needed to help others. Sometimes this was a sense of professional duty and other times it derived from religious teachings.

A high-level male activist practicing internal medicine described what motivates him to engage in single-payer activism. He says his biggest motivator is

"A sense of moral duty. Both as a human, just a sense of moral and social justice and what's right, and it's not right that people who we could help, we don't. And beyond that human social justice sense, I think there's a sense of professional duty. It's why most people who become physicians become physicians; because they want to help people. And some of us seem to discover that one of the ways we could help them better, is to work for this. So what I think motivates people is that combination of human/moral values and professional duty that amplifies that."

This quote illustrates how personal values learned during childhood and the professional identity of being a physician combine to impel some physicians to want to change the system to bring it more in line with their morals and values. It also illuminates how the physician recognizes the link between his political activism to change the system and how that can translate into tangible benefits for his patients. 
A male, retired from psychiatry echoed the belief that being a doctor means your purpose is to help others. Commenting on why physicians become involved in singlepayer activism, he said that activists have to

"...understand that medicine is a profession, a calling to serve humanity and not just [a job] that can put money in your pocket. They have to believe that healthcare is a right. You have to be outraged at the fact that people are denied access to healthcare because they don't have enough money."

He feels that doctors are meant to serve others and the multi-payer arrangement prevents some people from accessing needed care. He is outraged at the fact that people are denied access to care, a reflection of the violation of his moral principles, which motivates him to work collectively for change.

A practicing female oncologist who is a low-level activist reflected on the position of physicians in society. She said, "I believe that it's an honor and a privilege to be a physician and I think we owe something to society. I mean, we owe that training and that knowledge to take care of society and that's why we're physicians." She is frustrated by the fact that the complex US medical system makes it so that she can't properly take care of everyone and treatment is dependent upon ability to pay. She wants physicians to be able to use their training to meet the needs of the population and not only a subset of people.

Two Jewish physicians mentioned how their faith drives them to act. A retired male internal medicine physician describes how the principle of "Tikkun Olam" inspires him. He says, "Tikkun Olam means repair the world. In fact, when you're born and you're Jewish, that's your homework assignment. In between the time when you're born and you die, you're supposed to help repair the world. So I'm doing my homework 
assignment." He believes his engagement in single-payer activism is one way of trying to reduce inequalities and ensure people are not suffering unnecessarily; in other words, repairing the world.

He comments further on how his religious beliefs give him perspective on his position in the world:

"A lot of it comes from Judaism. Jewish people understand what it means to be persecuted, understand what it means to be an outsider, understand what it means to be not given your proper rights and there's a feeling that we need to help other people. If we're doing okay now, we can't just sit back and say, "Oh that's great. I got it made." We need to remember where we came from and help other people try to get to the place they should be."

Another Jewish doctor reflects upon this social position. This high-level activist, a male practicing anesthesiology said, "My family has always had enough money to do what we wanted. And there was also a consciousness that we were fortunate. And that we needed to spread the good fortune." Interestingly, this physician did not have a negative work experience involving eroded professional autonomy, but was still aware of the dysfunctions in our healthcare system. His concern for the social good drives his activism and is willing to sacrifice personally to ensure that. He says,

"I make more money than I need. I've made enough to live well, I've saved enough so I can retire when I need to. I can afford to sacrifice some of my future income for social good. I remember I was asked at one of our Mad as Hell Doctor tours, one of these contentious audience members asked, "Would you give up $30 \%$ of your income? Take a $30 \%$ cut?" I said, if the $30 \%$ cut in my income means that my family is absolutely assured of getting the healthcare they need no matter how old, sick, poor, retired, fired, or expired I become, and that my children are assured of healthcare no matter what happens to me. And my friends, and my grandchildren and everybody is assured of healthcare, including me, I'd give up that $30 \%$." 
In short, a willingness or sense of duty to help the disadvantaged is another important part of the collective identity as well as the recognition that collective action is necessary to accomplish this. In other words, they want to help people and recognize they cannot accomplish this by themselves in their practice so they turn to collective action that becomes politicized. They are engaging in the "public roles" promoted by Gruen, Pearson, and Brennan (2004) that advocate addressing systemic issues. The physicianactivists recognize the unjust situation that many people find themselves in when they experience difficulty accessing or paying for needed care. The physicians' emotional reactions to these situations are also telling. They experience frustration and outrage and the situations they confront. These emotions help motivate their desire to assist others.

\section{Networking Emphasizes a Focus on Financing}

The priority of changing healthcare financing before delivery comes to define the position of these doctors and forms an important belief of the collective identity. This assertion is solidified in the physician networks. Once the physicians had been practicing medicine, saw the system wasn't working well, and began seeking alternatives, they began networking with other like-minded physicians. Some of the respondents in this study founded physician single-payer groups of their own. Two physicians from the Corvallis area spearheaded the Mad as Hell Doctors group and another physician founded the Portland chapter of the national group Physicians for a National Health Program. There is substantial crossover in the membership of these groups, but once institutionalized, they provided a network that other sympathetic physicians could join. 
These organizations also provide a "free space" in which the doctors are geographically-separated from dominating structures and can openly discuss their counter-hegemonic ideas. The free space locations in which the social movement organizing is taking place include universities, churches, union halls, and activists' homes. It is in these organizations that the process of collective identity takes place. In their networks, physicians debated health policy and what was contributing to the dysfunctions of the healthcare system; essentially clarifying the main frames of the movement. The we-ness of the collective identity is anchored in these physician networks.

The physician-activists come to understand that the way the United States finances healthcare is substantially different from other countries and this is the main issue to tackle. The physicians socially produce an understanding that switching to a single payer, in which the population is combined into a single risk pool, is the only way to solve the problems of the medical system while upholding their values. The attributional frame describes the financing of the US healthcare system as the problem and the prognostic frame describes the solution as switching financing to a single, nonprofit payer. The emphasis on altering financing before delivery is the fourth main belief of the collective identity.

One physician describes how he came to learn about single-payer healthcare. This retired radiation oncologist was beginning to get involved and had suggested a group name along the lines of "Physicians for Sensible Insurance." He says of one of the meetings: 
"And then, one of the people coming, an internist said, "we really need single-payer." And I didn't know what it was. And my first response was "it sounds too governmental." But the more I learned about what was going on around the nation, I realized, that's the only way. You put everybody in a single risk pool instead of dividing us all up into hundreds of risk pools and insurance companies finding out who's the least risky."

Through interacting with one another, the physicians in these networks and at these meetings decide that the simplest and most effective way to expand care to everyone while not spending more money is single-payer financing of healthcare, cementing the prognostic frame.

For instance, the high-level activist male who practices anesthesiology explains why they believe that the priority must be on changing the financing of healthcare before delivery:

"You can couple almost any financing mechanism with almost any delivery mechanism. So far the United States has tampered almost exclusively with different kinds of delivery systems and we've made no progress. And we're using the same delivery systems that other countries use quite effectively. What's different is we have a dysfunctional financing system. We use American style private health insurance. Singlepayer's an alternative. European rules for insurance companies are another alternative. But no one, no country, no system has ever provided medical care to more people for less money using our system of financing. No reform of delivery will work until the financing is fixed."

The prognostic frame that places the priority on changing healthcare financing before delivery comes to define the position of these doctors and forms an important piece of the collective identity. If a physician does not support changing the financing of healthcare to create a single risk pool, then they would not fit in with this group of physicians. But, if a physician agrees with this perspective, they are more likely to adopt the collective identity produced by this group. 
A low-level activist male practicing family medicine explains his position: "I think financing has to change prior to delivery. Because if you change financing, then you change incentives, right? You gotta change the incentives. You gotta change the game." To further explain this point about changing the rules of the game, a high-level activist male practicing internal medicine likens healthcare financing to a Monopoly game:

"I don't think the current structure can get us where we want to get. It's a little bit like playing Monopoly. When you sit down to play Monopoly, it doesn't matter, you know you can sit down with your sweet grandmother who makes you cookies and milk, she's going to take all your land and money. Because that's the game. And it is impossible, it doesn't matter how nice you are, how well-intentioned you are, no amount of goodness in intent or altruism matters when you sit down to play Monopoly because you've created a set of rules that says 'everyone must try to get all the land and money they can'. [...] And in healthcare, we have structure that's a lot like that. So it doesn't matter whether you're with Kaiser or Providence, for-profits, not-for-profits, government agencies, it doesn't actually matter who sits down to the table because the rules are written in a way that produce the result we get. And so the thing that I think that is most important is to take that structure apart."

The structure he is talking about is the financing of our healthcare system in the United States that splits the population into numerous risk pools. Allowing companies to profit off of the financing of healthcare is just like the goal in monopoly - make the most money. And the way insurance companies gain financially is by taking in more money than they pay out. The anesthesiologist physician clarifies this point:

"The private insurance industry model is like any business model. You pay out less than you take in. Because it's an insurance industry, it takes the money in first and later provides the services. It's in the interest of insurance companies to take in as much as they can through premiums and pay out as little as possible, which means interpreting any benefits to the insurance company's advantage. It means that it's to the insurance companies' financial advantage to delay or deny payment because the longer the insurance company holds on to the money, the greater the 
return. This is the model. Any insurance company that doesn't honor that model will go out of business."

Insurance companies, as for-profit corporations and publicly-traded entities, have a goal to maintain or increase shareholder value. And this involves delaying or denying payment for services; services that the physicians often feel are necessary and beneficial. The physicians also recognize that the insurance companies are simply following a standard business model. What the physicians are fighting for is for medical care to be financed by a publicly-accountable, non-profit payer instead of being financed by companies whose main imperative is profit.

A core belief of activist physicians is that numerous risk pools allow insurance companies to profit handsomely when millions of Americans are left uninsured. One consequence is that the cost of care is higher in the US than in any other country. This forms the attributional frame. Once this understanding and belief is cemented, they are driven to focus on changing the financing of healthcare as their first priority, creating the prognostic frame.

In short, the fourth belief of the collective identity emphasizes a priority on financing and believing single-payer is the only way to fundamentally solve the systemic issues. As this low-level activist male practicing in family medicine succinctly explains, "Now, if you look at the statistics. If you look at the actual research and data, there's no system that works more efficiently, more cheaply, and better for the general population than single-payer." This shared belief emerges from the process of engaging in debate and discussions in the physician networks. The activist physicians strongly believe 
single-payer is the most effective way of paying for healthcare and forms a core belief of the collective identity.

\section{Political Opportunities Shifting to the State Level}

Policies of the state also shaped the collective identity of social movement activists (Meyer 2002). The election of Barack Obama in 2008 bestowed optimism for some activists that "real change" would be coming to America. Obama made healthcare reform a cornerstone of his presidency, but the exclusion of single-payer advocates from the healthcare reform debate diminished this optimism for real change. The resulting Affordable Care Act made it very clear that single-payer would not happen at the national level. Single-payer activists knew that they would have to change their target from the nation to the state. With Vermont's passage of Act 48, the state was poised to develop a single-payer system, serving as a beacon of hope for single-payer activists in other states. Hence, the final piece of the collective identity is an understanding that the ACA is insufficient to fuel real change and that single-payer is achievable at the state level.

Obama's campaign highlighted the idea that he wanted to change things, evidenced by his campaign slogan "Change we can believe in." A male retired from psychiatry tells about how this influenced his decision to get more engaged. He said, "And you know, when they elected a black man as president, I went, "God, there's still some sane people in the country. Now I'm ready to do something."'" He sensed a window of opportunity in which he felt that he could gain traction and make real changes. It gave him hope that activism could make a difference. 
A male family practice doctor also reflected on how he gained a sense of optimism with the election of Obama:

"But politics got a lot more radicalized while I was in practice mostly because you know, it was 2008 and the Obama administration had come in and I was kind of riding the wave of the "hope and change" nonsense. You know, all this stuff. And I was kind of buying that and everything."

Once Obama decided to make healthcare reform a keystone of his presidency, there were lots of town halls across the country and healthcare reform was a household topic. This period appeared to be an opportunity to make a difference to the physician-activists. A male low-level activist working in emergency medicine described how it colored his thinking:

"I kind of feel like back then there seemed to be this window of opportunity where this small group of activists might just make a difference. And I think we did a lot of good in our [MAHD] travels... But so I think there was this window of opportunity. Or apparent window of opportunity. You know, there was this moment of hope."

However, this optimism did not last long because the debates leading up the Affordable Care Act explicitly excluded advocates of single-payer. The male psychiatrist explained how this made him feel:

"So I got involved in the single payer movement because it's such a huge economic issue and we're in the middle of an economic crisis. And I said, "how can Congress ignore this?" He says he [Obama] wants to do this, that means that they've got to talk about single payer. Well they didn't. They refused to and they started arresting people who tried to stand up and speak about it at the Congressional Committees. So yeah, that was a real inspiration to me."

For him, hearing about physicians who protested the blackout of single-payer advocates from the health reform debates inspired him to want to take action. 
Witnessing other physicians stand up for their beliefs encouraged him to want to do the same.

The emergency medicine doctor makes a more pragmatic evaluation of Obama's decision to not allow single-payer activists in the discussions but reiterates his support for single-payer:

"It [the ACA] was absolutely well-intentioned and the fact that it barely passed means that he [Obama] probably calculated it correctly to do all he could do and get it done and not fail. The problem of course, is it's not going to solve the problem. It just empowers the insurance companies. It's more government subsidies for the insurance companies. We still don't have a system. Still people are going to go bankrupt and they're going to be underinsured."

In fact, this is how most, if not all, single-payer activists view the ACA. It is a step in the right direction, but it emboldens the insurance companies, which are precisely the source of the problems in American healthcare.

A male low-level activist practicing family medicine gave his viewpoint on the ACA. For him, the ACA with its reliance on private health insurance strengthened his position on single-payer:

"And then all the Affordable Care Act stuff came out, you know. So I started paying attention more once the ACA started coming out, and then I just really started feeling a lot stronger that single-payer was basically the only option."

Activists, who believe single-payer is the only way to fundamentally fix the great majority of problems in the healthcare system, realized that with the Congress we have in place, single-payer is impossible at the national level; it must be attempted at the state level. It was in this time frame that Vermont's single-payer campaign 
was making great strides and gave a renewed sense of optimism to many singlepayer advocates.

A male physician practicing family medicine described how this influenced him: "Once Vermont passed single-payer, then I was like, 'Oh, this is something that can happen. This is something that's real. Like, this is something we can do." Having a success story to look to as an example, made achieving single-payer at the state-level seem like a true possibility, increasing his sense of political efficacy.

The successful passage of single-payer legislation in Vermont acted as a beacon of hope for activists in Oregon. In fact, groups in Oregon invited a few activists from the Vermont Workers' Center to do a tour in Oregon explaining the keys to their success. A male retired from psychiatry reflected on the presentation given in Portland:

"There was a conference here in Portland that was sponsored by Jobs with Justice and it was a conference at which people from Vermont, where they had organized a successful drive for single-payer, had come to talk about their experience and share it with different communities in the state of Oregon. And that was a very inspiring conference, attended by maybe about 300 people and there was a lot of enthusiasm afterwards and I decided to join the meetings of the healthcare committee and Jobs with Justice. And I've been going regularly every since."

With the success in Vermont, the Oregon movement found renewed vigor. The Oregon movement adopted strategies used by the Vermont campaign and activists around the state began work in earnest.

The Affordable Care Act's reliance on subsidies to buy private health insurance plans irked many single-payer advocates because it amounts to public dollars going to for-profit businesses that have a history of denying and delaying payment for necessary medical care. The single-payer activists view the ACA as insufficient to usher in the 
changes needed to fix the systemic issues in the US healthcare system. The political system also influenced the physician-activists in two ways. First, the prohibition of single-payer supporters from national health reform debates incensed some people and effectively changed the target of single-payer action to the state level. And second, the successful passage of legislation intended to set up a single-payer system for Vermont gave renewed hope to Oregon activists that single-payer is achievable at the state level.

In summary, I find that the collective identity shared by activists provides substantial motivation as well as facilitates engagement in collective action for singlepayer healthcare. The physician must agree to all components of the collective identity in order to adopt it. Table 5.1 below shows the five beliefs of the collective identity and the extent to which the activists exhibit this belief.

Table 5.1: Collective Identity Beliefs

\begin{tabular}{|l|l|}
\hline \multicolumn{1}{|c|}{ Factor } & Activists \\
\hline Social justice value system & Strong \\
\hline Duty to help the disadvantaged through collective action & Strong \\
\hline Experience of deprofessionalization & Strong \\
\hline Priority of reforms is financing (Prognostic framing) & Strong \\
\hline Single-payer achievable at state level & Strong \\
\hline
\end{tabular}

\section{How they Mobilize}

Once physicians were practicing and experienced trouble and difficulty caring for their patients in the way they felt was best, many turned to the Internet to begin seeking alternatives. A majority of physicians in this study (11/14) first learned about singlepayer after they became frustrated working in a "broken system" and sought solutions. Three of the physician activists became aware of single-payer before or during medical school. 
Physicians came to join the movement in a couple ways. The most common scenario revealed the following path: The physician was discouraged by what $\mathrm{s} / \mathrm{he}$ observed as $\mathrm{s} / \mathrm{he}$ practiced medicine and went to the Internet in search of a better way to organize healthcare systems. Through doing some research, s/he found that most other developed countries utilize a non-profit financing system and provide universal access to medically-necessary care. S/he learned about the explicit treatment guidelines and the reduced administrative burden for physicians in these systems that make practicing medicine less cumbersome. S/he encountered the website for a national organization of physicians who support single-payer, found a local chapter in their area, and then joined the organization. Once integrated into the physician networks, they shared in the process of creating a collective identity.

Only two of the 14 activists report that they were directly recruited. One male physician tells how he made a comment on an online article favoring single-payer as a solution to the issue addressed in the article. Another physician, already activated and engaged in the single-payer movement, saw this comment and responded to him suggesting he join an organization and get more heavily involved. Likewise, another physician reports being recruited by someone already active in the single-payer movement. In this case, it was a member of his congregation who recognized his position on single-payer and his prior career as a physician and asked him to get involved. 


\section{What Does Physician Activism Look Like?}

The pro-single payer activities physicians reported engaging in are mostly focused on persuasion and mostly occur outside of their workplace. The activists recognize that factions of the public exalt individualism and might not support universal healthcare; therefore they work to counteract these sentiments. The physicians do this through a variety of outlets, including the radio, websites, email, video, public forums, and private events. They believe if people are educated about the issue in a way that speaks to the listener's values, then the listener can learn to see why single-payer makes ethical and economic sense. While a small number of respondents report speaking with patients, others report discouragement of single-payer activism from colleagues.

Physicians reported engaging in a wide variety of activities. Some of the activities were done independently of an organization, but most of the activities were in relation to the state-wide movement to pass single-payer legislation (Healthcare for All Oregon). The activities are divided into high, medium, and low categories depending upon the level of sustained effort involved in accomplishing the task. The high-level activists mostly engaged in activities from the high- and medium-effort categories whereas the low-level activists only engaged in low-effort activities. Table 5.2 includes some of the most commonly-reported activities; a full list of activities is included in Appendix C.

Table 5.2 depicts the effort-levels for different activities. Low-level activists tend to only engage in low-level activities and are not highly-involved in the organizing of the movement. They will sign a letter or petition that higher-level activists have drafted. Or, they promote single-payer in opportunities that they come across in the course of their normal lives; like responding to a post on social media or recommending a book to 
someone they had a conversation with. These activities require little time investment; anywhere from a few minutes to an hour. They tend not to go out of their way to seek opportunities or engage face-to-face with strangers, but are willing to invoke their collective identity by educating and informing people when convenient.

Table 5.2: Sample of Activities

\begin{tabular}{|l|l|l|}
\hline \multicolumn{2}{|c|}{ High-level Activists } & \multicolumn{1}{c|}{ Low-level Activists } \\
\hline Organizing conferences & Calling for donations & Low \\
\hline Lobbying in Salem & Manning a booth at a fair & $\begin{array}{l}\text { Signing a button } \\
\text { petition }\end{array}$ \\
\hline Public speaking & $\begin{array}{l}\text { Writing an opinion piece for a } \\
\text { group or newspaper }\end{array}$ & $\begin{array}{l}\text { Occasionally attending } \\
\text { meetings }\end{array}$ \\
\hline $\begin{array}{l}\text { Participating in a cross- } \\
\text { country tour }\end{array}$ & Paying member dues & Posting on social media \\
\hline Coordinating others & Doing the photo petition & Recommending a book \\
\hline
\end{tabular}

The high-level activists maintain leadership roles in the movement and take on long-term and administrative tasks. They primarily engaged in high- and medium-effort activities. These individuals utilize their spare time to engage in some of the more direct outreach strategies employed by the movement like manning a booth at a fair or doing the photo petition. The photo petition is a strategy borrowed from activists in Vermont where an individual writes their name below a picture of a nurse with the caption "healthcare is a human right." High-level activists are also willing to speak publicly at smaller events. These require engagement with strangers which can be intimidating because it requires the physician-activist to be able to articulate the diagnostic, prognostic, and motivational frames in a colloquial way. Trying to answer a stranger's question in a straightforward manner when the healthcare system is so complex can be difficult to accomplish. For that reason, physicians who engage in medium- and high-level activities have spent more time 
educating themselves about the single-payer alternative and why a priority on changing financing is the best way to solve the state or nation's healthcare problems.

High-level activists have organized and participated in some impressive outreach tactics. For example, some have organized conferences throughout the state of Oregon. Sometimes this required inviting and hosting speakers from out of state or sometimes the speakers at the conferences were the physician-activists themselves. Organizing events like these require coordination of volunteers, reserving locations, and ensuring that handouts and other information were available at the event. One high-level physician activist has taken responsibility to find the private funding needed to complete the economic study, which has proved to be a monumental task.

Some of the high-level activists participated in a cross-country tour to raise awareness about single-payer as a solution to the US healthcare crisis. Those who participated in the tour needed to be able to take time off of work, which was easier for physicians in flexible medical specialties or physicians who were financially comfortable and could take time off work. These might be physicians whose children were grown and whose financial needs were reduced by having paid for college, and long ago, having paid off student loans, if they had them. When they stopped at a town along the tour, the physicians would speak about the merits of single-payer and would engage in audience interaction by inviting individuals to speak for a minute about why they wanted singlepayer healthcare.

Additionally, the activity level was somewhat correlated with the career stage of the physician. Two of the 14 activist respondents mentioned that single-payer activism was easier in medical school because of the presence of the American Medical Student 
Association which promotes single-payer, universal healthcare (and is not affiliated with the American Medical Association). During residency, respondents reported that they were too busy to eat and sleep properly, let alone engage in activism. After residency in the early phase of the doctor's career, they were often starting families and working frequently to earn enough to pay back student loans. Mid-career, is when most activist respondents reported gaining an awareness that the system was broken and not meeting patient needs. In this study, activists were at all stages in their careers, but the high-level activists tended to be toward the end of their careers or retired. This afforded them more financial leeway, more seniority, and fewer family obligations which gave them more time to dedicate to the social movement.

A key informant highly-involved in health reform politics in Oregon with whom I had a conversation, believes that doctors are not effective activists because they lack an understanding of how politics works. After working in Oregon state government for many years, my informant feels that effective political activism requires the building of coalitions and alliances and that the physician activists advocating for single-payer are not fulfilling this important criteria. He has the sense that the physician-activists are relying solely on facts and numbers to make the case for single-payer instead of developing meaningful relationships with diverse groups in order to gain support.

While physicians in general may not be the most politically-savvy group, it appears that many of the activities physician-activists engage in are aimed at building coalitions and reaching out to diverse groups. One of the more common activities physician-activists reported was public speaking. They speak to varied groups in an effort to gain support and build partnerships including liberal groups, conservative groups, 
groups representing the business community, religious groups, and various social justice groups. The physicians also report that they know their time is probably better spent speaking to groups who doubt the arguments for implemeting a single-payer system instead of spending their time speaking to people who already support single-payer. Hence, the activist physicians in my study are willing to take some personal risk by speaking to groups where there is potential to elicit a hostile reaction. So, while some may perceive the physician-activists to be lacking the skills necessary to be effective in the political arena, it appears the activist-physicians are making efforts to gain support by reaching out to diverse groups in order to generate a broad coalition of supporters for single-payer healthcare in Oregon.

In short, physician-activism was varied. Low-level activists participated, but in a limited way and tended to be in the early or middle stages of their career. High-level activists engaged in outreach aimed at increasing the awareness of single-payer and counteracting misinformation through speaking and engaging the public. And only highlevel activists took on long-term projects and maintained leadership positions. High-level activists tended to be in the middle or late stages of their careers or retired.

\section{How do Physicians Choose Their Activities?}

Physicians select activities to engage in for three reasons: (1) It was something they found enjoyable or fit it with their skill set; (2) The activity fit into their schedule; and (3) People ask them to.

The most common reason given for choosing to engage in a particular activity was because it was something they found enjoyable or it fit with skills they have 
developed. There is no shortage of events activist physicians can attend, so they tended to select those that they find more enjoyable and abstained from activities which do not appeal to them. A male working in anesthesiology explained how he chooses what activities to participate in. He explains,

"I'm good at public speaking and enjoy it. And with enough work, I'm good at writing for the general public and enjoy it. I don't enjoy lobbying. I don't enjoy fundraising. I don't enjoy rallies. So I focus my efforts on the activities that I do well and that I enjoy."

The doctors also considered their strengths and often chose activities that match with what they are good at. For instance, a male working in internal medicine describes his thought process when he chose to get involved in single-payer activism. He first asked himself,

"What could I do given the fact that I'm already too busy and have a family and have a job and what am I good at that I can contribute? Ya know, I'm not good at making phone calls to ask for donations, I'm not good at that. There's stuff that I'm good at and stuff that I'm not good at. But as it happens, because I do research and teaching, I do a lot of public speaking in front of groups and there was a time when I was terrified of speaking in front of groups but it turns out to be one of the things in my skill set and so I started giving speeches first to doctors. So I went around the city and spoke at every hospital in to the doctors groups in those hospitals and that's kind of what got me started."

He chooses to focus his efforts on public outreach and public speaking because he feels that those are skills he has. Other doctors similarly reported selecting their pro-singlepayer activities on the basis of whether they will enjoy the activity and whether they are good at the tasks required of the activity.

Turning to the second reason, many doctors reported that their choice of activity was constrained by what would fit with their schedule. Their profession is their priority 
and activism comes second to that. A male working in radiology explains how he decides what to do:

"I choose them because... mostly based on my availability. I work fulltime. So I'm willing to do a lot of different things if I have the time to do it. For instance, being part of the traveling tour for a week and going to eight different cities was only doable because I was able to get that week off. Volunteering at a booth again, is just availability."

Since single-payer advocacy is important to this physician, he is willing to take time off of work to pursue activism, but reports that time constraints affect his selection of activities.

A practicing female obstetrician describes how her work and family life influence her activism. When asked about what prevents her from getting move involved, she said,

"I mean, I would just have to say, at this point in time, family. I have four children. I have an almost 10 year old and we decided to home-school them. I work part-time and in the rest of the time I home-school. Other times it's just having lack of information about when things are happening. There was a rally I think, last year, that they had for singlepayer in Salem and I live [nearby] so I could have gone. But I found out about it like three days before. So I couldn't really ask for time off at the office. I had patients."

The activities she chooses to do are things like give donations to single-payer physician groups and she adds, "I try to provide education where appropriate in patient-physician interactions. But I have to admit I have not gone to protests." Other demands in her life limit the flexibility of her schedule, which limit the activities in which she is able to participate.

A working female hospitalist limits her advocacy because of her emphasis on work. This physician experiences the same tension, but elects activities that permit her to focus on patients while still advocating for a more just system. She says, 
"I have participated in some of the public panels. I've done a couple of parades. But mostly I just sign letters that somebody else drafts or a petition that somebody else does. Because I'd would really rather be taking care of patients rather than spending all my time [doing advocacy/volunteerism]... So I'm more of a letter-writer, signer of petitions, and occasional meeting attending."

Striving for a single-payer system is still sufficiently important to her that she will participate in the movement, but in a limited fashion so she can still take care of patients.

The findings emphasize the constraints presented by structural availability. Availability is considered to be "unscheduled time" (Cable 1992). Physicians have demanding work schedules and also have personal lives, leaving little unscheduled time. Some physicians whose medical specialties permit reserving large blocks of time off work find it easier to engage in high-level activities like going on road trips and traveling to events. Physicians without flexible schedules fit in their activism around other demands in their life such as work and family. Indeed, taking care of dependents has frequently been found to be a limiting factor in social movement engagement (McAdam 1988; Cable 1992; Snow, Zurcher, and Ekland-Olson 1980). Due to this, finding out about events with enough time to ask for time off work makes it easier to participate. In general, greater awareness of events with enough time to rearrange other commitments makes it easier for physicians to participate.

The third reason physicians reported engaging in particular activities was because someone requested that they do it. A male working in family medicine described the status that doctors have in the single-payer movement and how that translates into their participation at events. He says,

"I think as a physician in the coalition, you're looked on as someone who can speak regarding the actual technical issues and also from your 
experience. You can look at both issues. Like how would a single-payer system work? How is it different from what we have now? Why is a single payer system better than what we have now in terms of bureaucracy and other things, so you can speak to that. And you can also speak to the experience of what we talked about before. Being in that situation where patients aren't getting the care they want simply because of how screwed up the system is. So I think you're often asked as a physician in the single payer movement to be at forums or be at panels or be at marches and give speeches because of that status that you have. So there's kind of some expectation there."

The social status and expertise people believe physicians to have is reflected in his statement. When someone with status and firsthand experience in the medical field argues for a certain type of healthcare reform, the message carries more influence than if it were delivered by an average member of the public.

Expanding upon how physicians are asked to participate in certain ways, a male retired from psychiatry explains how he arrived at his current position in the movement:

"Well, they kinda chose me and I chose them simultaneously. I think the way that it happens is that I had an interest, I expressed myself about my point of view and I guess I was recognized as someone informed and someone willing to work on these issues. I was asked to take leadership positions, which I did. And I guess, I selected the things where I thought I could be effective personally and agreed to be in the leadership to make this movement happen and go forward."

It is important to him that this movement is successful and since he is retired and has the availability, he accepted a leadership position that he was asked to fill.

\section{Discouragement at Work and Burnout}

The physicians who decided to engage in single-payer activism encountered challenges as they do so. In the workplace, physicians reported experiencing resistance from colleagues when they spoke about their beliefs. The physician-activists reported that doing anything that potentially threatens the bottom line of the business they work for is 
risky, even if the goal is providing excellent patient care. This situation also highlights the importance of free spaces in politicized collective action. The physicians are reacting against what they perceive as unjust policies of the state and find that they are not taken seriously when they engage in activism in the spaces tied to the hegemonic structure. This section reviews some of the obstacles to activism physicians encountered outside of their "free spaces" (single-payer organizations like MAHD and PNHP).

A male practicing internal medicine explains an aspect of the culture of medicine; the risks involved when deviating from the norm. This high level activist said, "I think for physicians, their reputation and belonging to the group are very, very important and standing out and being perceived as different is very, very threatening. So I think helps keep us in the herd, keeps us in line."

He said this leads to physicians "not wanting to take a risk of being perceived as different, radical, lefty, whatever, because that undermines credibility in other parts of your life." He is saying that if a physician speaks out at his/her place of employment about changing to publicly-financed medical care, it is seen as a radical opinion and that doctor may lose credibility when attempting to advocate for other issues in the workplace, effectively discouraging activism.

Similarly, another activist physician experienced the sense that you have to have a reputation and seniority if people were to take you seriously when talking about single-payer. He explained how he joined the board of the Oregon Medical Association (OMA) so that single-payer advocates would have some representation in that organization. When I stated, "I think you could make a pretty big impact being on that board," he qualified my optimism by responding 
"You have to gain respect and respect comes from time and service in the organization. So it's still early on in that, but hopefully." His reservations reflect the fact that single-payer is seen as radical and the only way one can talk about it with other medical professionals and be taken seriously outside of free-spaces, is to have a significant amount of respect and social standing with other physicians.

Another doctor talks about his experience at the Oregon Medical Association. He wanted changes that were seen as radical or zealous. A colleague of his had to tell him to make his choices more strategically. The male retired from internal medicine said:

"When I came up through the OMA, I was a real hot head. I wanted to move the OMA way to the left. I remember, one of the past presidents who's like me said, 'you need to be a littler more judicious in choosing your battles and how you battle them'. During the sixties you know, the approach to change was 'up against the wall, shake your fist' that kind of stuff. And he pointed out that that doesn't work at the Oregon Medical Association. So I learned from him."

This physician had to realize that far left-leaning policies may not be the most popular at hegemonic places such as the OMA and had to find other ways to engage in activism that were congruent with his values and goals.

A female practicing oncology reflected on how the business motives are paramount at her previous place of employment and it made her reticent about voicing her opinion:

"They're trying to bring in as many patients as they can with their billboards and their signs and their experts to make as much money as they can in cancer care and heart care. And anything you do that they see as being subversive to that agenda is... they have no qualms about getting rid of you as a physicians. It's much easier to get rid of a couple troublemaking physicians who are being central activists than it is to change your larger view of healthcare." 
In this group practice setting, if she spoke out about how the high cost of care and how the emphasis on profits makes it difficult for some to access care, the business would rather her leave the group than sacrifice a portion of its profits. For her, the incongruence between her personal values and the values of her employer caused her to leave and open her own practice.

A high-level activist male practicing family medicine also encountered some pushback from his employer when trying to draw attention to healthcare issues. When Michael Moore was making his movie Sicko about the dysfunctions of American healthcare, the filmmaker was looking for stories to use in the film. This activist explained what happened when he wanted to assist this cause:

"For some reason one of the assistants in the movie had gotten in touch with my wife who got in touch with me, and said hey, they're looking for medical stories for the movie and, I was like, 'oh, this is a perfect story.' Here's a 10 year old kid, it's totally out of his control, the health systemhow it works or whether he has insurance or not, just had a devastating stroke, devastating for the family and the most important treatment he can get, this physical and occupational therapy is cut off way too early in his case. I sent this to Michael Moore and I kinda got some feedback from work saying, 'hey, we need to make our Medicaid program happy here, we don't want them to be exposed in a movie like that'."

The activist wants to do what he feels is right; he wants people to know that the financing and multiple risk pools that leave some with poor access to care is threatening the health and longevity of this child's life. But his supervisor stopped him by noting the risk to the business.

Some high-level activists talked about how it can be difficult to sustain a high level of involvement. One physician reflects upon how he had to back off of responsibilities once he took them on. The male retired from radiation oncology said: 
I was elected president of Healthcare for All Oregon in April of 2012. And I had the burning passion. I didn't really know what the job would entail, but I wanted it to happen, so I accepted it. [...] Because we need to do this. We need to change legislation. And it's a tremendous job. [...] And there's a huge learning curve. I've likened it to building a ship for a voyage. You have all these passionate activists helping to build the ship. And they don't quite understand the engineering of the ship. All they want it to do is sail and get to that island. So if the ship is taking too long to build, people get discouraged and leave. Or some people start swimming. And some of them drown. So it takes the patience and the foresight to say, 'We have to build this ship [properly] because it's going to be buffeted by huge waves generated by huge corporations. It's got to be sea-worthy.' So leading that was more than I could do. I bowed out after about eight months."

This quote touches on numerous issues. His values and passion for single-payer healthcare made him feel that "we need to do this." He was asked to do the job and given that he was retried and had the time, he accepted the request. But learning how to perform this role involved a substantial learning curve. He was able to persevere, but found he lacked the leadership capabilities required of a diverse state-wide organization. He recognized the limits to his activism. He has not quit single-payer activism entirely; he had to choose a manageable position in which he could be effective which involved taking on less responsibility.

Another high-level male activist, practicing in family medicine reflected on how long he can sustain his activism. This high-level activist is a leader and organizes meetings and events. When asked whether he thinks single-payer will come to Oregon in his lifetime, he responded: "If it's going to happen in my lifetime, I don’t know. [laughs] Give it another 10 years, maybe, and then [I may] just put my head in the sand and give up." He can give it a good 10 or 15 years, but he feels at that point if single-payer has not been realized, he will accept defeat. This physician is still highly-involved at the time of 
writing and has not given up yet. But these quotes illustrate how even the stalwarts in the movement, presidents of organizations, have a limit to their drive to fight for singlepayer.

Illustrating the fatigue that can come with activism, another male physician, working in emergency medicine was highly involved for a number of years and then chose to reduce his level of activism. He has developed a certain level of cynicism after the debates on the Affordable Care Act. He feels that both state and national representatives in our government cater to the rich while ignoring common Americans. He feels that the amount of money politicians receive from lobbying clouds their judgment and prevents more left-leaning social programs from being implemented. The following quote demonstrates how his perception of the feasibility of single-payer influences his willingness to get involved:

"The only way we can fix the healthcare problem is using Washington, but we're not going to fix this problem until we fix Washington. Because any fix we get will be a false fix because it will be manipulated by the people who are trying to profit from it. So I'm going to go out there and bleed my heart out talking about healthcare and getting people to understand why we need a single risk pool when I know it's never gonna happen until we fix Washington? [...] I mean I'm still willing to talk to anybody; I'll educate. But in terms of putting my personal resources out there just because it feels good, I'm sort of not 'into' it as much as I was before. And I feel really guilty about it. Because there's a lot of people out that are there doing this because of my involvement."

He makes the point that he is less willing than he used to be to sacrifice his personal resources of time and energy contributing to the goals of the movement. But, notably, he says he feels guilty and bad about his decision to reduce his involvement. This is likely due to the solidarity with other physician activists he generated during his more active time. He still does participate somewhat in the movement, but has grown increasingly 
pessimistic about the possibility of successfully passing single-payer legislation through the government. He chooses to not be involved to a high degree but is still willing to educate others.

In sum, physicians reported discouragement from colleagues for speaking out about healthcare financing at work. Single-payer advocates were seen as radical or troublemakers, which was enough for some to leave their place of employment by starting their own practice or retiring early. This highlights the importance of free spaces for collective actors struggling against a hegemonic order. The free spaces act as safe places where the physicians can espouse their "radical" beliefs in relative safety. Additionally, physicians that had been activists for a long time or held prominent positions reported experiencing fatigue and questioned for how much longer they could remain engaged.

\section{Summary}

I find the most common way in which physicians became involved in single-payer activism is through becoming dissatisfied practicing in an environment in which profits are prioritized over patients and seeking solutions on the Internet, which led them to find and then join a local chapter of a single-payer organization. Physicians report becoming dissatisfied because they feel their medical ethics are compromised by continually taking into account financial considerations when making medical decisions. Activists report that their professional autonomy is diminished by gatekeepers, many without knowledge of their specialty and little knowledge of the case. They believe these issues would be mitigated or reduced through a single-payer system because everyone would have the 
same coverage and clinical decision-making will be evidence-based (the next chapter provides examples of greater professional autonomy for doctors working in single-payer systems in the US). All physician-activists share in common a strong commitment to social justice values of equality and fairness as well as a deep-seated imperative to help the less fortunate.

As these pieces come together and physicians meet other dissident doctors, through framing discourses clarifying the problem, solution, and rationale for action, the physicians decide that the focus of health reform must be on changing the financing of medical care to include only one risk pool (a universal system). Noticing that other countries achieve more efficient health outcomes using the same delivery models the US does, reveals why they believe the priority should be on changing financing. Furthermore, the physicians all agree that while the ACA is a step in the right direction, it does not come close to solving our problems. And, given the process that led to the ACA legislation, the activists know that single-payer is impossible at the national level and must be attempted at the state level.

In essence, the collective identity that activist doctors share has these five components to it: (1) a value system that promotes social justice, equality, and fairness; (2) a frustrating experience of deprofessionalization that compromises medical ethics; (3) a sense of duty to help the less fortunate; (4) a belief that healthcare reform must prioritize changes to the financing of healthcare instead of more delivery reforms; and (5) an understanding that single-payer is achievable at the state level.

These five beliefs produced in physician networks come to define the collective identity shared by physician-activists in the Oregon single-payer movement. And it 
involves many of the most important attributes of a collective identity. The activists are responding to policies of the state that have divided the nation into multiple risk pools that allows insurance companies to selectively cover the least risky which forces the state and public budgets to cover the sickest and most costly individuals. The activist physicians want the state to ensure medical care is a public good instead of a private good controlled by for-profit companies. Hence, the physicians' discontent and goals for change are directly tied to state policies, causing the identity to become politicized (Meyer 2002; Taylor and Whittier 1992; Klandermans 2002). The collective identity is also imbued with interpersonal values of social justice and fairness. And witnessing the violation of these values produces powerful emotional responses that induce the individuals to seek like-minded others in physician single-payer networks. In these networks, physicians interact and engage with one another, producing the sense of weness and solidarity to fight against the "they" that has been deemed responsible for the injustice.

Emotions played an important role in mobilization. Physicians reported feeling outraged, frustrated, angered, and pissed off that their patients couldn't get the care the physician felt was best. These emotions resulted from a violation of the actors' moral values (Klandermans 1997) and played an important role in their motivation for action (Jasper 1998; Klandermans 1999).

The next chapter discusses the subsample of non-activist physicians to reveal what blocks their engagement in single-payer activism even though they support the idea of a single-payer system in principle. 


\section{CHAPTER SIX: NON-ACTIVISTS}

To validate the finding on the factors leading to physician activism for singlepayer healthcare, this study included a smaller sample of physicians who agreed to single-payer healthcare in principle but did not engage in activism. It is prudent to examine physicians who are aware of single-payer and support it, but do not engage in activism for it to see which factors are similar and which are different among the two groups. Without a comparison group, it is impossible to know if the factors spurring activism are unique to activists (Weiss 1994). Having a subsample of pro-single-payer

physicians during the same time frame and who practiced medicine in the same state will illuminate the differences between the two groups and help ascertain the particularities that influence single-payer activism.

I find the non-activists maintain some pieces of the collective identity, but not all of them and additionally perceive immutable barriers that make single-payer seem like an impossible solution. Therefore, while the activists harbor substantial motivation with their collective identity, the non-activists lack this important motivational force and perceive barriers that would render their activism inefficacious, leading to their noninvolvement. This chapter begins by describing how non-activists experience less deprofessionalization in their workplaces which does not prime them to be upset in the way that activists are. Then, the barriers that prevent the possibility of passing singlepayer perceived by the non-activists will be discussed. The chapter ends with a discussion of how the non-activists resist the collective identity because they do not agree with its 
most important component, the prognostic frame asserting a priority on financing changes over delivery changes.

\section{Comparison of Motivational Factors}

Many of the motivational factors contributing to single-payer activism among the activists are absent or weaker among the non-activists. Table 6.1 below compares the extent to which activists and non-activists exhibit the collective identity beliefs. Whereas the activists strongly support each belief of the collective identity, the components were either weaker, absent, or mixed among the non-activists. The application of labels was based on the strength and direction of the belief as it was conveyed in the interviews. Sometimes this was ascertained quantitatively via the frequency of mentions of social justice values or the measurement of erosion of autonomy. For other factors, the decision was made based on my interpretation of the interview data. For instance, non-activists were assigned a moderate level to the belief "duty to help the disadvantaged" because three of the seven engaged in activism in other areas, demonstrating this was present, but not strong in the particular area related to this project. Similarly, there were mixed feelings among the non-activists about the feasibility of passing single-payer at the state level, so it is represented by the label "mixed." And last, because each non-activist was opposed to the belief that a priority of health changes needs to be on financing, that collective identity belief is absent among the non-activists in my sample. 
Table 6.1: Comparison of Extent of Collective Identity Beliefs

\begin{tabular}{|l|c|c|}
\hline \multicolumn{1}{|c|}{ Factor } & Activists & Non-Activists \\
\hline Social justice value system & Strong & Moderate \\
\hline Duty to help the disadvantaged & Strong & Moderate \\
\hline Experience of deprofessionalization & Strong & Weak \\
\hline Priority of reforms is financing & Strong & Absent \\
\hline Single-payer achievable at state level & Strong & Mixed \\
\hline
\end{tabular}

First, the non-activists still expressed a desire to help others conditioned by social justice values, but for this group, that willingness was conditioned by the perceived feasibility of passing single-payer legislation. The non-activists were convinced for multiple reasons that single-payer was "impossible" and concluded that there was no point in engaging in activism for it, if it could not be achieved. So, the non-activists still want to help the disadvantaged, but not through single-payer activism. For this reason, some of the non-activists in this study still engaged in collective action, but for goals they felt were more likely to be implemented in the near future.

Second, the sample of non-activists did not report infringements on their professional autonomy to the extent that activists did. In other words, the non-activists did not experience deprofessionalization to the degree that activists did due to their medical specialty or practice setting, but did report this experience to some extent. The reduced negative work experiences do not cause strong emotional reactions that prime single-payer activism.

Third, non-activists feel it is just as important, if not more important, to reform delivery aspects of medical care so they resist adopting the collective identity that emphasizes a priority on changing financing of healthcare. This belief is the most determinative piece of the collective identity. Not one of the non-activists agreed with the prognostic frame that the priority of healthcare reforms must be on financing. 
Therefore, because the non-activists only weakly support or actively oppose pieces of the collective identity, they never adopt the collective identity that promotes and motivates collective action for single-payer healthcare. The absence of the motivational force bestowed by the collective identity, coupled with the presence of barriers, combine to result in their non-activism for single-payer healthcare.

\section{Less Experience of Deprofessionalization}

Non-activists were more likely to work in systems which guarantee professional autonomy, such as the Veteran's Administration (VA) system and large-scale, physicianowned HMOs. The doctors in my sample working at these locations have tended to stay their entire careers because explicit treatment guidelines and lack of gatekeepers allow them to practice medicine without being second-guessed. A score of negative one was assigned to a passage when a physician reported unwelcome constraints on their autonomy, a zero assigned when the physician felt the limitations were appropriate, and a score of positive one was assigned when the physician reported that $\mathrm{s} / \mathrm{he}$ felt doctors had too much autonomy.

Comparing the autonomy scores of the non-activists, low-level activists, and highlevel activists reveal a gradient in this factor. The high-level activists reported the greatest amount of erosion to physicians' professional autonomy. The non-activists, while still generating a negative number indicating they sense unwelcome constraints on physician autonomy, reported the least amount of erosion of their professional autonomy. And, the low-level activists fell in between the high-level activists and non-activists in regard to their perception of changing professional autonomy. In short, non-activists reported the 
least erosion of professional autonomy while high-level activists reported the greatest constraints on professional autonomy.

The non-activists experienced less autonomy erosion which makes them less likely to experience negative emotional reactions that are known to motivate individuals to engage in political action. These physicians working in locations like the VA with safeguarded autonomy say that they know the system outside of their organization is broken because when they see new patients, they are on a variety of the most expensive medications, which would not be allowed in their system. For example, when asked if she commonly experienced situations where she wanted to order a test or treatment and it was denied by the organization, this female cardiologist working in the single-payer organization of the VA explains,

"I would say rarely. Occasionally there's medications you'd rather use that aren't on our formulary. Usually if there is a rational justification for why you need a special medicine, you can usually get it. Rarely is that a problem. Now, patients often come from a private doc and think they need the latest, greatest most expensive medication. Usually, we don't think they do need that, so that's a little bit of a headache of getting them switched to a less expensive, but as effective medication."

Rarely is her professional discretion questioned. This is in stark contrast to many of the activists who describe the oversight of their medical decision-making as continual and oppressive. If this non-activist's professional judgment goes against the formulary, all she needs to do is justify her case, and she can usually get the treatment. A psychiatrist who also worked at the VA explains how physicians' professional autonomy is safeguarded in single-payer systems:

I understand the need to contain costs and I think the VA does a fairly decent job of deciding which drugs are reasonable to have on the formulary and which ones you should have to ask for. And mostly they 
also have a pretty decent record, at least in my facility, of granting most requests. They have strict guidelines for exceptions and I usually don't have trouble making the argument that that person qualifies for an exemption. And if I can't make the argument, then I probably shouldn't be asking for it. [chuckles].

He describes how his medical judgment is respected and feels the limits on his professional autonomy are reasonable. Physicians experiencing safeguarded professional autonomy tend to be more complacent in their day-to-day work lives and less likely to advocate for change. In other words, they are less likely to experience a situation in which autonomy erosion due to insurance restrictions prevents them from doing what they feel is best for the patient.

The female cardiologist working at the VA describes her safeguarded professional autonomy and how she is permitted to do what she feels is best for the patient without too many financial considerations getting in the way:

But once you're in the system, as a physician, I can make purely medical decisions. Everyone I take care of gets everything I have to offer. And there's no penalty for doing more or doing less. I get to do what really makes sense based on my judgment and based on the medical data and literature. I guess I've never had an interest in being a business person or doing for-profit things.

Like the activists, she doesn't like medicine being treated as a for-profit business. But her work environment in the single-payer setting, without substantial gatekeepers and with safeguarded autonomy, does not frequently cause her to experience the emotions that the activists do as a result of their work experiences (e.g., anger, frustration, outrage). The non-activists in this study are less likely to have work experiences involving deprofessionalization and emotions resulting from negative work experiences. 


\section{Feasibility Makes Single-payer Activism Unattractive}

Perhaps the most powerful deterrent to single-payer activism for the non-activists is the limited perceived feasibility of passing legislation to enact it. This acts as a formidable barrier the physicians must confront. This section will discuss how the nonactivists view these barriers as immutable resulting in the conclusion that single-payer "impossible" in America. Two of the most frequently cited reasons are that Americans would never support a plan that appears to give more control to the government and that even if Americans wanted single-payer, Congress would never be able to pass such reform. Given that these physicians do not see single-payer as an attainable solution, they see no point investing personal resources trying to attain it. For these reasons, if the physician does engage in activism, it is for other causes deemed more feasible.

\section{Americans' Distrust of Government}

The first main barrier the non-activists perceive is that of the American people and their focus on individualism and small government. Single-payer systems are sometimes portrayed as a "government takeover" of medicine or increasing the size of "big government." This common perception runs counter to the ethos of individualism that is pervasive in American culture. Non-activist physicians believe Americans in general are distrustful of the government and would not support an entitlement system where everyone is provided equal care because it runs counter to values of individualism and the Protestant Work Ethic (Weber 2002[1920]; Skocpol 1996).

Every non-activist physician cited this as a formidable obstacle to the passage of single-payer legislation. The following quote from a retired male whose specialty was 
critical care demonstrates the link he sees between American culture and single-payer. He said, "Considering the antagonism towards government that so many people have in this country. It runs deep and it runs strong and I just can't see us going in that direction politically in the near future."

Doctors also mentioned that publicly-financed healthcare that is equally available to all is not attractive to the American people because of the belief that people must work for what they have and some people do not deserve access to high quality healthcare. In other words, they subscribe to the Protestant Work Ethic that says one must work hard to enjoy valuable goods like healthcare services. A retired, male, family practice doctor questioned,

"Why don't we have systems like other countries do that actually take care of their citizens? It's because it's in the American culture. Really going back to the founding of the country, which is this kind of individualism and every person for themselves."

He feels that American individualism is very strong and the public will not support a system where everyone is equal.

Along these lines, a practicing female cardiologist expressed her doubt of the public supporting a single-payer system:

"I think there's just no way because we're a society that's much more into "I want everything for me right now" especially if I can pay for it. And you know, really, it'd be hard to follow a more socialized society that's thinking of the common good, so I just think it's never going to happen in my lifetime and kind of give up."

We see how this sentiment influences activism. She surmises that it's never going to happen, which for her is the defining factor. Without being able to achieve the goal, she abstains from the process of activism. 
More evidence of American's hostility for them was seen in how some Americans want to repeal the few healthcare policies we currently have that seek to improve healthcare access for disadvantaged populations, like the Affordable Care Act (ACA) and Medicare. Non-activist doctors believed that if the American public doesn't like the small incremental changes in the ACA, they would never support the radical changes required by the establishment of a single-payer system. A retired, male, family-practice doctor explained it this way:

"There's a fairly large number of tea-party Republicans, whatever, who actually think we should get rid of social security and Medicare, you know? So why would they support Medicare for all when they don't even support Medicare as it currently exists? There's still fighting the battles of the 1930s. So you know, that's just true. It's stupid, but it's true."

The doctors do view these groups of Americans who want to roll back important social programs, as implacable foes of single-payer reform. They see this feature of American culture as unchanging; something that cannot be swayed with education and outreach.

A male endocrinologist echoes this hostile public sentiment and the confusion among Americans about single-payer:

"When you look at the right-wing reaction to the Affordable Care Act which is far from single-payer, which they're calling "socialized medicine" or "government medicine" and all that. There's so much hostility and anger and dishonesty and political power that whatever incremental improvement the Affordable Care Act brings is barely hanging on by its fingernails. To get from there to a true single-payer system, in our lifetime, I just don't see it."

These sentiments reflect Skocpol's (1996) assessment that Americans fear any programs that appear to give the government more ability to regulate business. Some vocal factions of America want less government involvement in the market and react in a hostile manner to an incremental improvement like the Affordable Care Act. It is reasonable for 
the physicians to think that if incremental reforms are this controversial, then a more comprehensive reform is dead on arrival.

Americans' distrust of government was the most frequently-mentioned theme among non-activists. They believe that the distrust of government and the commitment to individualism pervasive in American culture would prevent enough citizens from supporting a single-payer system, blocking its passage. And for the non-activists, if single-payer is an impossible outcome, any effort designed to achieve such a system is done in vain. These non-activists have little hope for changing this sentiment in American culture. Hence, they are unwilling to invest personal resources in the struggle if they do not think the outcome will be achieved. And they say the outcome will not be achieved due to the individualism prevalent in American culture and its preference for market solutions.

\section{Political Stalemate}

American culture was not the only obstacle to passing single-payer reform cited by non-activists. Non-activist physicians were also concerned about the feasibility of passing single-payer legislation through the government. All respondents recognized that if we were to establish such a system, it would require a process that involved our elected officials. All non-activists, though, were very pessimistic about the possibility of our elected officials cooperating to make a single-payer system happen, even if the American public was in support of it. For example, a retired female OBGYN stated, "So, could it happen? Yes. Do I think it will happen? No, not yet. I don't think so. Because I don't think there's the political will." She goes on to say that resources are not a barrier to 
expanding care, but the resistance to single-payer more deeply reflects the lack of commitment our government has for helping its citizens.

In the next quote, the "we" she is referring to is our government and elected officials. She said, "We have plenty of money. It's our priorities that are fucked up. We have plenty of money." In other words, we have the financial capacity to enact singlepayer, Congress simply refuses to do so. This is consistent with Mechanic's (2006:188) assessment of healthcare reform in the US: "Failure to overcome our health system dysfunctions is not a result of lack of knowledge or organizational capacity. It is an issue of will and commitment." This doctor's quote, again, illustrates how the unattainable outcome blocks her activism. Her perceived unwillingness of Congress to pass such a bill is a deciding factor in her choice to not become involved.

Echoing the perceived ineptitude of Congress, a retired male in family medicine exclaimed, "It's just not gonna happen given Congress and the way it is. I mean they can't even do anything!" This sentiment is understandable given that during the course of these interviews, the federal government was "shut down" because Congress could not agree on a budget for the coming fiscal year. It is widely understood that contention over funding for the Affordable Care Act was a primary cause of the "shut down." Observing how contentious the ACA had become, even though it would bring only incremental improvements, colors the non-activists' views about achieving major healthcare reform. A statement made by a retired male whose specialty was critical care reflects this: "It's kind of hard to be super enthusiastic, and I love my friends who are super enthusiastic about single-payer, but realistically number one it isn't going to occur in this country with 
the political split that we have." The political split in the $113^{\text {th }}$ Congress contributed to their notorious label as the "least productive Congress ever" (DeSilver 2013).

Six out of seven mentioned the corrupting influence of money in politics and how this limits the possibility of passing the necessary legislation. They specifically mentioned the medical-industrial complex (MIC) and the vested interests that compose it which Relman (1980) first warned about. The MIC control massive financial resources and respondents discussed this undermines more progressive goals politics. Respondents said that these entities benefit from the current arrangement of healthcare and will use their resources to resist single-payer legislation. It appears that Relman's prescient warning that the MIC, whose interests are opposite those of patients and society, would rise to prominence and control healthcare reform has come true.

A practicing female cardiologist explained the obstacles to single-payer legislation that she sees:

"I think politics definitely [is an obstacle]. And I think capitalism definitely [is another obstacle]. I mean, there's so much money in healthcare. A lot of what I've been talking about is the physician-provider role, but there's just so much financial interest and so certainly big lobbying groups, Big PhRMA, insurance companies..." [limit the feasibility of passing single-payer.]

She finds the amount of financial resources behind the opposition to single-payer daunting and something that limits the efficacy of single-payer activism. Another female, a retired endocrinologist agreed,

"I don't see it happening in my lifetime, I wish I did, among a lot of other things. Politics is, money and politics is in particular is interfering with everything. I'm not seeing that light at the end of the tunnel. [laughs] I don't know what to expect, I wish I could be more optimistic. Oh well." 
The non-activists view the quest for single-payer as a hopeless cause due to the big money interests that oppose single-payer. They think a grassroots movement will not be able to compete with the influence and reach of the MIC. Therefore, the non-activists view the political system necessary to pass and enact legislation as hopelessly corrupted by big money interests. The lack of passion for the issue is also clear in the last quote. Instead of reacting with outrage, she reluctantly accepts the situation by ending her discussion of these barriers with an "oh well."

Given that all respondents felt a single-payer system would be better than what we have now and given the strong feeling that advocacy for single-payer does not result in meaningful change, it is not surprising that some non-activists were working to effect change in other areas of medicine. Three of these doctors had the mindset that, 'given that single-payer is not happening, what are other areas in which we could make improvements?' These doctors focused their efforts in areas that they felt were more likely to be successfully-reformed in the near future. There was a variety of other medical issues that non-activists were advocating for. For instance, a retired male family medicine doctor is involved in a physician organization that is working on issues related to gun violence, women's reproductive health issues, and eliminating gag laws related to the environmental practice of fracking.

The female endocrinologist said she is concerned about what happens with patients' health information and privacy. She said, “That's the other thing I'm very concerned about, is patient privacy and what's happening with electronic records and all that kind of stuff." She has traveled to Salem and met with legislators and some nonprofit groups about this issue. She also wishes doctors would pay more attention to what 
patients have to pay for care. She said one of her goals is "...to craft a letter to the higherups at [a large $\mathrm{HMO}$ ] here to push for that transparency between the doctor and patient about costs."

A retired female in obstetrics and gynecology has chosen to focus her efforts on preserving access to safe abortion services. Speaking about her choice to focus in this area instead of single-payer she commented,

"I mean, there's a limit. There was actually something refreshing about when I chose to become an activist in abortion care; it sort of frees up you up from having the responsibility of taking care of all the world's other problems. You know what I'm saying? Focus on one."

The perceived futility in advocating for a single-payer system made activism for other issues more attractive. The doctors believed their activism in these areas was more likely to lead to changes that could be implemented relatively soon. In other words, they did not perceive there to be substantial barriers to enacting delivery reforms, but did view substantial barriers for attempting financing reforms. In addition, the last comment also demonstrates how there are limits to activism. The doctors recognized that there are numerous areas that would benefit from advocacy and reform, but a person only has so much energy to devote to these causes and it can be a relief to limit what you advocate for. Due to this, the physicians chose to work for reform in other areas of healthcare; areas in which they felt they could effect change in a more reasonable time frame.

\section{Interpretation of Political Opportunities}

As is clear from the quotes about Congress in the section above, many nonactivists still consider the debate about single-payer to be occurring at the national level. 
Whereas the activists responded to the health reform debates that culminated in the Affordable Care Act as signifying single-payer attempts must be made at the state level, the non-activists either are unaware of the state efforts or still see major complications confounding state-level efforts.

This physician working in emergency medicine believes even achieving singlepayer at the state level will be incredibly complex and difficult. He feels there are many unanswered questions as to how this will happen at the state level. He was discussing how money has corrupted our national Congress. When I probed about the possibility of achieving it at the state level, he had this to say:

And that's sort of the big debate. Well, let's just screw the federal system and do it at the state level. But the problem with single-payer at the state level is the complexity of what we have now. What do we do with Medicare dollars? Medicare's federal money. So if Oregon had a single payer, does Medicare give Oregon a block grant? What about Medicaid? What about Indian Health? What about veterans? That's the problem, is that we're starting with a nonsystem. How do you create a system out of a nonsystem?"

For him, even attempting single-payer at the state level is fraught with difficulty due to the challenges facing activists as they try to make a coherent system out of the nonsystem in place now. Political process theorists would note that the perceived closing of political opportunities is deterring activism among this group of physicians.

\section{Resistance of the Single-payer Collective Identity}

In the previous chapter I argued that the physician-activists create and sustain a collective identity that promotes a priority on reforming healthcare financing before other 
reforms and a belief that single-payer is the only way to solve the healthcare issues while staying true to social justice values. Recall that a collective identity is “.... sort of 'shorthand' reference point for insiders and outsiders that encapsulates key movement frames, issues, tactics, identities, ideologies and orientations" that can be perceived by those outside the movement (Flesher Fominaya 2010:397). The collective identity is produced through the interaction and framing discourses that take place in free spaces, like single-payer physician organizations.

I find that the non-activists are aware of the beliefs that make up the single-payer collective identity, but do not agree that the priority should be on reforming financing and that delivery reforms are just as important to implement. Also, non-activists choose to not seek single-payer chapters to join because of the factors presented above, like fewer negative work experiences and the belief that collective action will not be efficacious in attaining the goal.

This male retired from family medicine said he feels that single-payer is not sufficient to fix many of the issues facing the healthcare system today and chose to focus on other problems. He said:

"It's [single-payer] necessary maybe, but it's not sufficient; not even close to sufficient for the changes we need to make. There are many, many things that need to be reformed in US healthcare. I certainly agree that the insurance, the idea of this kind of multiple insurance companies and the profits that they're making, is an issue, but it's not the only issue."

This quote makes clear how this physician would have a hard time adopting the collective identity sustained by the activists. He believes aspects of delivery are important to change and that single-payer is not "even close" to sufficient. 
Financing reform, while important to him, is not the only issue he feels physicians should be advocating for.

This male, retired from critical care work, explains how he feels there are important changes to be made to the delivery system.

"You're going to see more nurse practitioners and physician's assistants and advanced nursing degrees, and people, physical therapists or whatever else, really playing the role. You know if somebody has chronic back pain, they don't need a doctor so much as maybe they need a physical therapist really to be their primary contact. And if they have obesity, and that's their primary problem, they're otherwise reasonably healthy, they don't need to go to a general practitioner to talk about obesity or quitting smoking, maybe they need to go to a dietician. We operate under a very archaic system of how we deliver care."

The non-activists do not emphasize changing financing like the activists strongly do. The non-activists feel that delivery is just as important to reform as financing or that financing is insufficient to make meaningful changes. Given the prominent role that the priority on financing plays in the collective identity promoting singlepayer activism, it's understandable that an emphasis on delivery would prevent adoption of the single-payer collective identity and prevent single-payer activism.

\section{Summary}

The smaller sample of non-activists in this study highlights the barriers preventing these physicians from becoming single-payer activists, even though they support the financing arrangement in principle. Disbelief in political efficacy and resistance of the collective identity combine to prevent activism. In other words, the non-activists lack the powerful motivating force of the collective identity and perceive immutable barriers in 
place, preventing single-payer activism. For the non-activists, the balance of motivators and barriers is tipped toward more barriers than motivators.

First, the non-activists did not report experiencing deprofessionalization to the extent that the activists did because they work in locations or have specialties where their autonomy is more protected. For this subsample, it was more common to have a practice that safeguarded their autonomy such as the Veteran's Administration and large physician-owned HMOs. In these settings, the physicians report being able to use their experience and professional judgment as they decide patient treatments. As explained earlier, the activists often had to struggle with the task of convincing gatekeepers to permit the desired treatment, causing them to experience anger and frustration from their work experiences. This matters because emotional reactions carry much of the causal force for mobilization and vitalize the process of developing a collective identity (Jasper 1998; Klandermans 2002). The result is that the non-activists lack the frustrating work experiences that cause emotional reactions stimulating the activist physicians to take action.

Second, the non-activists felt the healthcare system could be improved, but the perceived implausibility of passing single-payer legislation led them to focus their efforts in other areas. The non-activists had a desire to help others, but not through single-payer because they felt it was never going to happen. The non-activists believed that American culture and the American people would be resistant to a program that appears to give the government more control over private businesses. The non-activists felt that even if the American public supported such systems, the political split, the dearth of political will to enact such legislation, and money's influence in politics would prevent it from 
happening. They lack political efficacy, believing that the issues cannot be solved through the political system (Bandura 1997). With the goal determined to be impossible, they felt there was no point engaging in collective activism to achieve it.

Third, the non-activists all disagreed with the prognostic frame espoused by the activists. None of them agreed that the priority of reforms should be changing financing. The non-activists felt that single-payer is insufficient to solve our nation's healthcare troubles and delivery reforms are just as important as financing reforms. Last, they do not look to state-level single-payer movements with the same optimism that activists do. The non-activists believe state-level single-payer attempts will be frustrated by the complexity of creating a system out of a nonsystem presenting in an insurmountable obstacle.

Because the non-activist physicians perceive formidable barriers and disagree with key movement frames, they never join a chapter of local single-payer physicianactivists. This is critical, because it is in these organizations that the collective identity promoting collective and political action for single-payer is socially-constructed, adopted, and shared. Without participation in the physician networks, the non-activists cannot develop the shared sense of we-ness that contributes to solidarity nor the sense that collective action can achieve movement goals. Disagreement with movement frames combined with the perception of substantial barriers prevents cognitive liberation of this group and leads to their non-activism for single-payer. The non-adoption of collective identity and subsequent non-activism for single-payer promote the idea that adoption of the collective identity is necessary for single-payer activism. The next chapter will provide a thorough review of differences between activists and non-activists to produce 
the dual outcomes of activism and non-activism for single-payer among physicians in Oregon. 


\section{CHAPTER SEVEN: CONCLUSION}

The commercialized age of medicine has produced a crisis in American healthcare and fomented demands for a more equitable and affordable system. Singlepayer financing of healthcare has been has been championed by prominent physicians as a way of rectifying the social and economic crises produced by the commercialized system. Nationally-representative studies demonstrate widespread support for singlepayer among the physician community (Carroll and Ackermann 2008).

This dissertation sought to examine the factors that contribute to physicians becoming active in the Oregon movement for single-payer healthcare during a time of national reforms. Additionally, this study reviewed what physicians do in their activism for single-payer and what shapes the choice of the activities. These issues were explored through semi-structured interviews with 21 physicians in Oregon who support singlepayer healthcare and supplemented with participant observation data. The sample was split between 14 activists and seven non-activists. Including a comparative subsample

allowed examination of which factors were common to the two groups and how the two groups differed in order to ascertain the determinative factors for single-payer activism among physicians.

Oregon provides an excellent location for a case study of the single-payer movement because it has a rich history of attempting incremental delivery reforms that have brought limited success, buoying calls for comprehensive reform. Citizens, policymakers, and practitioners in the state are also more familiar with health reforms than those in other states, likely leading to greater willingness to attempt and implement 
reforms. With a physician Governor, Oregon has a history of physician involvement in healthcare reform. Additionally, it has many of the pieces in place that contributed to a successful state-level single-payer campaign in Vermont.

Yet, considering the power of the Medical-industrial Complex and the individualism characteristic of American culture and politics, the structure seems stacked against a movement trying to undo capitalistic forces in American healthcare. There are formidable barriers to successful passage of single-payer legislation. Examining this situation from any of the three main social movement paradigms covered in Chapter Two (rational actor theory, resource mobilization theory, and political process theory) might satisfactorily explain the non-participation of the non-activists. Non-participation makes sense because there has been no objective expansion of political opportunities and the opposition to single-payer has substantially more resources at their disposal than the single-payer movement (Marmor and Oberlander 2004). The non-activists cited the exclusion of single-payer advocates from the Affordable Care Act debates as evidence of this. While these theories can inform non-participation, they provide little insight into why physicians, in the face of such opposition, would choose to spend their scarce free time fighting for the healthcare of others.

With its emphasis on actors' interpretations and perceptions of the structure, collective identity theory provided the most convincing explanation for physician activism in the single-payer movement in Oregon. This chapter highlights and addresses the study findings in relation to the literature with attention to implications for activists and avenues for future research. Limitations of the study will be addressed last. 


\section{Barriers to Single-payer Activism}

I find that collective identity offers a compelling explanation for physician mobilization because it highlights how individuals interpret structural conditions. The activists and non-activists interpret the barriers to single-payer very differently resulting in the activists seeing the barriers as manageable or changeable while the non-activists interpret them as fixed. Table 7.1 compares the differential interpretation of structural barriers by activists and non-activists.

First, perceived efficacy of action influenced activism. The non-activists were certain that their activism would not bring about the goal of single-payer and hence saw no point in taking time to do it. The rationalizations of the non-activists were tied to American culture, American politics, and how powerful money interests like the Medical-industrial Complex that oppose single-payer prevent well-meaning reform. Given an impossible goal, they see no point in wasting their time or energy fighting for something that can never be attained. While they support the cause in principle, they conclude that it is not worth investing in activism if the goal will not be achieved. This disbelief in the feasibility of passing single-payer legislation and the disbelief that their activism will make a difference causes many of the non-activists in this study to engage in reform efforts in other areas.

The activists also recognize that the American public is distrustful of government and that money corrupts politics, but they know that establishing a single-payer financing system must happen through the government. For instance, the activists are trying to emulate the strategy in Vermont that mobilized grassroots support in order to ensure that candidates who openly supported single-payer were elected. Vermont Governor Shumlin 
credited his successful campaign to the single-payer activists that educated people to make sure the measure was politically-viable. Oregon activists are employing the same strategy which demonstrates they believe they can transform the political system at the state level to make it work for them. The activists strongly believe they can make singlepayer politically-feasible at the state level.

Table 7.1: Comparison of Perceived Barriers

\begin{tabular}{|l|c|c|}
\hline \multicolumn{1}{|c|}{ Factor } & Activists & Non-Activists \\
\hline American Politics & $\begin{array}{c}\text { At state level, make it work to our } \\
\text { advantage. }\end{array}$ & $\begin{array}{c}\text { Corrupted by money } \\
\text { interests and unhelpful. }\end{array}$ \\
\hline American Public & Can be educated. & Cannot be convinced. \\
\hline Efficacy of Action & Unsure, but have to try. & Ineffective. \\
\hline
\end{tabular}

The activists see the individualistic characteristic of American culture and realize it is a roadblock to reform and so they work to actively change it. This requires education of the voting public so they understand the benefits of single-payer and elect candidates who support single-payer. Activist-physicians believe they can educate and convince people to understand why single-payer makes sense and make the time to do so. The activists interpret the barriers of the American people and American politics as changeable and do not experience the same political feasibility barrier as the nonactivists.

The activists, though, while not entirely convinced that single-payer will be achieved in the near future, all feel compelled to try. The activists are unsure of the efficacy of their action, but remain cautiously-optimistic that their activism will make a difference. Their willingness to engage in single-payer activism is not conditioned on feasibility, but on what they perceive to be "doing the right thing." Confronted with the 
same trend in American culture, the non-activists view it as fixed and something activism will not be able to change.

Therefore, illuminating the different ways activists and non-activists interpret the barriers to activism partially explains the differences in activism. This demonstrates the critique of political opportunity theory that notes that in order for opportunities to influence activism, they must be perceived in such a way. Collective identity theory permits examination of differences in perception. But, it is not just the perceived mutability of barriers that shape activism. Whether the physician participates in the process of collective identity and adopts it also bears on mobilization.

\section{Comparison of Collective Identity Factors}

In the face of formidable structural barriers, activists need substantial motivation to overcome them (Klandermans and Oegema 1987). The physician activists in this study socially construct and share a collective identity that provides sufficient motivation and enables the activists to overcome the barrier of the implausibility of winning the singlepayer campaign. The five beliefs of the collective identity are (1) a value system that promotes social justice, equality, and fairness; (2) a frustrating experience of deprofessionalization; (3) a sense of duty to help the less fortunate; (4) a belief that healthcare reform must prioritize changing the financing of healthcare instead of more delivery reforms; and (5) an understanding that single-payer is attainable at the statelevel. Once physicians engage in the process of producing the collective identity in physician networks, they develop solidarity that facilitates participation in collective action for single-payer. 
The non-activists exhibit some of the pieces of the collective identity, but none of them agree with all of its components. This leads them to resist and not adopt the collective identity. The absence of the motivational force derived from the collective identity, coupled with an interpretation of structural barriers as immutable, combine to result in their non-activism. Table 7.2 (which is the same as table 6.1) lays out the differences between activists and non-activists with regard to the strength to which they exhibit each belief of the collective identity.

Table 7.2: Comparison of Extent of Collective Identity Beliefs

\begin{tabular}{|l|c|c|}
\hline \multicolumn{1}{|c|}{ Factor } & Activists & Non-Activists \\
\hline Social justice value system & Strong & Moderate \\
\hline Duty to help the disadvantaged & Strong & Moderate \\
\hline Experience of deprofessionalization & Strong & Weak \\
\hline Priority of reforms is financing & Strong & Absent \\
\hline Single-payer achievable at state level & Strong & Mixed \\
\hline
\end{tabular}

One key component of the collective identity is a value system that focuses on social justice, fairness, and equity. While some of the non-activists maintained a similar value set, social justice values were discussed much less often by the non-activists than the activists. This was measured by the frequency of mentions in the interviews relating to social justice values. The social justice value set figured prominently in the narratives of activists and was foundational to their motivations for activism, while rarely being mentioned by the non-activists. Therefore, this factor is weaker among the non-activists, yet still present, resulting in a moderate label.

Another piece of the collective identity is a willingness or sense of duty to help disenfranchised people. The activists reportedly felt religiously-, socially- or professionally-compelled to help the less fortunate. There was also a recognition that the 
physician could not do this alone in their practice and that collective action is necessary. The activist physicians working for change outside of the clinic walls are fulfilling the public roles of physicians advocated for by Gruen and colleagues (2004). The desire to help the less fortunate sometimes derived from religious teachings or secular parental teachings to "do the right thing" and "help others if you can." The non-activists exhibited this to a lesser extent as well. They are willing to help others as evidenced by the activism some of them do for issues other than single-payer. Therefore, non-activists exhibit this trait, but again, to a lesser extent than the activists, so it is represented by the label moderate.

Workplace experiences eroding physician autonomy also influenced levels of activism for single-payer. Both activists and non-activists scored negatively on the deprofessionalization scores, indicating they both experienced erosion of their autonomy. But, the non-activists reported this experience to a lesser extent than the activists, resulting in the label "weak" to indicate the level to which the non-activists exhibit this belief.

Non-activists were more likely to work in systems which guarantee professional autonomy, such as the Veteran's Administration system and large-scale, physician-owned HMOs. The doctors in my sample working at these locations have tended to stay there their entire careers because of the explicit treatment guidelines that make practicing medicine less complicated. Which is to say, they are less likely to experience a situation in which autonomy erosion due to insurance restrictions prevents them from doing what they feel is best for the patient. Their safeguarded professional autonomy lessens the likelihood that they will experience outrage and frustration in their work lives and 
without these powerful emotional reactions, they are less likely to be motivated to work for systemic changes.

In contrast, activist physicians reported greater constraints on their professional autonomy and clinical decision-making. This supports the predictions by Waitzkin (2001, 2012), Geyman (2005), and Freidson (2001) about physician experiences in the commercialized age of medicine. These scholars described how the physician has lost the legitimacy to make his or her own decisions as payers gain greater ability to dictate treatments. The activists wish they could always do what they feel is best for the patient by focusing on clinical factors rather than continually taking financial limitations into account. They expressed frustration, anger, and indignation at what they are forced to do because of insurance company limitations, which is also consistent with findings from Castellani and Wear (2000).

The activists were more likely to report witnessing the consequences of patients delaying seeking care and the sadness they feel when the disease has progressed to a point where they can no longer help the patient. Many activists reported that once they were out practicing and could see that the system was broken, they knew they needed to try to change it. These emotional responses carry weight in social movement mobilization and can powerfully influence someone to take political action (Jasper 1998). With the safeguarded professional autonomy of non-activists, they are less likely to experience these mobilizing emotions.

Moreover, physician-activists understand that medical ethics are compromised in the current system and a single-payer arrangement would alleviate most of the deprofessionalization issues physicians confront. The double agent and mercenary MD 
tension felt by physicians would diminish or disappear. This would allow them greater ability to uphold their medical ethics by doing what they feel is best for the patient, rather than being restricted by what is covered by the patient's insurance plan.

The fourth piece of the collective identity is the most crucial and acts as the determinative factor of whether a physician adopts the collective identity. The fourth factor is whether the physician agrees with the prognostic frame: that healthcare financing must be reformed before delivery. None of the non-activists agreed with this component and some strongly opposed it. The non-activists prefer the more feasible, incremental delivery reforms. In contrast, the activists refer to statistics demonstrating that countries utilizing the same systems of delivery achieve better outcomes for less money than the US does. This piece is fundamental to the single-payer activist collective identity. If a physician does not place priority on switching the financing of care to a single, non-profit payer, then the physician would not belong in the group of single-payer activists.

Additionally, interpretation of political opportunities differs between the activists and non-activists. The non-activists witnessed negative response to the Affordable Care Act, which makes them believe that comprehensive healthcare reform is unattainable in America whether at the state level or national level. The activists on the other hand, in response to the ACA debates and Vermont's single-payer campaign, have turned their efforts to the state level and believe single-payer is attainable at that level. The activists were particularly encouraged by the single-payer victory in Vermont. About half of the activists mentioned specifically that they were inspired by the passage of single-payer legislation in Vermont in 2011. Two non-activists mentioned Vermont, one with a 
positive sentiment and the other expressing concerns for the implementation of the legislation which means the non-activists in my sample have mixed feelings when it comes to this belief.

Using political process theory to interpret this finding would not account for the differing opinions of the non-activists and activists when confronted with the same political trends. Objectively there is no expansion of political opportunities occurring at any governmental level, which this theory proposes to explain the activism among activists. Instead, my findings bolster the critique of political process theory presented in earlier in that the theory neglects the important role of perception and social construction of meaning. Collective identity, on the other hand, with its emphasis on how actors interpret structural conditions according to their culture and values, reveals how physicians can view the same structure in different ways. Perception and interpretation are necessary components of an explanation for how collective actors relate to the political opportunity structure.

\section{Mobilization}

While the above discussion of barriers and motivators explains why the activists have sufficient motivation to become involved, it does not adequately explain mobilization. For instance, beyond the influence of the collective identity, the constraints of availability also shaped activism. The amount of time a physician has to dedicate to social movement activity varies over the career of the physician. It was reported that activism in medical school was facilitated by the presence of the American Medical Student Association, but then activism was impossible during residency due to 
overwhelming time demands. Availability is such a powerful influence, that a physician may interpret barriers to single-payer as mutable and adopt the motivational collective identity, but if they have zero availability (like what happens during residency), then they cannot mobilize and become engaged.

However, at any time other than residency, the physician does have some spare time. For a majority of activists in this study, they only came to learn about single-payer after become frustrated working in what they describe as a broken system. They learned about single-payer either through their own personal research on the Internet or were recruited by someone active in the movement. Once they became involved in a singlepayer physician organization, they engaged in the process of collective identity. Through interaction and discussion in these groups, key movement frames were clarified and boundaries erected to distinguish movement insiders from outsiders. The sense of weness and solidarity also happens in the physician networks. Those that agreed with every belief of the collective identity adopt it and go on to be activists (provided they have availability). Those that disagree with the beliefs, most importantly the prognostic frame, resist adoption of the identity and do not become single-payer activists.

The physician networks also facilitated learning of movement tactics and awareness of opportunities for activism. Once integrated into the social movement, the activists engaged in a wide range of activities. Low-effort activities include posting on social media, wearing a button, or voting for pro-single-payer candidates. Other activities physicians participated in were manning a booth at events, collecting signatures, calling for donations, and paying member dues. Physicians also embarked on ambitious campaigns, including a radio show promoting single-payer, making a pro-single-payer 
movie, organizing and participating in a cross-country tour to speak about the need for single-payer, founding and running local chapters of national single-payer organizations, and doing public speaking.

The activism level of the physician is conditioned by their availability which is linked to their career stage or specialty. The early career phase also came with limited availability as the physicians were working in earnest to pay back student loans or establish a family. They tended to be low-level activists engaged in supporting roles. Mid-career physicians tended to be low-level or medium-level activists. The physicians who were at the end of their careers or retired had the most availability and took on the most responsibility for social movement organizing.

The activities physicians choose to engage in are ones that fit well with their skillset or fit with their schedule. Physician-activists reported selecting activities they enjoy and avoiding those they dislike. And physicians often participate in activities because others have asked them to do so. People request the physicians to speak at certain events or be on a panel due to their credibility and their experiences on the front lines of medicine. They accept requests when they enjoy the activity and can fit it into their schedule.

In my study, both activists and non-activists emphasized the limited free time that working physicians have and how activism necessarily occupies some of that spare time (Rochford 1985). For activists who had all components of the collective identity, their activism can still be curtailed by limited availability. Non-availability appears to be partially tied to the financial situation of the doctor, which itself is linked to the career stage of the physician. Physicians early in their career working to pay back student loans 
experience more pressure to see patients to earn income. It is more costly for them to engage in activism, because they are forfeiting income that they could have used to help pay back student loans. Physicians toward the end of their career are more financiallysecure, which affords them greater flexibility in their schedules to fit in activism. The activists tailored their level of involvement and responsibility to the amount of time they had to dedicate. Some activists incorporated family time into their activism by bringing along their family members when appropriate. The non-activists though, no matter how much free time they had, were unwilling to use the time for single-payer activism. This is because they do not engage in the process of collective identity which facilitates and enables activism as well as their perception of immutable barriers which they believe will render action inefficacious.

In short, the critical difference between the activists and non-activists is the balance of motivators and barriers. All respondents were dissatisfied with the healthcare system and cared for their patients. But the non-activists felt achieving single-payer financing was politically- or culturally-impossible at both the federal and state levels. Because of this, they support reforms in the delivery of medical care. This barrier coupled with a dearth of motivation from not adopting the collective identity leads to their nonactivism for single-payer. What led physicians to becoming single-payer activists is interpreting barriers as mutable combined with the adoption of the collective identity that emphasizes a priority on financing and the necessity of collective action. The absence of barriers coupled with strong motivation result in their activism.

\section{Contributions to the Literature}


This study contributes to the social movement and medical sociology literatures. My findings uphold the idea that rational actor theory is more useful to explain nonactivism, that availability conditions activism, that collective identity is an important piece of the explanation for mobilization, and that physician autonomy is declining in the commercialized age. However, the claim that belief in efficacy spurs activism is only weakly supported by my study. And, in contrast to earlier physician agitation, I find that deprofessionalization was not the only factor driving activism.

As was common in other studies, availability proved to be linked to levels of activism (Rochford 1985; Cable 1992). Physicians in residency or early in their careers had less availability and due to this, engaged in lower-level activities. As mentioned above, physicians in the early stages of their career may experience more financial pressure to see patients in order to pay back student loans; a pressure removed from physicians in later stages of their career. Activist physicians with flexible specialties, nearing the end of their career, or who were retired tended to have greater availability and were able to take on leadership roles and engage in high-level activism.

This study supports the idea that rational actor theory is a more sufficient explanation for non-involvement. Olson (1965) asserted that actors calculate the costs and benefits of their involvement in social movement activities. The non-activist physicians in my study engaged in this process. Due to their belief that single-payer is impossible, they calculated that their participation would not make a difference, chose to not become involved, and let others pay the cost of activism for a goal they supported. While this explains the non-participation of the non-activists, the non-adoption of the 
single-payer collective identity also supplements the explanation for their noninvolvement.

My findings also lend credence to collective identity theory by providing an empirical application. Using collective identity theory to interpret the study findings helps to account for the perception and interpretation of structural conditions and political opportunities revealing why there are two reactions given the same set of structural constraints (McAdam 2004). Additionally, this case study reinforces many of the components that scholars believe compose the collective identity. The identity is politicized because the actors are responding to policies of the state that clash with their deeply-held social justice values (Meyer 2002; Taylor and Whittier 1992). The activists want the state to ensure that medical care is a public good, made available based on need, instead of a private good controlled by the medical-industrial complex. The activists' main goal then, is a change in state policies, which makes the state the culprit for their grievance and politicizes the identity (Klandermans 2002).

Additionally, in this study, as the activists engaged in the process of collective identity, they used framing discourses to clarify their position and to develop boundaries that distinguish insiders from outsiders (Snow and McAdam 2000; Melucci 1995). The frames agreed upon in the physician networks, in particular the prognostic frame, adjudicate between those who adopt the collective identity and those who resist it. This work reinforces the idea that boundaries are an important part of the process of creating a collective identity since they function to distinguish between insiders and outsiders. Once the two groups are defined, the insiders develop a group consciousness through 
interaction, generating solidarity and commitment which are necessary to facilitate action.

And this case asserts the important role that value systems and emotions play in encouraging mobilization. The violation of deeply-held values produces powerful emotions like outrage and indignation that serve as motivators for action (Jasper 1998; Gecas 2000; Klandermans 2002). The activists, much more so than the non-activists, reported these emotional reactions to experiences resulting from deprofessionalization trends. Common emotions resulting from moral violations reported by the activists include anger, frustration, and outrage saying the restrictions on their autonomy "piss them off" and are "maddening."

And, in relation to the debate on whether a collective identity is a process or a product, my findings offer evidence that both perspectives can be applied. There is little doubt that collective identity is a process in that there is an "active network of relationships between actors who interact, communicate, influence each other, negotiate, and make decisions" as promoted by Melucci (1995:45). The physicians in my study discussed and negotiated the key movement frames and boundaries to develop the sense of we-ness that is characteristic of those involved in the process of collective identity. Yet, once this active process has occurred, and the activists have engaged in proselytizing and recruiting, the collective identity as a shorthand reference for key movement frames, issues, and tactics (Flesher Fominaya 2010) can perceived by outsiders who did not engage in the process aspect, lending some credence to a collective identity being understood as a product. In collective identity theory then, studying both the process of 
collective identity as well as the key movement frames and issues subsumed under the collective identity reveals different aspects of collective action and mobilization.

The work experiences reported by physicians in my study match claims asserting that the commercialized age of medicine is characterized by declining authority of doctors and rising influence of payers. First, findings from my study corroborate those from the survey conducted by The Physicians Foundation (2012). In both studies, physicians were angry that their years of medical training and work experience were often not sufficient to admit a patient to a hospital or to select a particular treatment modality. What is additionally required of them is to seek permission from someone without medical training, underscoring their diminished professional capacity. It supports the assertion of declining professional autonomy among physicians espoused by Freidson $(1988,2001)$. Physicians have declining control over the content of their work and a diminished capacity to use discretion in individual cases (Freidson 2001).

Second, Navarro's (1993) claims are supported as well when he says it is the payers and insurance companies who will dictate what patients receive, instead of physicians. And third, it also confirms what Relman foretold in 1980, that physicians will be pressured by their superiors to increase profits and maximize revenues. Indeed, the medical-industrial complex has attained substantial economic and political power to safeguard their business interests and pressure medical practitioners.

My findings also expand upon the double agent concept promoted by Angell (1993). In her (1993) study of physician experiences in managed care, physicians had to focus on containing costs by not wasting resources and ordering unnecessary tests. The double agent position refers to the tension between what's best for the patient and what's 
best for the business financially. The physicians in this study also experienced a double agent contradiction, but in a different way; they were often pressured to increase revenues and spending because of the fee-for-service environment. While different, it was also similar because the physician must continually take financial aspects of care into account instead of only focusing their clinical decision-making on doing what is best for the patient. This is similar to what Waitzkin (2001) describes when he says physicians are irritated that financial considerations underlay all decisions. Physicians feel this attention to increasing revenues conflicts with their medical ethics because extra procedures come with risks which could increase the chance of harming the patient.

On the other hand, my research challenges the idea that believing in the efficacy of activism is a strong predictor of engagement. I find a belief in the inefficacy of action deterred many of the non-activists, but the activists themselves were not entirely convinced of the efficacy of their activism. Unlike the activists in McAdam's study (1988) who joined the Civil Rights Movement because they felt strongly their engagement would make a substantial difference in achieving the goal, the activists in my study harbored doubts about whether their action would make a difference. This is not unprecedented in the literature though. Klandermans and Oegema (1987) found that when activists doubt the efficacy of their action, their incentives are ideological in nature; the activists behaved according to their principles. In my study, both activists and nonactivists recognized the barriers to successful passage and implementation of single-payer legislation. Public attitudes, the Congressional stalemate, and the vast resources commanded by the medical-industrial complex put a damper on the spirits of single-payer supporters. The activists were unsure if the efforts of the movement could neutralize the 
formidable strength of the opposition, but they all agreed it was necessary to attempt to enact a single-payer system. This is reflected by one physician who said, "We still need to fight for what we know is right. [...] Whether or not we win the battle or not is almost beside the point." In the face of what can seem like an impossible task, it is the moral and ethical commitment to do what is right (manifested in the collective identity) that keeps physicians engaged in the movement; it is not the belief that their actions will achieve the stated goal.

Additionally, the motivators for physician activism in my study conflict with assertions of the motivations for past physician activism around universal healthcare. When the United States was considering universal healthcare during the $20^{\text {th }}$ century, physician action was largely due to resistance against infringement upon their professional autonomy (Quadagno 2004; Starr 1982). I found that this was a factor influencing physician activism, but it was not necessary nor sufficient for physician engagement for single-payer healthcare. Experiencing infringement upon professional autonomy was linked to activism, but the real driver pushing physician activism for single-payer was engaging in the process of the collective identity emphasizing a change in healthcare financing. I believe the emotional reactions of outrage and anger also played an important role in stimulating sustained engagement in single-payer activism.

In short, my research provides support for declining professional autonomy of physicians in the $21^{\text {st }}$ century, the notion that availability conditions activism, and the assertion that collective identity provides an adequate explanation for physician mobilization around single-payer healthcare. My findings build upon the double agent tension, only weakly support the influence of the belief in the efficacy of action, and 
undermine the idea that deprofessionalization is the main motivator for physician activism around universal healthcare.

\section{Future Research}

Future research might enlarge the scope of inquiry beyond what was accomplished here. A larger sample - ideally, a national sample - could uncover additional doubts and motivators to activism. Doing this would also expose whether the variations in my sample are reflective of the larger population of physicians. Conducting a similar study in other states with single-payer movements would reveal whether physician-activists in those places maintain a similar collective identity to physicianactivists in Oregon. It would also reveal if Oregon's history of healthcare reform and having a physician-Governor create a special circumstance that encourages physician activism in politics to change healthcare reform.

There were gender disparities in level of activism in this dissertation. All of the high-level activists were males while females were represented four of the seven nonactivists. Given that McCormick et al. (2004) found greater support for single-payer among women physicians, their lower levels of activism in my study merit further attention toward this group. Yet, I am reluctant to offer definitive conclusions about gender affecting single-payer activism for two reasons.

First, even though women were overrepresented in the non-activist category in this research project, two of the four women would be considered high-level activists in other research projects. One woman was highly-involved in ensuring access to abortion services and another was engaged in activism for privacy around medical data and 
pushed for transparency in medical costs. This leads me to believe that issues such as structural availability and gender norms of passivity for females do not apply. Since half of my non-activist females engaged in high-cost activism, I do not see gender acting in a way to discourage activism.

Second, it is reasonable to speculate that women physicians might not feel as occupationally secure as men in their workplaces and subsequently more afraid to voice an unpopular opinion. At first glance, this could explain women's lower rates of activism for single-payer. However, the activists report that most of their activism takes place outside of the workplace, making occupational security appear irrelevant. If women feel marginalized in a male-dominated environment of medicine, it is unclear how this would translate to reduced activism with the public outside of the workplace. For these reasons, I refrain from making claims about how gender influences single-payer activism because I do not believe my data lend credence to a theory that women either face more barriers to activism or are discouraged from activism due to gender hierarchies. Future research could examine the experiences of female physicians to understand if the ways they choose to engage in activism differ from those of male physicians.

Further, it may be useful to measure motivators of physician activism for singlepayer using a quantitative approach. Through open-ended answers, this study revealed important motivators for physicians to engage in single-payer activism. If these factors were converted into a likert-scale format and given to a representative sample of Oregon physicians in a survey, analysis could reveal the relative strength of these motivators. Measuring the statistical significance of motivators can inform the literature and 
contribute to the understanding of which factors are most important in activism for public goods.

Future research could spend more time looking at the efficacy of physician activism or whether physician activism is more influential than activism by non-medical professionals. If physician activism is not influential and met with skepticism, then it may not be worth the effort for the physicians to take spare time to educate the public.

Last, this study found that high-level activists experienced difficult issues related to their activism. The physicians spoke about challenges as they learned to be an effective activist. Some issues they mentioned included recruitment of new members, increasing the engagement of current members, crafting an appealing message, and disseminating information. These are skills required to be an effective activist, but were skills the physicians had to invest effort into learning. These issues did not directly relate to the research questions in this study, but additional examination could provide information about activist efficacy, retention, and burnout.

\section{Implications}

What can be learned from the findings to increase physician engagement in single-payer activism? The findings indicate the main barrier to engagement in singlepayer activism is the perceived implausibility of the outcome and the inefficacy of action deriving from an interpretation of structural barriers as immutable. The opinion that single-payer is "impossible in America" needs to be neutralized in order to activate sympathetic physicians. Recruitment efforts should emphasize why the perceived barriers are changeable, why single-payer is attainable at the state level, and outline a clear path 
toward its implementation. This can be done by clearly laying out a plan, the factors that promote the likelihood of passing single-payer legislation, and why physician involvement would help achieve the goals.

Additionally, if the main factor causing sympathetic physicians to resist adoption of the collective identity stems from their disagreement with the prognostic frame, recruitment efforts must clearly explain this piece. The prognostic frame in the collective identity formed by activist physicians for single-payer emphasizes that policy reform in healthcare must prioritize changes to the financing system before making more changes to the delivery system. The activists will need to convince others that more delivery reforms will not fix the systemic problems in the healthcare system and that a change in financing will facilitate changes in delivery. Getting other physicians to agree with the prognostic frame of prioritizing changes to financing is the most important strategy physicians can employ to facilitate other physicians adopting the collective identity that enables action.

Further, since most of the activist respondents found the physician single-payer organizations on their own, the organizations could improve their outreach to physicians in order to augment recruitment. Recruitment efforts should target those who have the most motivation, like primary care doctors or oncologists, and those who have the most availability, like physicians with flexible specialties and physicians nearing the end of their career. The findings also indicate it is important to let physicians know of events with enough advance notice so they may request time off of work or arrange their schedules to accommodate the event. 
Last, because medium- and high-level activism requires the ability to articulate complex health economics in everyday language, the organizations should continue facilitating this type of learning as new members join. If a physician is not confident in their ability to speak in front of others or communicate one-on-one with a stranger, it will be extremely difficult for them to move beyond the low-level activities of recommending a book or signing a letter. Some training of new recruits in the framing discourses used will improve their integration and likely increase their level of activism, provided availability is not their main constraint.

\section{Limitations}

There are a few limitations to this study. The sample is only a tiny portion of all the physicians in Oregon which can make it hard to generalize to the overall physician population. However, in order to make the sample as representative as possible, the researcher used targeted sampling to obtain a mix of specialties, genders, and those working or retired. It is possible if the sample size was expanded, additional factors affecting activism could have been illuminated. The researcher did continue collecting data until saturation was reached, thus, the small sample size should be representative of the subgroups of doctors discussed.

Even though the final sample contained a mix of different specialties, unfortunately there were not enough cases of each specialty to permit comparison among them. My sample included one radiologist, one neurosurgeon, one cardiologist, one hospitalist, and one anesthesiologist. There were two oncologists, two psychiatrists, two endocrinologists, and two physicians practicing obstetrics. There were four each in 
internal medicine and family medicine. With only one or two respondents representing each specialty, there is not enough data to justify claiming that the experience of one anesthesiologist is indicative of the experience of all physicians in that specialty. Due to the limited number of respondents representing each specialty, I refrained from utilizing medical specialty as an analytic category in my analysis. Future research with larger sample sizes may be able to examine how medical specialty influences physician views on single-payer and/or their activism for it.

It is possible the snowball sampling strategy may have resulted in a sample that over-emphasized activism on other issues among my non-activists and under-emphasized the contributions retired physicians make to single-payer activism. The nature of snowball sampling creates a sample that tends to be well-connected while leaving out potential respondents who do not have as many connections (Weiss 1994). It is possible the single-payer activists referred me to some non-activists because they knew them from other activism events. For this reason, the activism among my "non-activists" may be overstated.

And it is possible that some retired physicians who engage in single-payer activism were not referred to me because their networks have weakened since retirement. It is possible that the actual population of physician single-payer activists may include more retired doctors and it is possible that non-single-payer activist doctors don't engage in very much activism on other issues.

Also, characteristics of the researcher may have influenced the findings. First, the fact that the researcher is not a physician could be a potential limitation. This could have influenced the answers that respondents gave. On the one hand, they may have left out 
experiences that they thought the researcher would have a hard time understanding or experiences that they thought required too much explanation. On the other hand, this aspect may have led to the physicians to thoroughly explain their experiences which may have contributed to more detailed responses.

Second, the researcher is a supporter of single-payer, which may have colored the analysis or follow-up questions in the interviews. When non-activists expressed doubts or concerns about single-payer that the researcher knew were untrue, she did not challenge the respondents on their opinions, but instead let the respondents speak about their concerns without criticism, helping to minimize any effects this may have had.

Additionally, some of the interviews were conducted over the phone while some were carried out in person. It is possible that this dynamic influenced answers given by the respondents. Respondents who were interviewed in person may have felt greater rapport and been more open in their answers. However, it is also just as likely that the respondents interviewed over the phone may have been more open in their answers because they were in the privacy of their own home when giving answers and there were no strangers or members of the public nearby to hear. It is difficult to know how the medium in which the interview was carried out influenced the answers of respondents, but it is not believed to have biased the findings.

\section{Conclusion}

An organized and vocal medical provider community may make the difference in whether a state can pass single-payer healthcare reform. It is possible that if more physicians become involved, and more states pass single-payer legislation, the United 
States may follow the same path as Canada: go state by state (or province by province) until it makes sense to convert the entire nation to one system. If that were to be accomplished, healthcare resources could be used more effectively to provide medicallynecessary care to all Americans and physicians would have greater autonomy in their workplace.

Physicians who think single-payer healthcare is a good idea but do not get involved in collective action view formidable barriers to the passage of single-payer and lack a motivating force. The barriers these physicians believe will prevent single-payer legislation from passing include the American public and the American political system corrupted by money interests. Due to these factors, the non-activists believe any effort toward single-payer is done in vain and a waste of time. The non-activists are still compassionate and care about their patients, but their choices to engage in reform are structured by the perceived feasibility.

About half of the non-activists in my sample still engaged in activism, but for issues they felt were more likely to be implemented. The non-activists are not convinced it is possible to achieve single-payer at the state level, believing the complexity overwhelms good intentions. They also feel delivery reforms are more important to work towards than financing reforms. These physicians never come to develop the collective identity sustained by activists that prioritizes healthcare financing reform and promotes single-payer as the best way to solve issues. The presence of barriers coupled with a lack of motivation results in their non-activism for single-payer.

Physicians who engage in single-payer activism, though, interpret structural barriers as changeable and sustain a collective identity that motivates and encourages 
such activism. The Oregon activists interpret the political structure as something that they can be manipulated, like the activists in Vermont. They believe that through education of the public, evidence from a study bill supporting single-payer, and proper support for pro-single-payer candidates, it may be possible to pass the necessary legislation. In addition to an absence of fixed barriers for activists, they also sustained significant motivation deriving from the adoption of the collective identity. The activist-physicians produce and share a collective identity that encourages collective action outside of the workplace to implement a healthcare system that upholds their social justice values while minimizing preventable suffering. The activists feel a sense of duty to help the less fortunate and are willing to use their spare time engaging in political activism to create a system that ensures everyone has access to needed care. Even if they are unsure whether Oregon can achieve single-payer healthcare, the physician-activists still believe the right thing to do is to try.

The findings can inform recruitment efforts which might augment the movement for single-payer healthcare in Oregon. Perhaps with enough outreach by the physician community, Oregon can elect representatives that support single-payer and pass the legislation to ensure that no Oregonians go bankrupt due to medical bills and receive the care their physician feels is best. 


\section{REFERENCES}

$77^{\text {th }}$ Oregon Legislative Assembly. 2013. House Bill2922. Regular Session.

https://olis.leg.state.or.us/liz/2013R1/Measures/Overview/HB2922. Accessed 12 June 2014

Ackermann, Ronald T. and Aaron E. Carroll. 2003. "Support for National Health Insurance among U.S. Physicians: A National Survey." Annals of Internal Medicine. 139(10)

Angell, Marcia. 1993. "The Doctor as Double Agent.” Kennedy Institute of Ethics Journal. 3(3)

Association of American Medical Colleges. 2014. "Medical Student Education: Debt, Costs, and Loan Repayment Fact Card." https://www.aamc.org/download/152968/data/debtfactcard.pdf. Accessed 7 October 2014.

Baicker, Katherine, Sarah L. Taubman, Heidi L. Allen, Mira Bernstein, Jonathan H. Gruber, Joseph P. Newhouse, Eric C. Schneider, Bill J. Wright, Alan M. Zaslavsky, and Amy N. Finkelstein. 2013. "The Oregon Experiment - Effects of Medicaid on Clinical Outcomes." The New England Journal of Medicine. 368(18)

Bandura, Albert. 1997. "Exercise of Human Agency Through Collective Efficacy." Current Directions in Psychological Science. 9(3)

Benford, Robert D. and David A. Snow. 2000. "Framing Processes and Social Movements: An Overview and Assessment." Annual Review of Sociology. Vol. 26

Birenbaum, Arnold. 2002. Wounded Profession: American Medicine Enters the Age of Managed Care. CT: Greenwood Publishing Group, Inc.

Bodenheimer, Thomas. 1997. "The Oregon Health Plan: Lessons for the Nation." The New England Journal of Medicine. 337(9)

Bodenheimer, Thomas S., and Kevin Grumbach. 2009. Understanding Health Policy: A Clinical Approach. 5th ed. New York: McGraw Hill

Boulware, L. Ebony, Lisa A. Cooper, Lloyd E. Ratner, Thomas A. LaVeist and Neil R. Powe. 2003. "Race and Trust in the Health Care System." Public Health Reports 118:358-65.

Buechler, Steven M. 1995. "New Social Movement Theories." The Sociological Quarterly. 36(3) 
Burdi, Michael D. and Laurence C. Baker. 1999. "Physicians' Perceptions of Autonomy and Satisfaction in California." Health Affairs. 18(4)

Cable, Sherry. 1992. "Women's Social Movement Involvement: The Role of Structural Availability in Recruitment and Participation Processes." The Sociological Quarterly. $33(1)$

Caren, Neal. 2007. "Political Process Theory." Blackwell Encyclopedia of Sociology. Edited by George Ritzer.

Carlson, Matthew J., Jennifer DeVoe, and Bill J. Wright. 2006. "Short-Term Impacts of Coverage Loss in a Medicaid Population: Early Results from a Prospective Cohort Study of the Oregon Health Plan." Annals of Family Medicine. 4(5)

Carroll, Aaron E. and Ronald T. Ackermann. 2008. "Support for National Health Insurance among U.S. Physicians: 5 Years Later.” Annals of Internal Medicine. 148(7)

Casalino, Lawrence P., Sean Nicholson, David N. Gans, Terry Hammons, Dante Morra, Theodore Karrison and Wendy Levinson. 2009. "What Does It Cost Physician Practices To Interact With Health Insurance Plans?” Health Affairs. 28(4)

Castellani, Brian and Delese Wear. 2000. "Physician Views on Practicing

Professionalism in the Corporate Age." Qualitative Health Research. 10(4)

Charmaz, Kathy. 1990. "Discovering Chronic Illness: Using Grounded Theory." Social Science and Medicine. Vol. 30

----. 2006. Constructing Grounded Theory: A Practical Guide through Qualitative Analysis. CA: SAGE Publications

Commonwealth Fund. 2008. "Oregon Lottery Opens Enrollment After 3-Year Freeze." States in Action Archive. February/March Edition.

Collins, Karen Scott, Cathy Schoen, and David R. Sandman. 1997. "The Commonwealth Fund Survey of Physician Experiences with Managed Care." The Commonwealth Fund. March. http://www.commonwealthfund.org/publications/fund-reports/1997/mar/thecommonwealth-fund-survey-of-physician-experiences-with-managed-care. Accessed 18 November 2014

Conviser, Richard. 1990. "Case Study Plus: A History of Oregon Health Decisions." Civic Practices Network. http://www.cpn.org/topics/health/commoregon3.html Accessed 23 July 2014. 
Davis, Karen, Cathy Schoen, and Kristof Stremekis. 2010. "Mirror, Mirror on the Wall: How the U.S. Healthcare System Compares Internationally." The Commonwealth Fund. Publication No. 1400.

Department of Commerce. N.d. "Current Population Reports." Bureau of the Census. Series P-60. No.s 33, 37, 53, 66, and unpublished data. Page 72.

http://www2.census.gov/prod2/statcomp/documents/1970-03.pdf. Accessed 13 October 2014.

DeSilver, Drew. 2013. "Congress Ends Least-Productive Year in Recent History." PEW Research Center. http://www.pewresearch.org/fact-tank/2013/12/23/congress-ends-leastproductive-year-in-recent-history/ Accessed on 7 April 2014

DiPrete, Bob and Darren Coffman. 2007. "A Brief History of Health Service Prioritization in Oregon." http://www.oregon.gov/OHA/OHPR/HSC/docs/PrioritizationHistory.pdf?ga=t Accessed 23 July 2014

Dittmer, John. 2009. The Good Doctors. New York: Bloomsbury Press

Downs, Anthony. 1957. An Economic Theory of Democracy. New York: Harper and Row

Drasga, Ray E. and Lawrence H. Einhorn. 2013. "Why Oncologists Should Support Single-Payer National Health Insurance." Journal of Oncology Practice. 6(21)

Earnest, Mark A., Shale L. Wong, and Steven Federico. 2010. "Physician Advocacy: What Is It and How Do We Do It?" Academic Medicine. 85(1)

Edwards, Bob and Patrick F. Gillham. 2012. "Resource Mobilization Theory." The Wiley-Blackwell Encyclopedia of Social and Political Movements. Edited by David A. Snow, Donatella della Porta, Bert Klandermans, and Doug McAdam.

Flesher Fominaya, Cristina. 2010. "Collective Identity in Social Movements: Central Concepts and Debates." Sociology Compass. 4(6)

Fox, Daniel M. and Howard M. Leichter. 1991. "Rationing Care in Oregon: The New Accountability." Health Affairs. 10(2)

Freidson, Eliot. 1988. Profession of Medicine: A Study of the Sociology of Applied Knowledge. IL: The University of Chicago Press

------ 2001. Professionalism: The Third Logic. IL: The University of Chicago Press

Friedman, Gerald. 2012. "Funding a National Single-Payer System." Dollars and Sense. March/April Issue 
Gamson, William A. 1990. The Strategy of Social Protest. CA: Wadsworth

Gecas, Viktor. 2000. "Value Identities, Self-Motives, and Social Movements." Chapter 4 in Self, Identity, and Social Movements. Minneapolis: University of Minnesota Press

Geyman, John. 2005. "The Common Interest: Is It Time for National Health Insurance?" The Boston Review.

Goodwin, Jeff and James M. Jasper. 1999. "Caught in a Winding, Snarling Vine: The Structural Bias of Political Process Theory.” Sociological Forum. 14(1)

----- 2004. "Caught in a Winding, Snarling Vine: The Structural Bias of Political Process Theory." Chapter 1 in Rethinking Social Movements. Edited by Jeff Goodwin and James M. Jasper. Lanham, MD: Rowman \& Littlefield Publishers, Inc.

Graves, Bill. 2009. "Angry Oregon Doctors Take Health Care Message on Tour." The Oregonian, September 8.

http://www.oregonlive.com/news/index.ssf/2009/09/angry_oregon_doctors_take_heal.ht ml. Accessed 23 July 2014.

Gray, Christopher David. 2014. "Dembrow's Healthcare Study Imperiled by Lack of Private Funds." The Lund Report, March 19.

https://www.thelundreport.org/content/dembrow\%E2\%80\%99s-healthcare-studyimperiled-lack-private-funds. Accessed 25 July 2014.

Gruen, Russell L., Steven D. Pearson, and Troyen A. Brennan. 2004. "Physician-Citizens -- Public Roles and Professional Obligations." Journal of the American Medical Association. 291(1)

Hadley, Jack. 2003. "Sicker and Poorer-the Consequences of Being Uninsured: a Review of the Research on the Relationship Between Health Insurance, Medical Care Use, Health, Work, and Income." Medical Care Research and Review 60(suppl. 2):3s-75s.

Hall, Bennett. 2013. "Hundreds Rally for Single-Payer Health Care." Corvallis GazetteTimes, February 5. http://www.gazettetimes.com/news/local/hundreds-rally-for-singlepayer-health-care/article_da39fec6-6fle-11e2-bf35-001a4bcf887a.html. Accessed 25 July 2014.

Hammond, Terry Richard. 2012. "Feasible Models of Universal Health Insurance in Oregon According to Stakeholder Views." Ph.D. dissertation, Urban Studies, Portland State University, Oregon.

Hancock, Jay. 2012. "The New Normal In Health Insurance: High Deductibles.” Kaiser Health News. June 3, 2012 
Himmelstein, David U., Elizabeth Warren, Deborah Thorne, and Steffie Woolhandler. 2005. "Illness and injury as Contributors to Bankruptcy." Health Affairs (Web exclusive February 2nd) w5-66.

Himmelstein, David U. and Steffie Woolhandler. 2003. "National Health Insurance or Incremental Reform: Am High, or at Our Feet?" American Journal of Public Health. 93(1)

Hoff, Timothy. 2010. Practice Under Pressure: Primary Care Physicians and Their Medicine in the Twenty-first Century. NJ: Rutgers University Press

Hoffman, Beatrix. 2001. The Wages of Sickness. Chapel Hill: The University of North Carolina Press

Hoffman, Catherine and Julia Paradis. 2008. "Health Insurance and Access to Care in the United States." Annals of the New York Academy of Science. Vol. 1136

Hrinda, Stephen. 2007. “The Oregon Health Plan.” Paper for MPHP439, Case Western Reserve University, Clevland, Ohio. http://www.cwru.edu/med/epidbio/mphp439/Oregon_Health_Plan.pdf. Accessed 23 July 2014.

Hsiao, William C., Anna Gosline Knight, Steven Kappel, and Nicolae Done. 2011. "What Other States Can Learn from Vermont's Bold Experiment: Embracing a SinglePayer Health Care Financing System." Health Affairs. 30(7)

Hunt, Scott A. and Robert D. Benford. 2004. "Collective Identity, Solidarity, and Commitment." The Blackwell Companion to Social Movements. Edited by David A. Snow, Sarah A. Soule, Hanspeter Kriesi. Blackwell Publishing Ltd.

Huntington, Mike. "Health Movement History: In the Beginning." Healthcare for All Oregon. http://hcao.org/history/. Accessed 23 July 2014.

IHSP (Institute for Health and Socio-economic Policy). 2009. "Single Payer/Medicare for All: An Economic Stimulus Plan for the Nation." California Nurses Association. Report \#33688

Jasper, James M. 1998. "Emotions of Protest: Affective and Reactive Emotions in and around Social Movements." Sociological Forum. 13(3)

Joffe, Carole E., Tracy A. Weitz, and Clare L. Stacey. 2004. "Uneasy Allies: Pro-Choice Physicians, Feminist Health Activists and the Struggle for Abortion Rights." Sociology of Health and Illness. 26(6) 
KFF (Kaiser Family Foundation). 2012. "Health Security Watch.” June 2012. Publication $\# 8322$

Kitzhaber, John A. 1993. "Prioritising Health Services in an Era of Limits: The Oregon Experience." The British Medical Journal. Vol. 307

Klandermans, Bert. 1997. The Social Psychology of Protest. Massachusetts: Blackwell Publishers Inc.

-----. 2002. "How Group Identification Helps to Overcome the Dilemma of Collective Action." American Behavioral Scientist. Vol. 45

Klandermans, Bert and Dirk Oegema. 1987. "Potentials, Networks, Motivations, and Barriers: Steps Towards Participation in Social Movements." American Sociological Review. 52(4)

Klandermans, Bert and Marga de Weerd. 2000. "Group Identification and Political Protest." Chapter 3 in Self, Identity, and Social Movements. Minneapolis: University of Minnesota Press

Klein, Ezra. 2013. "Is the Future of American Health Care in Oregon?" The Washington Post, May 20. http://www.washingtonpost.com/blogs/wonkblog/wp/2013/05/20/is-thefuture-of-american-health-care-in-oregon/. Accessed 24 July 2014.

Leichter, Howard M. 1999. “Oregon's Bold Experiment: Whatever Happened to Rationing?" Journal of Health Politics, Policy and Law. 24(1)

Lofland, John, David Snow, Leon Anderson, and Lyn H. Lofland. 2006. Analyzing Social Settings: A Guide to Qualitative Observation and Analysis. CA: Wadsworth Press

Luhby, Tami. 2014. "Medicaid enrollment jumps by 3 million." CNN Money. http://money.cnn.com/2014/04/04/news/economy/medicaid-enrollment/. Accessed 7 October 2014.

Lundberg, George D. 2002. Severed Trust: Why American Medicine Hasn't Been Fixed. New York: Basic Books

Lupton, Deborah. 2003. Medicine as Culture: Illness, Disease, and the Body in Western Societies. London: Sage

Marmor, Theodore M. and Tom Hamburger. 1994. "The Missing Alternative: How Washington Elites Pushed Single-Payer Reform Plans off the Agenda." Chapter 10 in Understanding Health Care Reform. Edited by Theodore M. Marmor. CT: Yale University Press 
Marmor, Theodore M. and Jonathan Oberlander. 2004. "Paths to Universal Health Insurance: Progressive Lessons from the Past to the Future." University of Illinois Law Review. 2004(1)

Marshall, Catherine and Gretchen B. Rossman. 2006. Designing Qualitative Research. CA: Sage Publications

McAdam, Doug. 1982. Political Process and the Development of Black Insurgency. IL: University of Chicago Press

-----. 1988. Freedom Summer. New York: Oxford University Press, Inc.

-----. 2004. "Revisiting the U.S. Civil Rights Movement: Toward a More synthetic Understanding of the Origins of Contention." Chapter 13 in Rethinking Social Movements. Edited by Jeff Goodwin and James M. Jasper. Lanham, MD: Rowman \& Littlefield Publishers, Inc.

-----. 2013. "Political Process Theory." The Wiley-Blackwell Encyclopedia of Social and Political Movements. Edited by David A. Snow, Donatella della Porta, Bert Klandermans, and Doug McAdam.

McAdam, Doug and Ronnelle Paulsen. 1993. "Specifying the Relationship Between Social Ties and Activism." American Journal of Sociology. 99(3)

McCanne, Don. 2014. "Medicaid Patients Did Improve in the Oregon Health Insurance Experiment." Physicians for a National Health Program, Quote of the Day, February 4.

-----. 2003. "Why Incremental Reforms Will Not Solve the Health Care Crisis." Journal of the American Board of Family Medicine. 16(3)

McCarthy, John D. and Mayer N. Zald. 1973. The Trend of Social Movements in America: Professionalization and Resource Mobilization. New Jersey: General Learning Press

-----. 1977. "Resource Mobilization and Social Movements: A Partial Theory." American Journal of Sociology. 82(6)

McCormick, Danny, David U. Himmelstein, Steffie Woolhandler, and David Bor. 2004. "Single-Payer National Health Insurance: Physicians' Views." Archives of Internal Medicine. Vol. 164

McCurdy, Christen. 2012. "Campaign for Single-payer Building Up Steam in Oregon." The Lund Report, August 30. https://www.thelundreport.org/content/campaign-singlepayer-building-steam-oregon. Accessed 24 July 2014. 
McGill, Mariah. 2012. "Human Rights from the Grassroots Up: Vermont's Campaign for Universal Health Care." Health and Human Rights. June. 14(1)

Mechanic, David. 2004. "The Rise and Fall of Managed Care." Journal of Health and Social Behavior. Vol 45. Extra Issue: Health and Health Care in the United States: Origins and Dynamics 2004.

-----. 2006. The Truth about Health Care. Why Reform is Not Working in America. New Brunswick, NJ: Rutgers University Press.

Melucci, Alberto. 1995. "The Process of Collective Identity." Chapter 3 in Social Movements and Culture. Edited by Hank Johnston and Bert Klandermans. London: Routledge

Meyer, David S. 2002. "Opportunities and Identities: Bridge-building in the study of social movements." Introduction chapter in Social Movements: Identity, Culture, and the State. New York: Oxford University Press

Meyer, David. S. and Nancy Whittier. 1994. "Social Movement Spillover." Social Problems. 41(2)

Modern Healthcare. 2013. "100 Most Influential People in Healthcare - 2103 (text list)." http://www.modernhealthcare.com/article/20130824/INFO/130829987/100-mostinfluential-people-in-healthcare-2013-text-list. Accessed 28 August 2014.

Morra, Dante, Sean Nicholson, Wendy Levinson, David N. Gans, Terry Hammons, and Lawrence P. Casalino. 2011. "US Physician Practices Versus Canadians: Spending Nearly Four Times As Much Money Interacting With Payers.” Health Affairs. 30(8)

Morris, Aldon D. 1992. "Political Consciousness and Collective Action." Chapter 15 in Frontiers in Social Movement Theory. Edited by Aldon D. Morris and Carol McClurg Mueller. CT: Yale University Press

Mu, L., F. Shroff, and S. Dharamsi. 2011. "Inspiring Health Advocacy in Family Medicine: A Qualitative Study.” Education for Health. 24(1)

Mueller, Carol McClurg. 1992. "Building Social Movement Theory." Chapter 1 in Frontiers in Social Movement Theory. Edited by Aldon D. Morris and Carol McClurg Mueller. CT: Yale University Press

Navarro, Vicente. 1993. Dangerous to your Health: Capitalism in Health Care. New York: Monthly Review Press

Newman, Colin. 2008. "A Prescription for Democracy: Physician Activism and Canada." Proceedings of the 17th Annual History of Medicine Days. March 2008 
Oberlander, Jonathan. 2003. "The Politics of Health Reform: Why Do Bad Things Happen to Good Plans?" Health Affairs. (Web Exclusive August 27). W3-391-404

-----. 2007. "Health Reform Interrupted: The Unraveling of the Oregon Health Plan." Health Affairs. 26(1)

Oberlander, Jonathan, Theodore Marmor, and Lawrence Jacobs. 2001. "Rationing Medical Care: Rhetoric and Reality in the Oregon Health Plan." Canadian Medical Association Journal. 164(11)

Oberlander, Jonathan B. and Barbara Lyons. 2009. "Beyond Incrementalism? SCHIP And The Politics Of Health Reform." Health Affairs. 28(3)

Olson, Mancur. 1965. The Logic of Collective Action. Mass: Harvard University Press

Ollove, Michael. 2014. "Vermont Is the Single-payer Trailblazer." USA Today. http://www.usatoday.com/story/news/nation/2014/08/07/stateline-vermont-insurance-acaobamacare/13721355/ Accessed 21 October 2014.

Oregon Department of Human Services. 2010. "2009 Physician Workforce Survey." Division of Medical Assistance Programs.

Oregon Health Authority. 2014. "Oregon Health Insurance Survey: 2013." Office of Health Analytics. State of Oregon. http://www.oregon.gov/oha/OHPR/RSCH/docs/Uninsured/2013_OHIS_Age_FactSheet.p df. Accessed 6 October 2014.

Oregon Health Policy and Research. 2011. "How Many Oregonians Are Uninsured? A Technical Guide to Understanding the Estimates." Oregon Health Authority. September. http://www.oregon.gov/oha/OHPR/RSCH/docs/uninsured/reviewingestimatesoforegonsu ninsuredtechnicalbrief.pdf. Accessed 28 August 2014.

Pew Research Center. 2013. "Trust in Government Nears Record Low, But Most Federal Agencies Are Viewed Favorably." http://www.people-press.org/files/legacy-pdf/10-1813\%20Trust\%20in\%20Govt\%20Update.pdf. Accessed 4 April 2014.

Polletta, Francesca. 1999. "Free Spaces in Collective Action." Theory and Society. Vol. 28

Polletta, Francesca and James M. Jasper. 2001. "Collective Identity and Social Movements." Annual Review of Sociology. Vol. 27

Potter, Wendell. 2010. Deadly Spin. New York: Bloomsbury Press 
Quadagno, Jill. 2003. One Nation, Uninsured. New York: Oxford University Press

-----. 2004. "Why the United States Has No National Health Insurance: Stakeholder Mobilization Against the Welfare State, 1945-1996." Journal of Health and Social Behavior. Vol. 45 (special issue)

Quill, Timothy. 1993. Death and Dignity. New York: W. W. Norton \& Company, Inc.

Relman, Arnold S. 1980. "The New Medical-Industrial Complex." New England Journal of Medicine. 303(17)

-----. 2007. A Second Opinion: Rescuing America's Health Care. New York: The Century Foundation

Rochford, E. Burke, Jr. 1985. Hare Krishna in America. NJ: Rutgers University Press

Roe v. Wade. 1973. 410 US 113.

Ross, Johnathon S. 2009. "Health Reform Redux: Learning from Experience and Politics." American Journal of Public Health. 99(5)

Schlozman, Kay Lehman, Sidney Verba, and Henry E. Brady. 1995. "Participation's Not a Paradox: The View from American Activists." British Journal of Political Science. 25(1)

Schoen, Cathy, Jacob Lippa, Sara Collins, and David Radley. 2012. "State Trends in Premium and Deductibles, 2003-2011: Eroding Protection and Rising Costs Underscore Need for Action." The Commonwealth Fund. Publication 1648. Vol. 31.

Schoen, Cathy, Robin Osborn, Michelle M. Doty, David Squires, Jordon Peugh and Sandra Applebaum. 2009. "A Survey of Primary Care Physicians in Eleven Countries, 2009: Perspectives on Care, Costs, and Experiences." Health Affairs. 28(6)

Skocpol, Theda. 1996. Boomerang: Clinton's Health Security Effort and the Turn Against the Government in US Politics." New York: W.W. Norton \& Company, Inc.

Snow, David. 2001. "Collective Identity and Expressive Forms." Center for the Study of Democracy, UC Irvine. Working Paper Series. https://escholarship.org/uc/item/2zn1t7bj. Accessed 18 November 2014

Snow, David A., Louis A. Zurcher, Jr., and Sheldon Ekland-Olson. 1980. "Social Networks and Social Movements: A Microstructural Approach to Differential Recruitment." American Sociological Review. 45(5) 
Snow, David A. and Robert D. Benford. 1992. "Master Frames and Cycles of Protest." Chapter 6 in Frontiers in Social Movement Theory. Edited by Aldon D. Morris and Carol McClurg Mueller. CT: Yale University Press

Snow, David A. and Doug McAdam. 2000. "Identity Work Processes in the Context of Social Movements: Clarifying the Identity/Movement Nexus." Chapter 2 in Self, Identity, and Social Movements. Minneapolis: University of Minnesota Press

Starr, Paul. 1982. The Social Transformation of American Medicine. New York: Basic Books

Stecker, Eric C. 2013. "The Oregon ACO Experiment - Bold Design, Challenging Execution." New England Journal of Medicine. 268(11)

Tarrow, Sidney. 1996. "States and Opportunities: The Political Structuring of Social Movements." Chapter 2 in Comparative Perspectives on Social Movements. New York: Cambridge University Press

Taylor, Verta and Nancy E. Whittier. 1992. "Collective Identity in Social Movement Communities: Lesbian Feminist Mobilization." Chapter 5 in Frontiers in Social Movement Theory. Edited by Aldon D. Morris and Carol McClurg Mueller. CT: Yale University Press

----- 1998. "Collective Identity in Social Movement Communities: Lesbian Feminist Mobilization." Pages 349-365 in Social Perspectives in Lesbian and Gay Studies: A Reader. New York: Routledge.

The Physicians Foundation. 2012. "A Survey of American Physicians: Practice Patterns and Perspectives."

Thorne, Sally. 2008. Interpretive Description. CA: Left Coast Press

Tilly, Charles. 1978. From Mobilization to Revolution. Massachusetts: Addison-Wesley.

US Census. 2011. "Current Population Reports: Income, Poverty, and Health Insurance Coverage in the United States 2010." Compiled by Carmen DeNavas-Walt, Bernadette D. Proctor, and Jessica C. Smith. Washington DC: US Government Printing Office

----. 2014. "Current Population Reports: Health Insurance Coverage in the United States 2013." Compiled by Jessica C. Smith and Carla Medalia. Washington DC: US Printing Office

US Department of Health and Human Services. 2014. "Key Features of the Affordable Care Act by Year." http://www.hhs.gov/healthcare/facts/timeline/timeline- 
text.html\#2014. Accessed 12 June 2014

Vanderbilt, Susanne K., Matthew K. Wynia, Margaret Gadon, and G. Caleb Alexander. 2007. "A Qualitative Study of Physicians' Engagement in Reducing Healthcare Disparities." Journal of the National Medical Association. 99(12)

Waitzkin, Howard. 2001. At the Front Lines of Medicine. MD: Rowman \& Littlefield Publishers, Inc.

------. 2012. "The Commodification of Health Care and the Search for a Universal Health Program in the United States." Human Capital Blog at Robert Wood Johnson Foundation. October 11, 2012.

Waitzkin, Howard and Jennifer Fishman. 1997. "Inside the System: The PatientPhysician Relationship in the Era of Managed Care.” Pp 136-162 in Competitive Managed Care: The Emerging Health System edited by John D. Wilkerson, Kelly J. Devers, and Ruth S. Given. CA: Jossey-Bass.

Weber, Max. 2002[1920]. The Protestant Ethic and the Spirit of Capitalism. New York: Routledge

Weiss, Robert S. 1994. Learning from Strangers: The Art and Method of Qualitative Interview Studies. New York: The Free Press

Wilper, Andrew P., Steffie Woolhandler, Karen E. Lasser, Danny McCormick, David H. Bor, and David U. Himmelstein. 2009. "Health Insurance and Mortality in US Adults." American Journal of Public Health. 99(12)

Wright, Bill J., Matthew J. Carlson, Tina Edlund, Jennifer DeVoe, Charles Gallia and Jeanene Smith. 2005. "The Impact of Increased Cost Sharing On Medicaid Enrollees." Health Affairs. 24(4):1106-1116

Wright, Erik and Joel Rogers. 2011. American Society: How it Really Works. New York: W. W. Norton \& Company, Inc.

Wright, Leslie. 2013. "Special Report: Pre-Existing Conditions." http://www.sanders.senate.gov/newsroom/recent-business/single-payer-in-vermont. Accessed 24 July 20134.

Yardley, William. 2008. "Drawing Lots for Health Care." The New York Times, March 13. http://www.nytimes.com/2008/03/13/us/13bend.html. Accessed 23 July 2014. 


\section{Appendix A: Interview Guide}

A. The Problem

1. What has changed in medicine over your career? $<$ Prompt $>$ What has gotten better or worse or harder?

a. Are these changes good or bad for you or for patients?

2. Tell me what do you think the dilemmas are confronting physicians as they practice medicine today?

3. How do health insurance plans and their restrictions affect you in your work? $<$ Prompt $>$ 'this includes practices like documenting work, submitting forms for payment, clinical decision-making'.

4. Can you tell me about a time when a treatment or test you recommended was denied authorization?

a. How did that made you feel?

b. How did you get around that? $<$ How was that resolved? $>$

B. Action

5. Have you engaged in any activities to help us move toward single-payer healthcare?

a. If yes, what?

b. What made you choose those activities?

c. Are you currently doing these or was this in the past?

d. IF PAST - Why did you discontinue your activism?

6. Have you been involved in any organizations that are working toward single payer arrangements?

a. If yes, which one?

b. How did you get involved with that group?

c. Are you currently a member or was this in the past?

d. IF PAST - Why did you leave the group?

7. Have you had any earlier life experiences that led you to want to strive for healthcare reform? $<$ Prompt $>$ 'Maybe a mentor in medical school or something happened to a family member or close friend?'

8. Do you think there's a connection between your family's values growing up and your activism? $<$ Prompt $>$ Maybe religion or social class?

9. What do you think gets other physicians involved in activism for single payer? $<$ Prompt $>$ What motivates other physicians to join the cause?

10. What do you think prevents other physicians who support single-payer from becoming involved? $<$ Prompt $>$ What is stopping them from joining?

11. From your experience, what parts of the healthcare system do you believe are the most important to change in your lifetime?

12. Is there something else you think I should know?

13. Snowball Sampling 
Appendix B: Questionnaire

1. What year did you graduate from medical school?

2. What is your specialty?

Subspecialty?

Why did you choose that specialty?

3. After completion of training, please order with years the places you worked. (e.g., 1990-1997)
a. Hospital
b. Academic Medical Center
c. Veterans' Administration Facility
d. Community-based clinic/public health facility
e. Solo or small group practice with fewer than 5 physicians
f. Group practice of 5-20 physicians
g. Large or multi-specialty group practice with 20 or more physicians
h. Staff-model HMO
i. Other

4. To the best of your knowledge, what percentage of your patients are/were?
a. Covered by private insurance
b. Covered by Medicare
c. Covered by Medicaid
d. Uninsured
e. Other situation

5. How are you or were you paid?
a. Salary
b. Fee-for-Service
c. Capitated per patient
d. Other

6. How does your 2013 income differ from that of 2008 ? Let me know if you were still in training or not employed in one of these years.
a. Much more
b. A little more
c. About the same
d. A little less
e. A lot less

7. What is your gender? 


\section{Appendix C: Activities Reported by Activists}

\begin{tabular}{|c|c|}
\hline High & evel: \\
\hline$\bullet$ & Exercising leadership \\
\hline$\bullet$ & Background coordination \\
\hline$\bullet$ & Trying to organize people to work toward the same goal \\
\hline$\bullet$ & Public speaking \\
\hline & $\circ \quad$ Being a speaker at events \\
\hline & O Panel discussions \\
\hline & o Seminars \\
\hline & ○ Invited talks \\
\hline$\bullet$ & Chairing a single-payer committee \\
\hline$\bullet$ & Monthly leaders phone conversation \\
\hline$\bullet$ & Organizing outreach events to educate others \\
\hline$\bullet$ & Lobbying representatives at the state capitol \\
\hline$\bullet$ & On the national board of a single-payer group \\
\hline$\bullet$ & Teaching a health reform class at a medical school \\
\hline$\bullet$ & Establishing and running a local chapter of a national single-payer group \\
\hline$\bullet$ & Helping draft and carry out the legislative process of single-payer bills and the study bill \\
\hline$\bullet$ & Creating media events \\
\hline$\bullet$ & Going on a cross-country tour to speak about the dysfunctional healthcare system \\
\hline$\bullet$ & Writing editorials and letters to the editor and getting them published \\
\hline$\bullet$ & Co-writing pieces with activists \\
\hline$\bullet$ & Finding funding for the study bill \\
\hline$\bullet$ & Organize public conferences on healthcare reform \\
\hline$\bullet$ & Recording a radio/internet show \\
\hline$\bullet$ & Making a movie \\
\hline Medi & n Level: \\
\hline$\bullet$ & Pay member dues to a single-payer organization \\
\hline$\bullet$ & Mentioning to colleagues and the Oregon Medical Association that single-payer is needed \\
\hline$\bullet$ & Manning a booth/handing out information \\
\hline$\bullet$ & Collecting signatures \\
\hline$\bullet$ & Doing the photo petition \\
\hline$\bullet$ & Calling for donations \\
\hline$\bullet$ & Writing a blog \\
\hline Low & evel: \\
\hline$\bullet$ & Voting with universal healthcare at the front of their mind \\
\hline$\bullet$ & Being vocal with patients or family \\
\hline$\bullet$ & Posting on social media \\
\hline$\bullet$ & Commenting on blogs about the need for universal healthcare \\
\hline$\bullet$ & Replying to mass emails with a pro-single payer message \\
\hline$\bullet$ & Wearing a button \\
\hline$\bullet$ & Having a sticker/decal on your vehicle \\
\hline$\bullet$ & Occasionally attending meetings \\
\hline$\bullet$ & Signing letters or petitions \\
\hline$\bullet$ & Recommending or sending someone a book \\
\hline
\end{tabular}

